University of Tennessee Health Science Center UTHSC Digital Commons

6-1992

\title{
Hospital Patients' and Nurses' Perceptions of Quality
}

June Hansen Larrabee

University of Tennessee Health Science Center

Follow this and additional works at: https://dc.uthsc.edu/dissertations

Part of the Health Services Administration Commons, Health Services Research Commons, and the Nursing Commons

\section{Recommended Citation}

Larrabee, June Hansen , "Hospital Patients' and Nurses' Perceptions of Quality" (1992). Theses and Dissertations (ETD). Paper 419. http://dx.doi.org/10.21007/ptd.cghs.1992.0424.

This Dissertation is brought to you for free and open access by the College of Graduate Health Sciences at UTHSC Digital Commons. It has been accepted for inclusion in Theses and Dissertations (ETD) by an authorized administrator of UTHSC Digital Commons. For more information, please contact jwelch30@uthsc.edu. 


\title{
Hospital Patients' and Nurses' Perceptions of Quality
}

\begin{abstract}
Hospital quality assurance programs have been provider-oriented, focusing on structure and process elements of care rather than outcomes specific to patient needs and values. This study tested the relationship between quality and value, proposed in Larrabee's model of quality, by developing prediction indices for patient and nurse quality and value.
\end{abstract}

The sample consisted of 199 adult patients. Patient quality was measured by a $100 \mathrm{~mm}$ visual analog scale (VAS) (PQUALG) and a modified version of an existing instrument (PQUALT). Patient value was measured as patient goal achievement (PGOAL), the average of three VAS scores for patient defined goals of hospitalization. Nurse quality (NQUAL) was measured as percent agreement between process standards selected for each patient and nursing care documented. Nurse value (NGOAL) was measured as nurse goal achievement, the percent agreement between outcome standards selected for each patient and outcomes documented. Seven patient demographic, seven financial, six illness, and six hospital variables were also measured. PQUALG, PQUALT, PGOAL, and NGOAL were positively skewed and dichotomized for multiple logistic regression analysis.

Patient quality was correlated with PGOAL and NGOAL. PQUALG was correlated with PQUALT. NQUAL was not correlated with PQUALG, PQUALT, PGOAL, or NGOAL . PQUALG predictors were pain severity on exit interview (PAINNOW), clinic referral, unit, PGOAL, and being a Medicare recipient. PQUALT predictors were PAINNOW, PGOAL, clinic referral, unit, and worry score on admission. PGOAL predictors included PAINNOW, working part time, being a Blue Cross recipient, being white, being female, and combined household income. NQUAL predictors were being widowed and being a recipient of Medicaid. NGOAL predictors were PAINNOW, being married, and severity of illness score .

The results support the relationship between quality and value postulated by Larrabee's model of quality, identify pain management as an important aspect of care for nursing quality improvement programs, and demonstrate that patients and nurses evaluate different dimensions of nursing care. Future research based on Larrabee's model of quality should verify the accuracy of estimates of the odds ratios for predictors of value and quality and should test the relationships among quality and value and the remaining model concepts, beneficence, prudence, and justice.

\section{Document Type}

Dissertation

Degree Name

Doctor of Philosophy (PhD)

\section{Program}

Nursing

\section{Research Advisor}

Veronica F. Engle, Ph.D., R.N.

\section{Keywords}

quality assurance, patient perception, nurse perception, hospitalization

\section{Subject Categories}

Health Services Administration | Health Services Research | Medicine and Health Sciences | Nursing This dissertation is available at UTHSC Digital Commons: https://dc.uthsc.edu/dissertations/419 
Hospital Patients' and Nurses' Perceptions of Quality

\author{
A Dissertation \\ Presented to
}

The Graduate Studies Council

The University of Tennessee, Memphis

In Partial Fulfillment

of the Requirements for the Degree

Doctor of Philosophy

From The University of Tennessee

By

June Hansen Larrabee

June, 1992 
c 1992 The University of Tennessee, Memphis. June Hansen Larrabee, author.

\begin{abstract}
All rights reserved.
No part of this publication may be reproduced in any form without written permission.
\end{abstract}


Dedication

This work is dedicated to:

Glenn A. Hansen, my late father,

Barbara F. Hansen, my mother,

James A. Larrabee, my husband,

and

Lauralee Kathryn Larrabee, my daughter 


\section{Acknowledgements}

I gratefully acknowledge my dissertation committee members, who shared their expertise, challenged me intellectually, guided my development as a researcher, gave me encouragement, and enabled my successful completion of this work: Veronica Engle, Ph.D., R.N., my chair, was most instrumental in my acquisition of scientific inquiry skills and facilitated my steady progress.

Michael A. Carter, D.N.Sc., R.N., helped me appreciate theoretical thinking and encouraged my venture into theory development. Cyril Chang, Ph.D., helped me aquire an appreciation for the economics of health care.

Carol Thompson, Ph.D., R.N., facilitated my critical thinking about my theorical model and its investigation. Elizabeth Tolley, Ph.D., helped me acquire and enjoy the use of statistical analysis skills.

Also, I gratefully acknowledge the following people who contributed to my successful completion of this work: Marie Knight, R.N., M.S.N. (Senior Vice President for Inpatient

Operations at the Regional Medical Center), friend and colleague, supported, encouraged, and facilitated the research. Kathryn Barnoud, R.N., M.S.N., my friend, contributed many hours of assistance with preparation of tables and figures. Kathy Beck, R.N., B.S.N., assisted with the research. Renia Kimbrel, B.A., provided support services for the research. Teresa Cable, R.N., M.S.N. and Frank Cable, friends provided continuous encouragement. 
Employees of The Regional Medical Center, Memphis:

Lucy Shaw, M.B.A., President

Stuart Polly, M.D., Chief of Medical Staff

Rhonda Corsey, R.N., M.P.A., Director of Medical Surgical Nursing

Virginia Rodgers, R.N., Nurse Manager, and her staff

Jacky Harwell, R.N., B.S.N., Nurse Manager, and his staff

Donna Andrews, R.R.A., Assistant Director of Medical Records and

her staff

Mary Knox, R.N., B.S.N., Director of Hospital Quality Resource and

Utilization Department, and her staff

Susan Orahood, R.R.A., Manager of the Quality Information System

Billy Ray Jennings, Ph.D., Director of Hospital Information

Systems (HIS) department and his staff

J.B. Morris, Analyst in the Marketing and Planning Department

Employees of the University of Tennessee, Memphis:

Department of Biostatistics:

Kristopher L. Arheart, M.S., Research Associate

The Biomedical Information Transfer Center:

Ginny Butler, M.S., Senior System Analyst

College of Nursing:

Debora Sampson, C.P.S., Administrative Services Assistant

Kathleen Stewart, Administrative Services Assistant

Mary M. Goode, C.P.S., Staff Assistant

Marsha Chorice, Administrative Assistant

Finally, I gratefully acknowledge the encouragement of many family members and friends, especially my sister Ellen Hansen and my in-laws Laureta, Austin, and Kathryn Ann Larrabee. 


\section{Abstract}

Hospital quality assurance programs have been provider-oriented, focusing on structure and process elements of care rather than outcomes specific to patient needs and values. This study tested the relationship between quality and value, proposed in Larrabee's model of quality, by developing prediction indices for patient and nurse quality and value.

The sample consisted of 199 adult patients. Patient quality was measured by a $100 \mathrm{~mm}$ visual analog scale (VAS) (PQUALG) and a modified version of an existing instrument (PQUALT). Patient value was measured as patient goal achievement (PGOAL), the average of three VAS scores for patient defined goals of hospitalization. Nurse quality (NQUAL) was measured as percent agreement between process standards selected for each patient and nursing care documented. Nurse value (NGOAL) was measured as nurse goal achievement, the percent agreement between outcome standards selected for each patient and outcomes documented. Seven patient demographic, seven financial, six illness, and six hospital variables were also measured. PQUALG, PQUALT, PGOAL, and NGOAL were positively skewed and dichotomized for multiple logistic regression analysis.

Patient quality was correlated with PGOAL and NGOAL. PQUALG was correlated with PQUALT. NQUAL was not correlated with PQUALG, PQUALT, PGOAL, or NGOAL. PQUALG predictors were pain severity on exit interview (PAINNOW), clinic referral, unit, PGOAL, and being a Medicare recipient. PQUALT predictors were PAINNOW, PGOAL, clinic referral, unit, and worry score on admission. PGOAL predictors included PAINNOW, working part time, being a Blue Cross recipient, being white, being 
female, and combined household income. NQUAL predictors were being widowed and being a recipient of Medicaid. NGOAL predictors were PAINNOW, being married, and severity of illness score.

The results support the relationship between quality and value postulated by Larrabee's model of quality, identify pain management as an important aspect of care for nursing quality improvement programs, and demonstrate that patients and nurses evaluate different dimensions of nursing care. Future research based on Larrabee's model of quality should verify the accuracy of estimates of the odds ratios for predictors of value and quality and should test the relationships among quality and value and the remaining model concepts, beneficence, prudence, and justice. 
Table of Contents

Chapter 1. Introduction

Concern About Quality: Pertinent Contributing

Factors

Economic Concerns: Escalation of Health Care Costs

Philosophical Views

General Expectations of Quality

Summary of Concern About Quality

Limitations of Current Models of Quality

Lack of Consistency of Concepts

Limited Scope

Existing Quality Models Limit Knowledge Acquisition

Summary of Justification

Chapter 2. Conceptual Framework 17

Larrabee's Model of Quality 17

The Model 17

Model Assumptions 19

The Model and Aristotle's Philosophy 20

Achieving Beneficial Goods in Health Care 22

Quality Literature Supports Model Concepts 22

Value $\quad 22$

Beneficience $\quad 23$

Prudence $\quad 24$

Justice 25

Summary of Literature Support of Model Concepts 26

Utility of Larrabee's Model of Quality 26

$\begin{array}{ll}\text { The Study } & 27\end{array}$

$\begin{array}{ll}\text { Purpose } & 27\end{array}$

Aims and Research Questions 29

Operational Definitions 30

Assumptions 31

Chapter 3. Methodology 33

Design 33

Site 33

Description of the Hospital 33

$\begin{array}{cc}\text { Description of the Nursing Units } & 34 \\ \text { Sample } & 37\end{array}$

Sample Size $\quad 37$

Measurement of Patient and Nurse Quality Variables 38

Patient Quality Variables 38

Nurse Quality Variables $\quad 45$

Measurement of Predictor Variables 48

Patient Demographic Variables 48

Financial Variables 49

Illness Variables 51

Hospital Variables $\quad 52$ 
Procedure $\quad 53$

Site Preparation $\quad 53$

Data Collectors $\quad 55$

Data Collection $\quad 57$

Descriptive Data Analysis 59

Patient and Nurse Quality Variables $\quad 59$

Predictor Variables 60

Analysis of Aims $\quad 62$

Aim 1: Identify Relationships Among Patient and

Aim 2: Develop Prediction Equations for Patient

Aim 3: Develop Prediction Equations for Nurse Perceived Quality and Nurse Goal Achievement 64

Aim 4: Determine Congruence Between Predictors of Patient Perceived Quality and Nurse Perceived Quality

Aim 5: Determine Congruence Between Predictors of Patient Goal Achievement and Nurse Goal Achievement

Chapter 4. Results 66

Demographic and Descriptive Statistics 66 Sample 66

Descriptive Statistics 71

Analysis of Aims $\quad 71$

$\begin{array}{ll}\text { Aim 1: Identify Relationships Among Patient and } & \\ \text { Nurse Perceived Quality and Goal Achievement } & 71\end{array}$

Aim 2: Develop Prediction Equations for Patient
Perceived Quality and Patient Goal Achievement

Aim 3: Develop Prediction Equations for Nurse
Perceived Quality and Nurse Goal Achievement

Aim 4: Determine Congruence Between Predictors of Patient Perceived Quality and Nurse Perceived Quality

Aim 5: Determine Congruence Between Predictors of Patient Goal Achievement and Nurse Goal Achievement

$\begin{array}{lll}\text { Chapter 5. Discussion } & 106\end{array}$

Specific Aims $\quad 106$

$\begin{array}{ll}\text { Aim 1: Identify Relationships Among Patient and } & \\ \text { Nurse Perceived Quality and Goal Achievement } & 106\end{array}$

Aim 2: Develop Prediction Equations for Patient Perceived Quality and Patient Goal Achievement 112

Aim 3: Develop Prediction Equations for Nurse Perceived Quality and Nurse Goal Achievement

Aim 4: Determine Congruence Between Predictors of Patient Perceived Quality and Nurse Perceived Quality

Aim 5: Determine Congruence Between Predictors of Patient Goal Achievement and Nurse Goal Achievement 
Strengths and Limitations $\quad 124$

Generalizability 124

$\begin{array}{ll}\text { Measurement } & 125\end{array}$

Design 131

Theoretical Framework 132

Theoretical Framework 133

Quality and Value as Intrinsic Worth 133

Quality and Value as Relative Worth 134

Quality and Beneficence 135

Quality and Prudence and Quality and Justice 135

Future Research 136

Measurement 136

Design 138

Generalizability 138

Theoretical Framework 138

$\begin{array}{ll}\text { Conclusion } & 140\end{array}$

Chapter 6. References 142

$\begin{array}{ll}\text { Appendices } & 155\end{array}$

Initial Interview Schedule 156

Exit Interview Schedule 163

Chart Review Form 172

$\begin{array}{ll}\text { Vita } & 177\end{array}$ 


\section{List of Tables}

Table 1. Patient and nurse quality variables. 39

Table 2. Predictor variables. $\quad 40$

Table 3. Least square means and standard errors of
age for sample attrition.

Table 4. Characteristics of participants, lost participants, and nonparticipants:

$\begin{array}{ll}\text { discrete variables. } & 69\end{array}$

Table 5. Description of sample. 70

Table 6. Descriptive statistics for patient quality

Table 7. Descriptive statistics for financial variables. 78

Table 8. Descriptive statistics for illness variables. 79

Table 9. Descriptive statistics for hospital variables. 80

Table 10. Estimated Pearson correlations among patient
quality variables and nurse quality variables.

Table 11. Beta coefficients, standard errors, p values, and deltas from simple logistic regression for predictors of patient perceived quality global (PQUALG) $(\mathrm{n}=199)$.

Table 12. Likelihood ratios estimated as odds ratios for predictors of patient perceived quality global (PQUALG) $(\mathrm{n}=199)$.

Table 13. Prediction index from multiple logistic

regression for patient perceived quality global (PQUALG) $(n=199)$.

Table 14. Adjusted odds ratios and $95 \%$ confidence intervals from multiple logistic regression of predictors of patient perceived quality global (PQUALG) $(n=199) . \quad 86$

Table 15. Beta coefficients, standard errors, p values, and deltas from simple logistic regression for predictors of patient perceived quality total (PQUALT) $(\mathrm{n}=199)$.

Table 16. Likelihood ratios estimated as odds ratios for predictors of patient perceived quality total (PQUALT) ( $n=199)$. 
Table 17. Prediction index from multiple logistic regression for patient perceived quality total (PQUALT) $(n=199)$.

Table 18. Adjusted odds ratios and $95 \%$ confidence intervals from multiple logistic regression for predictors of patient perceived quality total (PQUALT) ( $n=199)$.

Table 19. Beta coeficients, standard errors, p values, and deltas from simple logistic regression for predictors of patient goal achievement (PGOAL) $(n=199)$.

Table 20. Likelihood ratios estimated as odds ratios for predictors of patient goal achievement (PGOAL) $(n=199)$.

Table 21. Prediction index from multiple logistic regression for patient goal achievement (PGOAL) $(\mathrm{n}=199)$.

Table 22. Adjusted odds ratios and 95\% confidence intervals from multiple logistic regression of predictors of patient goal achievement (PGOAL) $(n=199)$.

Table 23. Estimated regression coefficients and standard errors from multiple regression for predictors of nurse perceived quality ${ }^{2}$ (NQUAL) $(n=199)$.

Table 24. Two-way analysis of variance: mean nurse perceived quality by Medicaid recipient status and widow status $(n=199)$.

Table 25. Least squares means and standard errors for nurse perceived quality from two-way analysis of variance $^{a}(n=199)$.

Table 26. Beta coefficients, standard errors, p values, and deltas from simple logistic regression for predictors of nurse goal achievement (NGOAL) $(n=199)$.

Table 27. Likelihood ratios estimated as odds ratios for predictors of nurse goal achievement (NGOAL) $(\mathrm{n}=199)$.

Table 28. Prediction index from multiple logistic regression for nurse goal achievement (NGOAL) $(n=199)$.

Table 29. Adjusted odds ratios and $95 \%$ confidence intervals from multiple logistic regression for predictors of nurse goal achievement (NGOAL) $(n=199)$. 


\section{List of Figures}

Figure 1. Larrabee's model of quality. 18

Figure 2. Model for investigation. 28

$\begin{array}{lll}\text { Figure 3. Sample attrition. } & 67\end{array}$

Figure 4. Distribution of patient perceived quality global.

Figure 5. Distribution of patient perceived quality total.

Figure 6. Distribution of patient goal achievement.

Figure 7. Distribution of nurse perceived quality. 76

Figure 8. Distribution of nurse goal achievement. 


\section{Chapter 1. Introduction}

Health care organizations today are struggling to provide quality health care in a politically and economically constrained environment. Interest in the quality of health care has increased as consumerism ${ }^{1}$ and costs of health care have escalated in this country..$^{2-4}$ And, we have crossed the threshold of an era when reimbursement for health care is tied to patient outcomes. The voluminous literature on health care quality reveals: (a) long-standing provider concern about quality; $i^{2,5-15}$ (b) several useful, though conceptually limited, quality assessment models $i^{8,16-22}$ (c) great strides in the measurement of quality, using narrow, discipline-specific operational definitions of quality; $;^{9,19,23-27}$ and (d) opportunities for the improvement of care. ${ }^{28-32}$ However, a new model of quality is needed, because most of the quality assessment models are conceptually limited and, therefore, limit knowledge acquisition about care improvement strategies.

None of the existing quality models explicated or implied in the literature provide a framework for a comprehensive, wholistic view of the concept of quality. The gaps in the models suggest that there are aspects of quality about which we will learn little or nothing. Some of these gaps regard individual well-being and the general welfare. None of the existing models are interdisciplinary, even though they are appropriate for use by many disciplines. None consider the issue of fair distribution (distributive justice) of public funds for health care, even though more recent models incorporate economic concerns. Also, none view patient and/or family perceptions as integral dimensions of quality or incorporate patient and/or family contributions to health care outcomes, even though more recent models 
incorporate patient satisfaction. These conceptual limitations in existing models of quality limit investigation of such questions as what influence differences in patient and provider value have on outcomes.

The significance of these limitations of existing models is highlighted by the escalation of health care costs, forcing imperative questions about how to justify choices for the expenditure of scarce health care dollars, both private and public. ${ }^{27,33-39}$ Therefore, a new model of quality is needed which will include both ethical and economic perspectives, will bridge the gaps in current models, and provide a framework for comprehensive, wholistic understanding of quality.

The purpose of this study is to test the theoretical relationships among quality and value in Larrabee's model of quality by identifying predictors of patient and nurse perceived quality and goal achievement. In this chapter, justification of the need for a new model of quality is presented by first discussing pertinent factors contributing to the present concern about quality of health care and second by discussing limitations in existing models of quality. Then, key points will be summarized.

\section{Concern about Quality: Pertinent Contributing Factors}

The factors which have precipitated the current nationwide concern for quality of health care are multiple and complex. Factors which are thought to have a significant influence include: (a) the escalation of health care costs; (b) differences in philosophical view; and (c) general expectation of quality in products and services. Each of these are addressed in turn. 


\section{Economic Concerns: Escalation of Health Care Costs}

Escalation in health care costs have been dramatic. Between 1950 and 1977 the cost of health care in this country rose $277 \%$ while the general price level rose $152 \%{ }^{40}$ Today, health care represents $13.1 \%$ of the gross national product (GNP), an increase from $7.4 \%$ in $1970 .^{2}$ Together, government agencies and private insurance companies pay for approximately $60 \%$ of physician services and $90 \%$ of hospital services. ${ }^{2}$ When all health care services are considered, $50 \%$ of costs remain the burden of the consumer. ${ }^{2}$ Health care could cost as much as $25 \%$ of the GNP by the year 2010, because the current rate of growth is expected to continue. ${ }^{2,10}$ A number of factors have contributed to the health care cost escalation, including increased utilization, subsidization of services by government funds and private insurance, and technological advances in diagnostic and treatment services. Understandably, payors, including self-paying recipients, are very concerned about this continuing escalation.

The escalation of health care costs has been accompanied by a growing concern for quality of health care on the part of recipients, consumer advocates, payors and providers. Recipients and consumer advocates want the best quality care for the price paid, question whether they are getting it, and are pressing for improvements. ${ }^{1,2,10,27}$ Both the federal government and providers have made quality improvement efforts. The federal government has linked the quality of care with eligibility to receive Medicare or Medicaid reimbursement by requiring that hospitals have professional standards review and that nursing homes engage in quality assurance activities. ${ }^{41,42}$ 
Provider quality improvement efforts include expanding knowledge about the most effective diagnostic and management strategies for health problems. This knowledge about efficacy is limited; ${ }^{31,43}$ therefore, knowledge about quality in health care will be limited to those aspects of care for which efficacy in management is known. Most provider efforts at quality assessment have not included alternative strategies for care improvement ${ }^{28}$ or associated costs of care. ${ }^{8,16,17,21,23,25,44-49}$

Despite quality improvement efforts by the federal government and providers, the ability to assure reasonable quality at a fair price is limited by lack of agreement about what quality is. Definitions of quality include different fundamental concepts and most exclude consideration of the economic implications of the cost to society of quality health care. Most definitions of quality also exclude the recipient's expectations of quality, goals for health care, or view of the economic worth of quality health care. Therefore, a new model of quality is needed to incorporate these issues, identify fundamental concepts of quality, and provide a framework for viewing quality wholistically.

The cost of health care has and is continuing to escalate. Simultaneously, recipients are demanding high quality care at a fair price, the assurance of which is limited both by efficacy and by using available definitions of quality. As mentioned, several factors have contributed to health care cost escalation. Underlying these factors is, perhaps, a more fundamental reason: philosophy. Philosophical differences can contribute to differences in definitions of quality. 


\section{Philosophical Views}

There are two types of philosophical orientation which can influence definitions of quality. The first type is economic in nature and the second type is philosophical in nature.

Economic view. Individuals with an economic perspective will make different decisions about quality of care than those with either a romantic or monotechnic perspective. ${ }^{34}$ Providers with an economic perspective will recognize that there are scarce resources and that there are competing demands for those resources. The person with the "romantic" perspective fails to recognize the scarcity of resources relative to wants and thus fails to recognize the need for making choices on either an individual level or at a policy-making level. Individuals who are highly educated in one technology, such as health care providers, possess a "monotechnic" perspective. They may apply that perspective when making choices about using scarce resources. This "monotechnic" perspective fails to recognize the claims of competing wants or the diversity of individual preferences for the use of resources. ${ }^{34}$ The provider with either a romantic or a monotechnic perspective is at risk for making decisions about quality of care without considering how much care costs or who will pay.

With a few exceptions, ${ }^{19,50}$ most definitions of quality exclude consideration of the economic orientation. ${ }^{9,15,17,44,51,52}$ While philosophy influences decisions about what quality is and what care will be given, the care given determines costs of care. Therefore, economic orientation must be considered in any definition, measurement, and improvement of quality, because of the economic consequences of the care given. 
Ethical philosophy. The second philosophical orientation upon which the definition of quality depends is the ethical philosophy about whether the individual is preeminent to society or visa versa. Providers are ethically responsible for giving care that has some degree of desired quality, is appropriate, and has value and benefit for the recipient. ${ }^{53}$ Providers and policy makers whose ethical philosophy is that the welfare of society is morally preeminent to the welfare of the individual will make different decisions than those who believe that the welfare of the individual is morally preeminent to the welfare of society. ${ }^{53}$

This basic philosophic difference will influence the view of quality. The provider who believes that the welfare of the individual is preeminent to the welfare of society is at risk of making decisions about quality of care involving expenditure of public funds that may not be in the interest of the general welfare. Most definitions of quality imply consideration of individual well being but not the individual's or society's financial welfare. Ethical philosophy influences both the quality and the cost of health care and, therefore, must be considered in any definition, measurement, and improvement of quality.

Thus, philosophical perspectives are potential contributing factors to the escalation of health care costs in the last 25 years. Pressure to achieve an egalitarian society has motivated governments, providers, and consumers to adopt the objective of the best possible health care for everyone. ${ }^{35,36}$ This objective ignores the economic premises that resources are limited, that there are competing wants for resources, and that everyone does not value health equally. ${ }^{34}$ 
Providers and policy makers with either the romantic or the monotechnic, as opposed to the economic, perspective have partially driven the technological advancement in care, the increased utilization, and the increased costs of care. ${ }^{34}$ Another potential contributing factor is society's general expectation of quality in products and services. This general expectation of quality, in addition to health care cost escalation and philosophy, has contributed to the nationwide concern for quality.

\section{General Expectations of Quality}

Interest and concern for quality in Western culture has become pervasive over the past 30 years. Media advertisements barrage us daily with promises of quality: "quality is job one"; "quality is built in before the name goes on"; "good to the last drop and the last drop's good too"; "old fashioned quality"; "quality above all"; "quality above the rest"; and "quality you can depend on". Interest in quality was not always widespread in this country. This interest has escalated throughout all American businesses because of the immensely successful economic competition from Japanese businesses that had adopted the quality control strategies of Deming and Juran. ${ }^{54-61}$ Meeting the needs of the customers is the cornerstone of this quality control model in industry and business, because even if they cannot define quality, they "know it when they see it". ${ }^{2}$

Even when consumers cannot define what quality means, they expect particular characteristics of products and services which they want or need. Demand, and thus profit, is generated by wants and needs. When consumers' expectations of a product or service are not met, their demand for those commodities decreases or they change suppliers. 
Therein lies the motivation for providers to know what their recipients expect from health care services and how they define quality.

Health care providers have pursued two related activities that are attempts to ensure that their customers' expectations are met. The first activity is investigation of patient satisfaction ${ }^{1,63-73}$ and the second is adoption of Total Quality Management.

Patient satisfaction. Some of the diverse patient satisfaction instruments have solicited patients' perceptions of technical care quality, ${ }^{68-71}$ even though many providers consider patients unqualified to make those judgments. Predominately, the categories patients express opinions about are interpersonal care, provision of information, communication, living arrangements, or the amenities, $^{64-67,74}$ rather than the technical care. No instruments were located which evaluate the influence on patient satisfaction of patient expectations about health status on discharge. Research findings indicate that patients can distinguish between kinds of staff and services $^{75-78}$ and that they prefer a comfortable hospital environment with amenities, good food, adequate information, and interpersonal care that communicates respect and caring. ${ }^{65-67,72,73}$ However, despite the various studies which have been conducted, whether or how to use patient satisfaction information in evaluating and improving technical care quality remain unclear.

Total Quality Management. The second customer responsive activity recently adopted by various health care agencies and providers is Total Quality Management (TQM). TQM is an application of the industrial quality control model. While concern for health care quality is 
historic $5,7,79,80$ and pursuit of quality has included a variety of strategies, ${ }^{7,13,20,81-84}$ the industrial quality control model is appealing to health care agencies ${ }^{85-88}$ because its strategies have benefited organizations in competitive markets, may help improve care quality, and focuses on consumer expectations. Many principles in the industrial model are useful in the health care field and are likely to help providers meet many of their customers' expectations.

However, at least one principle from this model is problematic for the health care field. Providers in health care do not have total control over all the inputs that produce health care outcomes. Crosby $^{57}$ advocates zero defects in products and services. Attempting to achieve excellence in health care is realistic, expecting zero defects is not. There are fundamental differences between controlling the structure and performance of inanimate objects to produce specified outcomes, the focus of industry, and controlling the dynamic social, psychological, and physiological behaviors of the human organism to achieve desired outcomes, the focus of health care. Using careful and precise workmanship, machine parts can be finely tooled to near perfection and can be joined together properly to make the desired product. The achievement of desired health care outcomes is not analogous.

While the dramatic technological improvements in health care diagnostic and treatment services have increased our knowledge about the efficacy of various care alternatives, there are many health care problems for which effective management remains elusive. ${ }^{2,89}$ As with general expectations of quality in products and services, recipients of care have expectations of health care quality. If those expectations 
are unrealistic or differ from those of providers, it is likely that there will be discrepancies between the recipient's definition and perceptions of quality and those of providers.

In fact, the recipient of care is often a major contributor to health care outcomes. Yet, neither patient satisfaction instruments nor quality assessment models assess how well satisfied the patient is with his contribution to his care, to what extent his participation influenced outcomes, or whether he accepted and implemented provider recommendations. Instead, these instruments may convey the impression that providers do have total control over health care outcomes, when in fact, knowledge of the efficacy of technical and interpersonal care remains quite limited. Thus, we do not know how differences in patient and provider value influence outcomes or perceptions of quality.

\section{Summary of Concern about Quality}

Three interrelated factors that have contributed to the current nationwide concern for quality of health care have been discussed. First, and perhaps most significant, is the dramatic escalation in health care costs over the last 25 years, with its economic implications for payors. Second, although a more subtle contributing factor to the concern about quality, philosophical perspective has probably strongly influenced decisions about health care alternatives, as well as, health care policy. Exclusion of ethical and economic orientations from most definitions of quality limit the ability to understand quality wholistically. And, third, society's general interest in quality of products and services has been extended to health care services, especially in light of the remarkable technological advancements of the past 25 years. Thus, providers have 
considerable motivation to pursue high quality, cost effective care. Yet, this pursuit is limited by efficacy and by current definitions of quality.

\section{Limitations of Current Models of Quality}

What is quality? Quality has been acknowledged as a complex multidimensional construct, ${ }^{8}, 9,13,16,27,30$ one which has been suggested eludes definition. ${ }^{90,27}$ Significant inroads have been made over the years by numerous authors in operationally defining and measuring quality. $8,14,19,20,23,25,27,29,50,80,91-93$ Despite the progress in measurement, both a broad understanding of quality and efforts at quality improvement are hampered by two major limitations inherent in the current conceptualizations of quality and related assessment methodologies. These limitations, which pertain to the complex multidimensional nature of quality, are (a) lack of consistency in concepts included in the conceptualizations of quality, and (b) limited scope of these conceptualizations.

\section{Lack of Consistency of Concepts}

The major limitation is that the various abstract and operationalized definitions of quality have not consistently included the same fundamental concepts. Some of the elements of the construct of quality have been easier to define and to measure than others $^{8,27,31,94}$ Specifically, it has been easier to define and measure the structure and process elements of care quality than outcomes..$^{8,27,30,31,49}$ Therefore, structure and process approaches to quality assessment have predominated, although outcome assessment is currently of renewed interest. ${ }^{94-99}$ Quality assessment approaches have 
examined these three elements of care (structure, process, and outcome) either singly or in various combinations. This inconsistency impedes wholistic understanding of quality. Much of this inconsistency is due to the second significant limitation of existing models of quality: limited scope.

\section{Limited Scope}

Limited scope is inherent in the current conceptualizations of quality and related assessment methodologies. Scope has been limited in at least five ways. First, most work has focused on quality assessment of health care intervention for disease or illness, usually in hospital settings. However, much of health care is given in homes, clinics, offices, rehabilitation centers, and nursing homes. Also, much of health care is given to maintain health and prevent illness. An abstract definition of quality that is broad enough to be appropriate for all sites and for any point on the health continuum is needed to increase understanding of quality and appropriate improvement strategies.

Second, most operational definitions of quality have limited the focus to one provider discipline, such as medicine or nursing, rather than the multidisciplinary health care team. ${ }^{8,9,16,17,19}$ Because the outcomes of care are often partially dependent upon the judgments and actions of providers in other disciplines, single discipline oriented conceptualizations of quality will yield limited and perhaps invalid assessments of quality. ${ }^{2,30}$

The third way scope has been limited is by predominance of a monotechnic orientation in the conceptualizations of quality. In other words, the majority of the health care quality literature has been 
oriented exclusively to assessing technical care effectiveness with little or no consideration of the economics of care. $8,15-17,20$ Exceptions include several authors who have advocated simultaneous assessment of quality and costs. ${ }^{19,30,50}$ The most notable exceptions are two proposed assessment models incorporating quality and costs. ${ }^{19,50}$ While these models are the most comprehensive to date, their scope is limited to the individual recipient of care. They exclude the contribution the recipient's decisions and behaviors make to outcome achievement. And, these models exclude the ethical issue of distributive justice in the utilization of public resources for financing health care.

The fourth way scope has been limited is that the vast majority of conceptualizations of quality have not integrated the recipient's perception of the quality of care. Over the last thirty years, there has been interest in evaluating patient satisfaction, but Donabedian, Wheeler, and Wyszewianski ${ }^{50}$ and Doessell and Marshall ${ }^{19}$ are the first to incorporate patient satisfaction within quality assessment models. Recipients' prefer to be treated with respect by providers and they prefer to receive care in an environment that has amenities. Still much remains to be learned about what concept is being measured by measuring patient satisfaction and how it fits within a complex construct of quality. Specifically, knowledge is needed about the relationship between recipients' satisfaction with the amenities, interpersonal care, or technical care and either their estimation of the value of the care or the providers' estimation of the quality of care. This task could be facilitated by including within a broad construct of quality the concept of relative value: The value the 
recipient places on his health and alternative health care options, considering his other wants and needs. Including value as a concept within the construct of quality corrects for overlooking the possibility that individuals have limited resources which they must expend on competing wants and needs, an error of the monotechnic perspective.

And, finally, most of the conceptualizations of quality have focused on the individual recipient's well-being to the exclusion of social or general welfare. This limitation is problematic because it suggests an erroneous assumption that societal resources for health care are unlimited. Individual well-being is valued highly in our society. Much of the governmental intervention in the last twenty-five years represents attempts to improve accessibility of health care to those individuals with limited financial resources. Yet, it is a fact that subsidization of health care via public programs uses funds from other members of society and those funds are limited. Ignoring that resources are scarce when making care decisions that expend public funds can compromise the general welfare of society. Thus, the limited scope of quality conceptualizations is a problem because individual well-being will eventually be threatened when the general welfare is compromised.

\section{Existing Quality Models Limit Knowledge Acquisition}

The limitations of current conceptualizations are likely due to differences in philosophical assumptions, evolution in the field of quality assurance, and pragmatic reasons. The inconsistency of fundamental concepts and the limited scope of many quality assessment approaches have had practical utility for the emerging field of quality 
assurance. Narrowing the scope of operational definitions has facilitated the refinement of assessment criteria and instruments for the aspects of care being assessed by a particular discipline. Discipline specific quality assessment approaches have targeted some problems for improvement.

However, the limited scope and inconsistency of concepts have produced fragmented views of quality and indicate that there are gaps inherent in the current conceptualizations. None of the models provide a framework for a comprehensive, wholistic view of the construct of quality. The existing quality models cannot yield knowledge about those aspects of quality implied by concepts excluded from those models. For instance, existing models cannot be used as a framework for examining the influence on health care outcomes of recipient expectations and behaviors. Likewise, existing models cannot serve as a framework for investigating relationships among patient and provider value and quality.

Bridging the conceptual gaps in existing models will be necessary to acquire knowledge about quality from a more comprehensive viewpoint. Therefore, a new, broader model is needed to provide a framework for conceptually organizing prior work and for generating future operational definitions that can lead to understanding quality more wholistically than is possible with the existing models of quality.

\section{Summary of Justification}

Health care organizations today are struggling to provide quality health care in a politically and economically constrained environment. Three factors have contributed to the present concern for health care quality: (a) escalation in health care costs; (b) differences in 
philosophical views; and (c) the general societal expectation of quality in products and services. However, knowledge acquistion about quality improvement, in general, and the influence of differences in patient and provider value on outcomes, in specific, is constrained by lack of conceptual consistency and limited scope of exiting models of quality. Therefore, a new wholistic model of quality, which includes both ethical and economic perspectives, is needed to provide a framework for comprehensive, wholistic understanding of quality. 
Chapter 2. Conceptual Framework

\section{Larrabee's Model of Quality}

The conceptual framework for this study is Larrabee's model of quality, a new wholistic model of quality. This model was synthesized using concepts from Aristotle's ethical and political philosophies, ${ }^{100-106}$ concepts inherent in the quality assurance literature, and concepts from a linguistic analysis. ${ }^{107-109}$

\section{The Model}

In Larrabee's model, quality is the presence of socially-acceptable, desired attributes within the multifaceted wholistic experience of being and doing and quality encompasses at least the four interrelated concepts: value, beneficence, prudence, and justice (Figure 1). Value is defined as: (a) something intrinsically desirable; (b) relative worth, utility, or importance; and (c) a fair return in goods, services, or money for something exchanged. Beneficence, is defined as actual or potential capability for (a) producing good and (b) promoting well-being. Beneficence encompasses harmlessness. Well-being is of value to individuals, groups, and society, but Aristotle viewed general welfare of society as preeminent to the well-being of individuals. ${ }^{100,101}$ Prudence is defined as: (a) good judgment in setting realistic goals and (b) good judgment and skill in using personal resources to achieve goals. Justice is defined as fairness, ${ }^{100}$ which has these two components: (a) distributive justice, using common resources proportionately to the individual's contribution to those resources and (b) corrective justice, correcting an injustice by finding the mean between the extremes of profit and loss. ${ }^{100}$ 


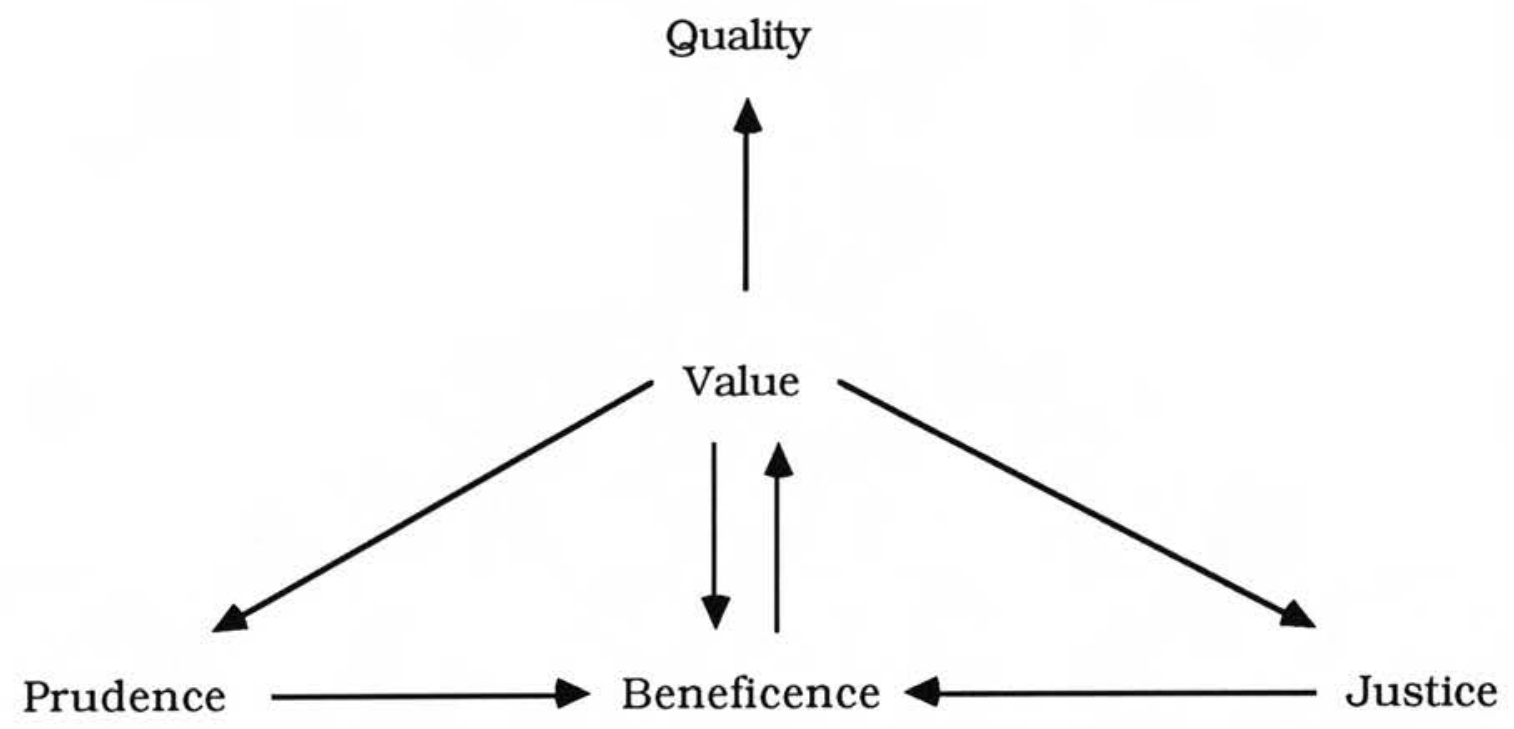

Figure 1. Larrabee's model of quality. 
Beneficence is the most fundamental concept in Larrabee's model of quality and is influenced by quality, value, prudence, and justice. It is postulated that the extent to which benefits are valued should influence the expenditure of personal (prudence) or public funds (justice). Also, it is postulated that the quality of care delivered will influence beneficence. Benefits achieved will, in turn, influence patient perceptions of quality, depending on the relative value of the benefits to the patient. Thus, it is also postulated that value is a possible intervening or a weighting concept between quality and the remaining concepts in this model.

\section{Model Assumptions}

The major underlying assumptions in Larrabee's model of quality are that (a) human experience is a wholistic dynamic process, (b) experiences can be understood, (c) humans possess hierarchies of goals which are tempered by social acceptability and the good of society, (d) quality is a multifaceted construct, and (e) perception influences the estimation of all concepts, including quality.

The defining characteristics of quality in this model are:

1. A desired attribute, characteristic, or property of a person, a thing, a goal, an action, an accomplishment, or a metaphysical experience.

2. The desired attribute has degrees or ranks of desirability, reflecting social and cultural values.

3. The desired attribute is socially and ethically acceptable and not harmful to society.

4. When the desired attribute is capable of causing sensory perceptions in another, it can be empirically measured. 
5. When the desired attribute is metaphysical, the individual desiring the attribute for himself is able to determine the degree to which it is present.

6. The desired attribute meets the criteria of being the appropriate or involving the right:
a. thing
b. person
c. amount
d. time
e. reason
f. way

7. The degree of desirability of the attribute is dynamic, influenced by changing contextual circumstances of the individual, society, culture, and by the political envi ronment.

8. The degree of desirability of the attribute is influenced by whether the attribute of being/doing pertains to one's self or to others.

9. The desired attribute of a goal is valued more highly than the goal-driven actions.

The Model and Aristotle's Philosophy

Aristotle's ethical philosophy demonstrated a model for evaluation of quality. ${ }^{100,101,103}$ He described quality as a predicate by which people categorize things. Aristotle described some predicates as value-neutral and some as value-ladened. Defining value-ladened predicates causes questions of value to become questions of fact which are answerable by factual evidence. ${ }^{108}$ For instance, in the statement "Plato is honest", honest is a value predicate. Honesty can be defined, producing criteria against which Plato's actual behavior can be judged. Thus, applying this logic to Larrabee's model of quality, 
the proposed defining characteristics of quality can be used to evaluate a person, thing, goal, action, judgment, accomplishment, or metaphysical experience.

Aristotle's ethical and political philosophies contributed further to a wholistic model of quality because it proposed a hierarchy of "goods" for individuals and society. ${ }^{100,101}$ Aristotle's use of "goods" implied beneficial goals. In the hierarchy of goods, actual achievement of goods is valued more highly than the means of achievement. Also, in this hierarchy, the good of the group is valued more highly than the good of the individual, since the individual will suffer if society suffers.

Larrabee's model of quality incorporates principles of Aristotle's hierarchy of goods and evaluation of value-laddened predicates. For instance, in health care, there are many activities and intermediate goals which may be necessary to produce desired health outcomes. The quality of the activities, the intermediate goals, and the final outcomes can be measured because evaluation criteria can be defined. The quality of health care activities and intermediate goals are of importance primarily because of their influence on outcome achievement. Ultimately, the importance of the quality of process and outcome is weighted by how valuable the outcome is to the individual or to society. Thus, in Larrabee's model of quality, value is proposed as a possible intervening, or a weighting, variable between quality and the remaining variables in the construct (beneficence, prudence, and justice) . 


\section{Achieving Beneficial Goods in Health Care}

Conscious goal-setting in health care is usually done by the provider without collaborating with patients. This tradition presumes that providers always know what is best for patients. The industrial model of quality is so focused on customer responsiveness that it suggests the patients always know what is best for themselves. Probably, neither extreme is the best approach.

Goals provide direction for life experience, regardless of conscious awareness of one's goals. Patients have goals for health care experiences. Providers should find out what patients' goals are, because goal incongruence may adversely effect goal achievement. Some patient goals may be realistic, others may not be. When an individual's goal is harmful or potentially harmful to self, others, or society, that goal will be viewed as socially undesirable. Providers can help patients with unrealistic or socially undesirable goals modify those goals. Awareness of and planning for patient goals should have a positive impact on the quality and cost effectiveness of health care.

\section{Quality Literature Supports Model Concepts}

Larrabee's model of quality was synthesized from Aristotle's ethical and political philosophies and a linguistic analysis of quality. In addition, support for the model of quality including the concepts of value, beneficence, prudence, and justice can be found either explicated or implied in the literature.

\section{Value}

Value is defined as: (a) something intrinsically desirable; (b) relative worth, utility, or importance; and (c) a fair return in 
goods, services, or money for something exchanged. Support for a model of quality including the concept of value is either explicit or implicit in most of the literature.

The first two meanings of value have been explicitly linked with quality by many authors, ${ }^{21,93,110,111}$ most notably by Steffen, ${ }^{51}$ Donabedian, $^{8}$ and Donabedian et al. ${ }^{50}$ Quality has been implied as a value-ladened standard of comparison in numerous references to care that is good, bad, poor, better, appropriate, inappropriate, minimally acceptable, desirable, undesirable, inferior, optimal, or suboptimal. $3,8,15,19,27-29,31,33,50,51,91,93,111-113$.

Also, discussions of quality have implied the third meaning of value, especially in reference to cost-benefit tradeoffs. $^{3,8,19,27,29,50,91,110,111}$ Many of these references have addressed cost of care as an important companion variable to be considered with quality of care. ${ }^{3,8,19,50,110}$ Most notably, two recent models of quality assessment have explicitly ${ }^{50}$ and implicitly ${ }^{19}$ linked value with quality, incorporating costs of care in the assessment and analysis of quality. Thus, there is substantial explicit and implicit support in the literature for including value in a model of quality.

\section{Beneficence}

Beneficence, is defined as actual or potential capability for: (a) producing good and (b) promoting well-being. Beneficence encompasses harmlessness. Support for this concept being included in a construct of quality abounds in the literature on quality.

Many discussions of quality have explicitly mentioned benefits to recipients of care. $3,19,27,31,50,51,93,110,114$ In fact, Donabedian stated that "the balance of health benefits and harms is the essential 
core of a definition of quality." ${ }^{114}$ Numerous authors have implied benefits to recipients when discussing both preventing undesired outcomes, such as disability and death ${ }^{3}, 8,15,27,29,50,111$ and achieving desired outcomes, such as survival, improved functional ability, recovery, and restoration. $8,15,19,21,33,91,93,111,112$ Most of the quality assurance literature has focused on the benefit to individuals, ${ }^{8}, 17-19,21,29,31,33,47,51,111,112$ with a few considering benefit to society as a whole..$^{3,15,50,91,93,110}$ Still, there is such extensive support for beneficence being included within the construct of quality that it is the most fundamental concept.

\section{Prudence}

Prudence is defined as: (a) good judgment in setting realistic goals and (b) good judgment and skill in using personal resources to achieve goals. Some authors have suggested consideration of the recipient's decisions about using personal resources for health care $^{4,8,19,22,38,39,50,51,91}$ and Donabedian et al. ${ }^{50}$ and Doessel and Marshall $1^{19}$ have implied this concept in their models of quality assessment. However, no model of quality assessment considers the contribution recipient behaviors make to outcomes, despite acknowledgement that recipient decisions and behaviors can influence outcomes. ${ }^{8}, 21,51,91,93,111$ Also, no model of quality assessment includes consideration of the relationship between patient estimation of quality and outcomes, providers' estimation of quality, personal financial burden for health care, or the value recipients' place on the anticipated benefits of care, despite consideration of patient satisfaction with care. ${ }^{1,29,63-73,91,93}$ Prudence needs to be included in a broad construct of quality to support the investigation of the 
contribution to quality made by the recipient, as well as, investigation of factors that contribute to recipients' estimation of quality.

Justice

Justice is defined as fairness, ${ }^{100}$ which has these two components: (a) distributive justice, using common resources proportionately to the individual's contribution to those resources; and (b) corrective justice, correcting an injustice by finding the mean between the extremes of profit and loss. ${ }^{100}$ While no quality assurance articles explicitly refer to justice, this concept is implied by several authors discussing quality, economics, and care the public is willing to subsidize. $.^{3,8,19}, 30,33,50,93$ Medicare and Medicaid were initiated to correct the injustice to the elderly and the poor in distribution of health care. ${ }^{3}$

The ethical issue of justice is bonded to economic and public policy issues because much subsidized health care is financed by finite public funds. ${ }^{2,10}$ When the costs of health care are bourne entirely by the individual, decisions about "what care" and "how much care" are personal. But when health care is financed by society, those decisions become a matter of public policy. ${ }^{37}$ The experience of the past 25 years validates that pursuit of quality improvement must include choices based on considerations of costs, because both public and private financial resources are finite. ${ }^{30,40,89}$ The quality and the costs of health care must be balanced to provide the consumer/recipient reasonable quality of care for a reasonable price to the payor. ${ }^{2,3,31}$ Assessment and improvement of care quality in an economic manner must be based upon an understanding of what quality means. While there 
has been much concern about the costs of health care in general $^{2,31,40,93}$ and publically-subsidized health care specifically, ${ }^{3,27,30}$ no model of quality assessment has included the concept of justice. Still, the continuing escalation of health care costs and public subsidization, as well as disparity in health care access, support the need for inclusion of justice within the model of quality.

\section{Summary of Literature Support of Model Concepts}

The majority of the literature either explicitly or implicitly incorporates value and beneficence in definitions of quality, substantially supporting their inclusion in a model of quality. Prudence and justice are implied concepts linked with quality by several authors. Nationwide concern for the unabated escalation of health care costs provides additional support for including justice and prudence in a model of quality. ${ }^{2,3,10,30,40}$ Larrabee's model of quality is the first to explicitly propose that beneficence, value, justice, and prudence are concepts within a contruct of quality.

\section{Utility of Larrabee's Model of Quality}

Larrabee's model of quality is value-ladened and wholistic. The model encompasses well-being of individuals and the general welfare of society, perceptions of supplier and consumer of products or services, individual judgments about use of personal resources, and providers' and policymakers' judgments about use of public funds. Because of it's wholistic nature, Larrabee's model can serve as a framework for investigating the influence on outcomes of patient behavior, cost, and quality of care. 
The model provides a framework for investigating the influence of ranked importance of patient goals upon patient judgments to use personal resources and, subsequently, on health outcomes. The model can be used to evaluate personal and societal cost/benefit ratios of different but effective treatment or care strategies. On a larger scale, the model can be used to evaluate the societal cost/benefit ratio of different health care programs competing for the same health care dollars. Also, this model provides a framework for investigating how patient perceptions fit in a model of quality and whether differences in patient and provider value influence quality and outcomes. Thus, Larrabee's model of quality provides a framework for knowledge acquisition about some dimensions of quality which is not possible using existing models of quality.

\section{The Study}

\section{Purpose}

The purpose of this study is to test the theoretical relationships among quality and value proposed in Larrabee's model of quality by identifying predictors of patient and nurse perceived quality and goal achievement (Figure 2 ). This study is limited to the relationship between quality and value, because of feasibility issues, even though the relationships among all of the concepts in Larrabee's model need to be investigated. The relationship between quality and value was examined first because value has been proposed as a possible intervening variable between quality and the remaining concepts in the model (beneficence, prudence, and justice). 


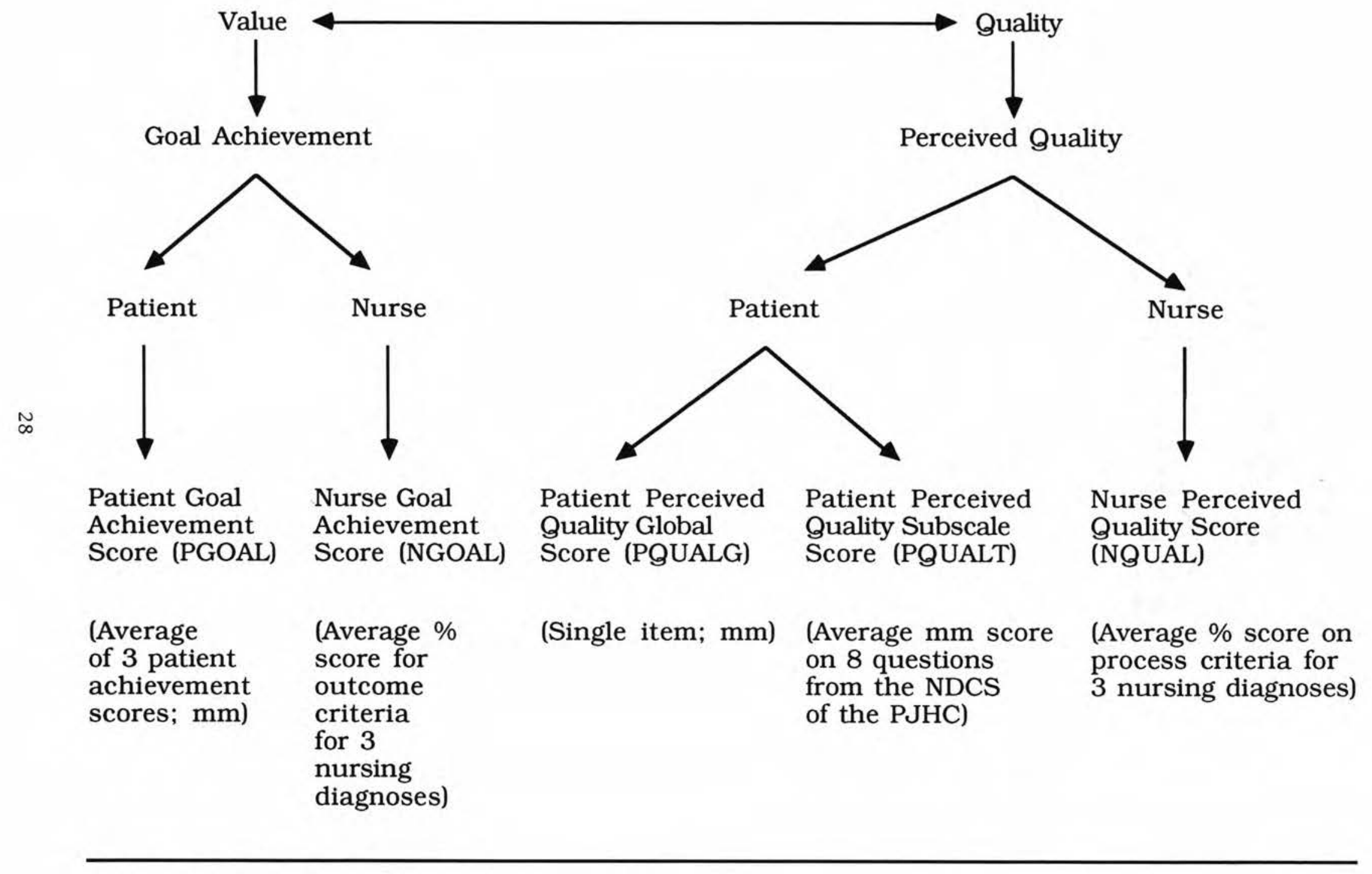

Figure 2. Model for investigation. 
In this study, nurse quality and value were proxies for provider quality and value because studies have shown patient perception of nursing care quality to be the major predictor of patient perception of hospital quality. ${ }^{76,115}$ Quality was measured as patient perceived quality and nurse perceived quality. Value was measured as patient goal achievement and nurse goal achievement. Goal achievement was selected because health care goals are assumed to have intrinsic value to the patient when they are patient identified goals and to the nurse when they are nurse identified goals.

\section{Aims and Research Questions}

Aim 1. Identify relationships among patient and nurse perceived quality and goal achievement.

\section{Research Question:}

1. What are the relationships among patient perceived quality, nurse perceived quality, patient goal achievement, and nurse goal achievement?

Aim 2. Develop prediction equations for patient perceived quality and patient goal achievement.

\section{Research questions:}

1. What are the predictors of patient perceived quality?

2. What are the predictors of patient goal achievement?

Aim 3. Develop prediction equations for nurse perceived quality and nurse goal achievement.

Research questions:

1. What are the predictors of nurse perceived quality? 
2. What are the predictors of nurse goal achievement?

Aim 4. Determine congruence between predictors of patient and nurse perceived quality.

Research question:

1. Are there differences in the predictors of patient and nurse perceived quality?

Aim 5. Determine congruence between predictors of patient and nurse goal achievement.

Research question:

1. Are there differences in the predictors of patient and nurse goal achievement?

Operational Definitions

Patient perceived quality. Patient perceived quality was measured by a $100 \mathrm{~mm}$ visual analogue scale (VAS) (global score) and by a modified version of the Nursing and Daily Care Subscale of the Patients' Judgments of Hospital Quality Questionnaire (total score).

Patient goal achievement. Patient goal achievement was measured as the average of three scores on VASs indicating patient perception of achievement of a maximum of three goals for hospitalization. The higher the score, the greater the patient's estimation of goal achievement. Patients defined their own goals.

Nurse perceived quality. Nurse perceived quality was measured as the percent agreement between process standards of care selected for each patient and the nursing care documented for a maximum of three 
nursing diagnoses per patient. The higher the score, the closer the congruence between the nursing care standards and the nursing care documented.

Nurse goal achievement. Nurse goal achievement was measured as the percent agreement between outcome standards selected for each patient and outcomes documented for a maximum of three nursing diagnoses.

\section{Assumptions}

There are several assumptions underlying this study. A major assumption is that the new model of quality and its underlying assumptions are valid. In addition, the investigator makes the following assumptions:

1. the patient perceived quality subscale score and patient perceived quality global score accurately estimate the patient perceptions of the quality of nursing care they received during hospitalization.

2. the patient goal achievement score accurately estimates patient perceptions of the extent to which their goals for hospitalization were achieved.

3. the nurse perceived quality score accurately measures the congruence between nursing care standards and the nursing care given.

4. the nurse perceived quality score accurately measures the nursing care given.

5. the nurse goal achievement score accurately estimates the extent to which patients achieved the nurse goals for the patient outcomes. 
6. patients can distinguish between care given by nursing staff and care given by other hospital staff. ${ }^{63}$

7. nurses accurately assess patients and select appropriate nursing diagnoses when planning nursing care.

8. nurses' use of the nursing process facilitates achievement of desired outcomes for patients. ${ }^{17,23,25,116-118}$ 
Chapter 3. Methodology

\section{Design}

This study tested the relationships among quality and value proposed by Larrabee's model of quality by identifying the predictors of patient and nurse perceived quality and goal achievement. Patient data were collected at two points in time. Patients were interviewed within 24 hours of admission so that patients' goals for hospitalization could be identified prospectively for later use in measuring patient goal achievement. Refer to Appendix I for the initial interview schedule. Patients were interviewed a second time to obtain data about patient perceived quality and patient goal achievement. This second interview occurred within 24 to 48 hours prior to anticipated discharge. Refer to Appendix II for the exit interview schedule. Data about nurse perceived quality and nurse goal achievement were collected retrospectively after patient discharge, using chart review. Refer to Appendix III for the chart review instrument.

Site

\section{Description of the Hospital}

The site for this study was a 455-bed urban hospital with a public mission, or "safety net" hospital, ${ }^{119}$ located in the Mid South. It provides health care for the majority of uninsured and underinsured persons in Shelby County. ${ }^{120}$ The study hospital has more than 22,000 admissions and more than 200,000 outpatient visits per year. Annually, the study hospital delivers more than $\$ 100$ million in charity and indigent care. 
The patient population at the study hospital is predominately black $(76.5 \%$ ) with $64 \%$ being females and $76.6 \%$ being 35 or younger. Payor source for hospitalization expenses were $39 \%$ Medicaid, $11 \%$ Medicare, $18 \%$ county government funds, $21 \%$ private insurance, and $11 \%$ self-pay, in $1990 .^{120}$

Results of this study are generalizable to other metropolitan, safety net hospitals with similar patient populations. Such hospitals, members of the National Association of Public Hospitals, ${ }^{19}$ provide health care to the nation's uninsured and under-insured persons. Patient demographic characteristics of the study site cannot be compared since those characteristics are not available for safety net hospitals except for AIDs and other HIV+ patients. However, payor source for hospitalization at safety net hospitals are similarly proportioned, with only $15 \%$ from private insurance.

\section{Description of the Nursing Units}

Reasons for selection. Two medical-surgical nursing units were selected for this study for two reasons. First, both units had nursing care standards in a computerized bedside system with care planning and care documentation capabilities. The system enabled nurses to electronically develop individualized nursing care plans. The nurses used these care plans to guide care given each shift. Nurses on these units also documented care on the computerized system, addressing the specific items in the individualized nursing care plan. The computerized system had previously been shown to improve the comprehensiveness of nursing documentation; thus, decreasing the amount of missing data. ${ }^{121}$ 
Second, nurses on both units have participated for two years in a unit-based nursing quality assurance program. This program received the highest rating by the Joint Commission on Accreditation of Health Care Organizations. Therefore, these nurses were accustomed to evaluating their care using nursing care standards.

Unit characteristics. Both units, with 22 beds each, provide care to medical and surgical patients. The average annual occupancy rate for Unit 1 is $94 \%$ and Unit 2 is $92 \%$. The average monthly number of direct admissions for Unit 1 is 88 and for Unit 2 is 77 . The average monthly number of direct admissions for July through September of 1989 and of 1990 did not differ from the respective monthly average of either unit. The average length of stay for patients on Unit 1 is 3.4 days and on Unit 2 is 5.9 days.

Population characteristics. The racial mix on these units is estimated to be the same as for the hospital. Patients must be at least 14 years old to be admitted to medical-surgical units. Generally, the patients on these units are treated by the Medicine Service. Medicine service patients are $51 \%$ male, $82 \%$ black, and 25\% are over 64 years of age.

The nurse managers estimated that the education level of these units' patients ranges from 7 th to 12 th grade, and that $3 \%$ to $10 \%$ of the patients cannot read. Because $25 \%$ of the Medicine Service patients are over 64 years of age, the reading level may not be as high as with the younger patients.

Nursing staff. The nursing care delivery model on both units is a synthesis of team nursing and primary nursing. A registered nurse (RN) 
is each unit's Patient Care Coordinator, who plans, delegates, supervises, and gives direct care each shift. Staffing on these units usually is composed of $25 \%$ RNs (25\%), $50 \%$ licensed practical nurses (LPN), and 25\% nursing assistant (NA) on all three shifts. In comparison, staffing at safety net hospitals was $55 \%$ RNs, $13 \%$ LPNs, $20 \%$ NAs, and $12 \%$ other in $1988 .{ }^{119}$

The average annual staff turnover rate for all nursing units at the study hospital was $14.9 \%$ in 1991 , compared to $22 \%$ reported for safety net hospitals in $1988 .^{119}$ Length of service on Unit 1 ranged from 2 to 7 years for RNs, 3 to 24 years for LPNs, and 2 to 24 years for NAs. On Unit 2, length of service ranged from 1 month to 3 years for RNs, 4 to 29 years for LPNs, and 2 to 35 years for NAs.

Including the nurse manager, the educational preparation of the RNs on Unit 1 is $17 \%$ baccalaureate degree in nursing, 17\% diploma, and $66 \%$ associate degree in nursing. On Unit 2, the educational preparation of the RNs, including the nurse manager, is $17 \%$ diploma and $83 \%$ associate degree in nursing.

Use of computerized nursing information systems on the study units limits the generalizability of the findings, because most hospitals do not yet have such systems. However, the recent Nursing Service Standards from the Joint Commission on Accreditation of Health Care Organizations strongly advocated implementation by hospitals of such systems in the immediate future. ${ }^{122,123}$ Therefore, this study was a pilot for future research which could include multiple sites with computerized nursing information systems. 


\section{Sample}

The sample of patients was drawn sequentially from a series of adults directly admitted from home, a nursing home, or another acute care hospital to two medical-surgical units at the study hospital. Only patients directly admitted to Unit 2 or Unit 1 were included, since transferred patients had experienced nursing care on other units. Such experience may influence the patient perceived quality for care received on the study units.

Inclusion criteria were the following:

1. Consent to participate in the study;

2. Ability to communicate in English;

3. Sufficent vision and use of hand to mark or point to a location on the visual analog scale (VAS) used to score the questions;

4. Age 18 years or older; $;^{124,125}$

5. Direct admission to one of the two study units;

6. Not imprisoned.

\section{Sample Size}

The sample included 199 patients. The sample desired, 200, was obtained by multiplying the potential number of variables in the analysis (32) by five to arrive at 160 . According to Draper and Smith, ${ }^{126}$ when the number of variables is greater than ten, a sample size equal to five to ten times the number of variables "will usually be quite informative". An additional 39 patients were included, since the dependent variables had not previously been measured as defined in this study and there was no a priori information about the nature of their distributions. Likewise, there was no a priori information upon 
which to base a power analysis. However, this study yielded information needed for power analyses in future studies involving quality and value in Larrabee's model of quality.

\section{Measurement of Patient and Nurse Quality Variables}

Patient and nurse perceived quality and goal achievement will hereafter be referred to as patient quality variables and nurse quality variables. There are three patient quality variables and two nurse quality variables (see Table 1 ). There are also predictor variables including seven patient demographic, seven financial, six illness, and six hospital variables (see Table 2). Each variable will be described in turn.

Patient Quality Variables

Patient perceived quality global (PQUALG). The patient perceived quality global score was defined as the score on a single global question about the patient's overall perception of the quality of nursing care. The global question was included to obtain a wholistic estimate of patient perceived quality. At discharge, patients were asked to rate "overall, how good was the nursing care you received?" The response scale was a $100 \mathrm{~mm}$ visual analogue scale (VAS), with "very poor" as the left anchor and "very good" as the right anchor (see Appendix II). Scoring was done by measuring from the lower right angle stop to the middle of the patient's mark made through the horizontal line and recorded in millimeters. A clear plastic ruler was overlayed on each VAS to obtain scores.

A visual analogue scale was selected as the response scale primarily because the VAS elicits data about multidimensional, dynamic, 
Table 1. Patient and nurse quality variables.

Variable

Data source

Data type

Patient quality variables

Patient perceived quality global

PQUALG Interview Ratio

Patient perceived quality total

PQUALT

Interview

Ratio

Patient goal achievement

PGOAL

Interview

Ratio

Nurse quality variables

Nurse perceived quality

NQUAL

Chart review Ratio

Nurse goal achievement

NGOAL

Chart review

Ratio 
Table 2. Predictor variables.

Variable

Variable name Data source

Data type

Patient demographic variables

$\begin{array}{llll}\text { Age } & \text { AGE } & \text { MEDFILE } & \text { Interval } \\ \text { Gender } & \text { GENDER } & \text { MEDFILE } & \text { Nominal } \\ \text { Race } & \text { RACE } & \text { MEDFILE } & \text { Nominal } \\ \text { Marital status } & \text { MARITAL } & \text { Interview } & \text { Nominal } \\ \text { Education } & \text { EDUC } & \text { Interview } & \text { Ratio } \\ \text { Religion } & \text { RELIGION } & \text { Interview } & \text { Nominal } \\ \text { Religion score } & \text { RELIGSCR } & \text { Interview } & \text { Ratio }\end{array}$

Financial variables

Currently employed

Employed in past year

Hours worked/week

Personal income

Combined household income

Payor source

Total charges for care

CURNTJOB Interview Nominal

JOBPAYR Interview Nominal

HRSPERWK Interview Ratio

PINCOME Interview Ratio

HINCOME Interview Ratio

PAYOR MEDFILE Nominal

CHARGE MEDFILE Ratio

Illness variables

Severity of illness score

Symptom score

Worry score

Pain experience in hospital

Severity in general

Amount of time in pain

Severity at exit interview

SIS

SYMPTOM Interview Ratio

WORRY Interview Ratio

PAINAMT Interview Ratio

PAINTIME Interview Ratio

PAINNOW Interview Ratio

Hospital variables

Referral source

Admission class

Number of previous hospitalizations

Length of stay

Discharge disposition

Unit

RSOURCE MEDFILE Nominal

ADMCLASS MEDFILE Nominal

NUMHOSP Interview Nominal

LOS Interview Ratio

DISCHARG MEDFILE Nominal

UNIT Observation Nominal 
subjective constructs, such as patient perceived quality and patient goal achievement. The VAS has previously been used for measuring a variety of such phenomena $a^{127}$ and is simple to use. ${ }^{128}$ Additionally, it has been found to be more sensitive to changes in subjective phenomena than a graphic rating scale or a 4-point rating scale. ${ }^{129,130}$ The VAS also yields ratio level data, which allows use of parametric statistical procedures. ${ }^{127}$ Multiple VASs have been used in several studies, including an investigation of the quality of life for cancer patients. ${ }^{131-135}$

The VASs used in this study were $100 \mathrm{~mm}$ horizontal lines. ${ }^{127}$ The horizontal line has been demonstrated to yield a more uniform distribution of responses than the vertical VAS $^{136}$ and subjects have expressed preference for the horizontal VAS. ${ }^{137}$ Right angle stops were included, since these have been effective in limiting responses beyond the ends of the line. ${ }^{138}$ Each scale was unipolar, providing options for selecting the complete absence or the maximum presence of the phenomenon. The answer sheets were generated with the millimeter ruler in the Aldus PageMaker ${ }^{r}$ software program. ${ }^{139}$ Then, the answer sheets were printed since photocopying has been found to distort the length of the lines. ${ }^{127,140}$

The dynamic and subjective nature of constructs measured using the VAS limits establishing its reliability. ${ }^{127}$ Test-retest is inappropriate because of the dynamic nature of the study phenomenon and measures of internal consistency are constrained by the single-item format of the VAS. ${ }^{127}$ Concurrent or criterion-related validity has been established for several applications of the VAS by comparing to other instruments measuring the same phenomena. ${ }^{127,141-143}$ However, 
validity of the VAS for one application is not generalizable to another application. Despite these psychometric limitations of the VAS, it was the scoring scale used in this study's patient interview questions because it is appropriate for the dynamic, subjective nature of the study construct, it is simple to use, it has demonstrated more sensitivity to changes in a measured phenomenon than other scales, and it yields ratio level data. Also, a panel of nurse managers at the study hospital have judged the VAS to be appropriate for use with the patient population.

The estimated education level of patients on the two nursing units ranges from 7 th to 12 th grades. The reading level of medical-surgical patients at this site has not been measured but the nurse managers estimated that $3 \%$ to $10 \%$ of the patients cannot read. For this reason, the patient goal achievement questions were written with a minimum of words with three or more syllables, since such words increase reading difficulty. ${ }^{144}$ It was assumed that the vocabulary used in the questions needed to be understandable to all the patients, even though the patients were not required to read during their participation in the study. A panel of nurse managers, experienced in working with the patient population at the study hospital, participated in the development of the questions.

Patient perceived quality total (PQUALT). The patient perceived quality total score was defined as the average score of eight modified questions on the Nursing and Daily Care Subscale (NDCS) of the Patients' Judgments of Hospital Quality Questionnaire (PJHQ). ${ }^{63}$ At discharge, patients were asked to rate the quality of eight types of nursing care behaviors, using a $100 \mathrm{~mm}$ VAS. Scoring was be done by 
measuring from the lower right angle stop to the middle of the patient's mark made through the horizontal line, and recorded in millimeters. The PQUALT score was obtained by summing the scores on the eight questions and dividing by eight. Refer to Appendix II for the PQUALT questions.

The $\mathrm{PJHQ}$ is a standardized patient satisfaction questionnaire with 100 items. This instrument was developed in a six-month study at ten hospitals. The patient population sampled was $92 \%$ white and $63 \%$ female with a mean age of $46,30 \%$ having a high school education and $51 \%$ having more than a high school education, and $55 \%$ haD annual incomes greater than $\$ 25,001$. Results indicated that patients were able to evaluate several components of hospital care separately: admissions, nursing and daily care, hospital environment and ancillary staff, medical care, and discharge/billing. ${ }^{75}$

The NDCS items were originally designed to obtain data about patient estimates of the nurses' consideration of patient needs, helpfulness, skill and competence, attentiveness, responsiveness, concern and caring, and provision of information. These concepts about nursing care have previously been associated with patient satisfaction. ${ }^{64-66,68,72}$ The NDCS score was the largest predictor (46.5\% of explained variance) of overall patient judgment of hospital care quality. ${ }^{63}$ Therefore, the NDCS was selected as a measurement of patient perceived quality for this study.

Factor analysis of the PJHQ instrument revealed six distinct subscales (admissions, nursing and daily care, hospital environment and ancillary staff, medical care, and discharge/billing) which measure patient opinions about features of care that vary independently. ${ }^{115}$ 
Internal consistency ranged from 0.87 to 0.95 across the six scales. The questions had good discriminate validity between subscales. Also, the questions demonstrated high inter-item correlations within subscales, suggesting that reduction in number of subscale items could result in acceptable reliability without loss of content validity. ${ }^{145}$ The PJHQ and the NDCS have a 10th grade reading level, using the SMOG test for readability. ${ }^{144}$ since the patient population in this study was anticipated to have some patients who cannot read and some with lower than 10 th grade reading level, the NDCS was modified. Three questions of the original items were omitted from the scale because they were redundant with one other item. Three questions originally included reference to other hospital staff and were modified to address nurses only, since this study estimated patient perceived quality for nursing care. The vocabulary of the remaining eight NDCS questions was modified in collaboration with a panel of nurse managers at the study hospital who have extensive experience working with the patient population.

Also, for use in this study, the NDCS response scale was changed from a five-point excellent to poor evaluation scale to a VAS, because the VAS was judged to be a more appropriate response format for the patient population. The panel thought many patients would not understand the word "excellent"; therefore, "very good" was selected as the right hand anchor. After the questions were modified, the panel thought that the content of the questions were valid restatements of the original questions. The modifications reduced the reading level from 10 th to 6 th grade, as measured by the SMOG test. 
Patient goal achievement (PGOAL). Patient value was measured as patient goal achievement. Patient goal achievement (PGOAL) was defined as the average score of the patient's perception of the achievement of three goals. Upon admission, patients were asked to identify three goals for hospitalization. Refer to Appendix I for PGOAL questions in the initial interview schedule. At discharge, they were asked to rate the achievement of their three goals using a $100 \mathrm{~mm}$ VAS. Scoring was done by measuring from the lower right angle stop to the middle of the patient's mark made through the horizontal line, and recorded in millimeters. The average PGOAL score was obtained by summing the scores for the three VASs and dividing by three. Refer to Appendix II for the PGOAL questions.

\section{Nurse Quality Variables}

Nurse perceived quality (NQUAL). Nurse perceived quality was defined as the average score on process criteria for a maximum of three nursing diagnoses. Patients' nursing care was organized around as few as one nursing diagnosis but usually more. Care pertaining to a maximum of three nursing diagnoses, goals, and actions were reviewed because that is the maximum number that gave some variability of the data generating the scores and was still feasible to collect.

Upon admission, a nurse identified nursing diagnoses and related nursing actions. These selected nursing actions served as process criteria for evaluation of care given. These criteria were different for each patient's care, since the care plans were individualized to guide nurses in meeting specific patient needs. 
After discharge, the patient's chart was reviewed by trained data collectors to determine the congruence between the care given and the process criteria. A percentage score was obtained for one to three process criteria for a maximum of three nursing diagnoses. An average score for each nursing diagnosis was obtained by summing the scores for the related process criteria and dividing by the number of criteria. The NQUAL score was then obtained by summing the scores for the nursing diagnoses and dividing by the number of nursing diagnoses. See Appendix III for the NQUAL questions.

Prior to conducting the retrospective chart review, the data collector transcribed as many as three nursing actions for each of the first three nursing diagnoses onto a data collection form. These nursing actions became the process criteria for evaluating nurse perceived quality. For instance, for the nursing diagnosis "impaired gas exchange", three process criteria are the following:

"During the patient's stay on the unit, there is documentation that:

1. The patient was positioned every 8 hours to improve gas exchange (head of bed in high-Fowler's, support arms with pillows, or place pillow on overbed table for patient to lean on.

2. Oxygen was administered as ordered $q$ hours.

3. Dyspnea is assessed at least $q$ hours."

After transcribing the process criteria onto the data collection form, the data collector reviewed the nursing care from admission to discharge. Each criterion had two questions: "how many times should it have been done?", the demoninator, and "how many times was it done?", 
the numerator. If an action should have been done once every eight hours and the patient was in the hospital for 72 hours after the nursing intervention was selected, then the action should have been done nine times. Nine became the demoninator for that criterion. The number of times the action was actually done became the numerator. If the nurse neglected to chart an action, that decreased the numerator; therefore, the percentage score accounted for missing data. The percentages for all process criteria were averaged to arrive at the NQUAL score.

Nurses goal achievement (NGOAL). Nurse value was measured as nurse goal achievement. Nurse goal achievement was defined as the average score of the outcome criteria for a maximum of three nursing diagnoses. Upon a patient's admission, the nurse identified nursing diagnoses and related goals. These selected nursing goals served as outcome criteria for evaluation of nurse goal achievement. These outcome criteria were different for each patient, since specific patient needs were different.

The nurse goal achievement score, the percent agreement between the three outcome criteria per nursing diagnosis and the documented outcomes, was obtained using retrospective chart review by trained data collectors. The nurse goal achievement score for each nursing diagnosis was calculated by summing the nurse goal achievement scores for maximum of three goals and dividing by the number of goals. The average nurse goal achievement score for each patient was obtained by summing the nurse goal achievement scores for a maximum of three nursing diagnoses and dividing by the number of nursing diagnoses. As explained under the Design section, care pertaining to a maximum of 
three nursing diagnoses and three goals was reviewed. This number was chosen because of the desirability of some variability within patient care plans and feasibility constraints with data collection. See Appendix III for the nurse goal achievement questions.

The nurse goal achievement questions were developed by the investigator to obtain data about nurse goal achievement related to specific nursing care needs. Available instruments do not measure nurse goal achievement as defined in this study ${ }^{146}$ or were infeasible. ${ }^{23,147}$

\section{Measurement of Predictor Variables}

\section{Patient Demographic Variables}

Age (AGE). Age was measured as years old on last birthday. Age was a predictor of patient judgments of overall quality of hospital care. ${ }^{115}$

Gender (GENDER). Gender was recorded as male or female. Recent studies have found gender to not be a significant predictor of patient judgments of overall quality, ${ }^{77,148}$ although an earlier study demonstrated males to be more satisfied with care than females. ${ }^{66}$

Race (RACE). Race will be recorded as black, white, or "other". Race was not found to be a significant predictor of patient judgments of quality in the study by Meterko, Nelson, \& Rubin. ${ }^{63}$ However, blacks were underrepresented in the sample: $92 \%$ were white, $4 \%$ were black, and $4 \%$ were "other". ${ }^{148}$ The racial mix in this study's patient population underrepresents whites. 
Marital status (MARITAL). Marital status was recorded as married, single, separated, widowed. Recent studies have not shown marital status to be related to patient perceptions of quality, ${ }^{76,149}$ however, an earlier study found married people to be more satisfied with their care than single people. ${ }^{66}$

Education (EDUC). Education was recorded as years of formal education. In the study by Meterko et al.,$^{63}$ education was not a significant predictor of patients' judgments of quality. However, $81 \%$ of their sample had high school or higher education. Mean education level is anticipated to be lower in this study's patient population.

Religion (RELIGION). Religion was recorded as Catholic, Protestant, Jew, Muslim, other, and none. A religion, as a value system, may influence perceptions about nursing care, although no studies were located in which religion was a predictor of perceptions of care quality.

Religion score (RELIGSCR). Religion score was the patients' response to the question: "How much is religion a source of strength or comfort to you?" The response scale was a $100 \mathrm{~mm}$ VAS, with a left hand anchor of "not at all" and a right hand anchor of "a whole lot".

\section{Financial Variables}

Currently employed (CURNTJOB). Current employment status was reported by the patient during the initial interview and recorded as yes or no. Financial status may influence expectations and perceptions of care quality. However, other studies have not examined the relationships among employment and perceptions of quality. $66,68,72,76,115$ 
Employed in past year (JOBPAYR). Employment status during the past year was reported by the patient during the initial interview and was recorded as yes or no.

Hours worked per week (HRSPERWK). The number of hours worked per week was reported by the patient during the initial interview and recorded as whole numbers of hours.

Personal income (PINCOME). Monthly personal income was recorded as the dollar amount reported by the patient during the initial interview. In the study by Meterko et al.,$^{63}$ income was not a predictor of patients' judgments of hospital quality. However, only $14 \%$ of that sample had incomes less than $\$ 7,500$ per year, indicating different income characteristics than anticipated for this study's sample.

Household income (HINCOME). Monthly combined household income was reported by the patient during the initial interview and recorded as dollars.

Payor source (PAYOR). Payor source was recorded as Medicaid, Medicare, other government, private insurance, or self-pay. In the study by Meterko et al.,$^{63}$ hospitalization insurance was not a significant predictor of patient judgments of quality. However, the majority of patients ( $55 \%$ ) had annual incomes greater than $\$ 25,000$, suggesting that the majority may have had hospitalization insurance. Payor source data for this study were retrieved from the Hospital Information System. 
Total charges for care (CHARGE). The total charges for care was the sum of all itemized charges for hospital care during the hospitalization in which patients participated in this study. These data were retrieved from the Hospital Information System. There is much concern that reduced costs of care may adversely affect quality of care, ${ }^{150,151}$ yet some authors suggest that may not be true. ${ }^{152-155}$

\section{Illness Variables}

Severity of illness score (SIS). Severity of illness score was the score assigned by the MEDISGROUPS ${ }^{\text {TM }}$ software program. ${ }^{156}$ MEDISGROUPS $^{\text {TM }}$ is a computerized medical care quality assessment program which calculates a standardized SIS based on objective physiological findings during the first two days of hospitalization. The retrospective chart data used to generate the SIS was collected by trained abstracters in the Hospital quality and Resource Utilization (HQRU) department. The SIS data were subsequently retrieved by the investigator from the HQRU department. Severity of illness may influence both patient and nurse goal achievement.

Symptom score (SYMPTOM). Symptom score was the patients' response to one question about how "bad" their chief symptom was. The response format was a $100 \mathrm{~mm}$ VAS, with "not bad at all" as the left hand anchor and "very bad" as the right hand anchor. Symptom score was intended to obtain a measure of how important (value as relative worth) the symptom was to the patient.

Worry score (WORRY). Worry score was the patients' response to one question about "how worried" they were about their current health problem. The response format was a $100 \mathrm{~mm}$ VAS, with "not worried at 
all" as the left hand anchor and "very worried" as the right hand anchor. Worry score was intended to obtain a measure of how important (value as relative worth) the current health problem was to the patient.

Pain experience during hospitalization. Three variables for pain experience during hospitalization were included: pain severity in general (PAINAMT), amount of time in pain (PAINTIME), and pain severity at exit interview (PAINNOW). These were measured using $100 \mathrm{~mm}$ VASs. In the study by Meterko et al. , ${ }^{63}$ pain was a significant predictor of patient judgments of hospital quality.

\section{Hospital Variables}

Referral source (RSOURCE). Referral source was recorded as physician, clinic, other health agency, emergency department. On the average, most admissions to safety net hospitals are through the emergency department. ${ }^{19}$ These data were retrieved from the Hospital Information System.

Admission class (ADMCIASS). Admission classification was recorded as emergency, urgent, elective, and unknown. On the average, most admissions to safety net hospitals are emergencies. ${ }^{119}$ These data were retrieved from the Hospital Information System.

Number of previous hospitalizations (NUMHOSP). The number of previous hospitalizations was reported by the patient during the initial interview and recorded in whole numbers. Previous experience with hospitalization may influence expectations and perceptions about care. 
Length of stay (LOS). Length of stay was recorded as days of hospitalization on the study unit. If length of stay exceeds a patient's expectations, it may influence both patient perceived quality and patient goal achievement.

Discharge disposition (DISCHARGE). Discharge disposition was recorded using the coding scheme from the study site: discharged home; left against medical advise; transferred to another short-term hospital; transferred to a long term care facility; dead; or status unknow. Patient perceived quality may be influenced by whether patient goal to return home is met or not.

Unit (UNIT). Unit of hospitalization was recorded for each patient. Previous studies have demonstrated that patients on different units perceive nursing care quality differences. ${ }^{68,125}$

\section{Procedure}

\section{Site Preparation}

Site preparation included interaction with individuals at the study hospital to create a computer file for electronically collecting demographic and cost data, to facilitate access to patients, to facilitate access to patient charts, and to obtain the severity of illness score from the Hospital Quality and Resource Utilization department. The President of the study hospital agreed to use of medical-surgical units as the site for this study and approved the sharing of hospital information in the computer file.

The Analyst in the Marketing and Planning department made arrangements for the creation of the Hospital Information System (HIS) computer file by personnel in the Hospital Information Systems 
department. Details about the necessary programming were finalized before initiation of data collection. At completion of data collection, the HIS computer file was electronically transferred to the investigator's account in the mainframe at the University of Tennessee for subsequent analyses.

To facilitate access to patients, the investigator obtained approval of data collection on the two medical-surgical units from the Vice President for Nursing and Patient Services, the Director of Medical-Surgical Nursing, and the two nurse managers. Prior to initiation of data collection, the investigator met with nursing staff on each unit to discuss the study. First, the investigator met with the two Nurse Managers and described the study, explained the data collection procedure the investigator was to use for interviewing patients, and requested their overt support throughout the data collection. The investigator asked the nurse managers to assure that the nurses had a nursing care plan on all patients, so that lack of a nursing care plan would not cause attrition from the study.

Next, the investigator met with day, evening, and night shift unit staff, including RNs, LPNs, NAs, ward managers (WMs), and ward clerks (WCs) during scheduled unit meetings. At this time, the investigator told the nursing staff that the purpose of the study was to learn about patients' opinions about quality of nursing care. The investigator asked that when the staff admitted each patient that they tell the patient a nursing study was in progress and that they would be approached to participate. The staff were asked to encourage patients to participate. The investigator requested that the staff notify the investigator of each new admission when the investigator or 
Administrative Aide came to the unit each day. More importantly, the staff were asked to inform the investigator when patients were going to be discharged.

To facilitate obtaining the exit interview, the investigator arranged for a letter from the Chief of Staff to be sent to all physicians treating patients on the two nursing units. The letter requested the physicians to make a notation in the progress notes regarding discharge, or, to otherwise notify the investigator.

To facilitate access to patient charts, the investigator arranged with the Director and Assistant Director of Medical Records to make charts available for review within one week after discharge. The Administrative Aide notified Medical Records personnel of discharges periodically.

To obtain the severity of illness score for each patient, the investigator made arrangements with both the Director of Hospital Quality and Resource Utilization (HQRU) department and the Manager of Quality Information Systems (QIS). The Manager of QIS was periodically provided with a list of discharged study patients. The Director of HQRU requested HQRU data abstracters to collect data on study patients prior to collecting data on patients not in this study.

\section{Data Collectors}

Data about nurse perceived quality and nurse goal achievement were collected by the investigator and one RN, using retrospective chart review. The Bedside Terminal Coordinator provided inservice for the investigator and RN data collector about guidelines for documentation which the coordinator teaches to nursing staff. 
The investigator trained the RN data collector, incorporating information about the documentation guidelines and identifying documentation acceptable to meet each criterion. Then, interrater reliability, calculated as the number of agreements divided by the number of agreements plus the number of disagreements, ${ }^{157}$ was measured on five charts prior to data collection and an additional 19 charts throughout the data collection. At the end of the study, percent agreement for these 24 charts was calculated. Also, a paired difference t-test was performed to establish that there was no difference in scores between the two data collectors.

For NQUAL, percent agreement between the two raters was $84.2 \%$. Polit and Hungler observe that there is no standard for what the reliability coefficient should be. ${ }^{157}$ However, they suggest that when an instrument is to be used for obtaining information about groups, a reliability coefficient of .60 to .70 would probably be adequate. Both NQUAL and NGOAL were intended to obtain information about individuals in a group, not to obtained information for making decisions about individuals. Therefore, the percent agreement of $84.2 \%$ represented acceptable interrater reliability for NQUAL. The Wilcoxin Sign Rank t-test for paired difference in skewed data also indicated that there was no significant difference between the raters' scores $(p=.82)$. Thus, both measures of interrater reliability indicated that there was acceptable interrater reliability for NQUAL.

For NGOAL, the percent agreement between the two raters was $89.3 \%$. Also, there was no significant difference $(p=.70)$ between the scores of the two raters using the Wilcoxin Sign Rank t-test for paired difference in skewed data. Thus, both measures of interrater reliability indicated that there was acceptable reliability for NGOAL. 


\section{Data Collection}

The data was collected during an 18 week period. The length of the data collection period was influence by the number of direct admissions to the units, participation rate, the length of time required to conduct the patient interviews, patient attrition, and the time required to collect data from charts. The initial interview required approximately 10 minutes and the exit interview required approximately 15 minutes. Chart review time ranged from 15 minutes to 6 hours per chart, with the average chart requiring approximately 2 hours to review. The length of time for the collection of patient data, 11 weeks, was sufficiently short to reduce the influence that staff turnover, or other environmental changes, might have on the quality of nursing care.

Patient data were obtained by the investigator during interviews. Every morning and afternoon, the investigator went to both units and obtained the names and locations of patients who had been admitted directly to the unit during the past 24 hours. The investigator talked with the patient's nurse or nursing assistant about an acceptable time to approach the patient without interferring with care. The investigator introduced self to the patient and any significant others present, informed the patient about the study, determined willingness to participate, and determined acceptability of time for the interview. Patients who either verbally or in writing consented to participate were then interviewed. The investigator read the questions to all patients. This initial interview lasted about 10 minutes. Demographic data were obtained first as a means of initiating the conversation. Data were then collected to identify the patient's goals for hospitalization, with the investigator writing the patient's response. 
Within 24 to 48 hours prior to anticipated discharge, the exit interview was conducted, using the PQUALG, PQUALT, and PGOAL questions. The time frame for this interview was chosen because by then patients should have opinions about their care. Also, at the time of discharge patients eager to leave may have declined the second interview. This second interview lasted about 15 minutes. Patients were positioned comfortably to respond on the answer sheet held on a clipboard. During this interview, the investigator read each question and asked the patient to respond by drawing a line at right angles through the VAS. The investigator provided any necessary assistance for patients unable to hold the clipboard with the answer sheet. When patients were unable to hold the pencil but could otherwise indicate the location for their response, the investigator marked the patients' response. When enrolled patients were unable to participate by indicating a response, they were excluded as patients at that time. Patient data from both interviews were entered into an EXCEL ${ }^{\text {TM }}$ spreadsheet, ${ }^{158}$ stored on diskettes, and, later, transferred to a file in the investigator's account on the mainframe at the University of Tennessee for analysis. Nurse quality data were collected by the investigator and one RN data collector. After patients were discharged, the charts were reviewed in the Medical Records Department, using the NGOAL and NQUAL questions to extract data, as described in the Measurement section. The data were entered into an EXCEL ${ }^{\text {TM }}$ spreadsheet, ${ }^{158}$ stored on diskettes, and, subsequently, transferred to the investigator's account in the mainframe at the University of Tennessee. The patient and nurse quality data from the EXCEL ${ }^{\mathrm{TM}}$ file were merged with the HIS computer file data for subsequent data analyses. 


\section{Descriptive Data Analysis}

All data analyses were completed using the Statistical Analysis System (SAS) software, version six. ${ }^{159,160}$ SAS is available for use on the VAX cluster, which is located in the Biomedical Information Transfer (BIT) center at the University of Tennessee, Memphis.

\section{Patient and Nurse Quality Variables}

Patient quality variables. Patient perceived quality global (PQUALG), patient perceived quality total (PQUALT), and patient goal achievement (PGOAL) were analyzed using the UNIVARIATE procedure. PQUALG, PQUALT, and PGOAL were negatively skewed. The skewness of these variables necessitated subsequent analyses using nonparametric statistical procedures. The patient quality variables were dichotomized, using 96 or higher as the cutpoint. This cutpoint was selected because (a) $25 \%$ of the sample had scores of 96 or higher for patient perceived quality total and (b) the attenuation of intercorrelations among dependent variables was less at 96 than at 90 or 95 , two other cutpoints suggested by plots of the distributions. Subsequently, when the score for the two patient perceived quality variables was 96 or higher, it was interpreted as excellent versus not excellent. For instance, a score of 96 or higher on patient perceived quality global meant excellent patient perceived quality global. Likewise, a score lower than 96 meant "not excellent" patient perceived quality global, meaning that the individual thought there was some room for improvement in the nursing care quality. Similarily, a score of 96 or higher for PGOAL was interpreted as successful PGOAL versus unsuccessful PGOAL. 
Nominal variables (payor source, referral source, admission class, marital status,) were also dichotomized using dummy variables for further analyses of associations with the patient quality variables and NGOAL. Payor source had six subgroups (no third party, Medicare, Medicaid, Blue Cross, commercial insurance, and other insurance) which were dichotomized for six dummy variables, one for each subgroup contrasted with all those not in that subgroup. For instance, the Medicare dummy variable contrasted those having Medicare with those not having Medicare. Referral source, with five subgroups (emergency department, physician, clinic, other health facility, and unknown), admission class, with four subgroups (emergency, urgent, elective, and unknown), and marital status, with four subgroups (married, single, widowed, legally separated), were similarly dichotomized.

Nurse quality variables. Nurse perceived quality (NQUAL) and nurse goal achievement (NGOAL) and were analyzed using the UNIVARIATE procedure. NQUAL was approximately normally distributed; therefore, parametric procedures were used for further analyses. NGOAL was negatively skewed; therefore, the same procedure as described for dichotomizing the patient quality variables was used to dichotomize NGOAL, at scores $\geq 96$, prior to further analyses.

\section{Predictor Variables}

Patient demographic variables. Patient demographic data for continuous variables (age, education, and religion score) were analyzed using the UNIVARIATE procedure to estimate means, variability, frequency, and distribution to produce a description of the patient population. Also, the UNIVARIATE procedure was used to estimate 
frequency and distribution for patient demographic categorical variables (gender, race, marital status, and religion.)

Financial variables. Financial variables were analyzed using the UNIVARIATE procedure to estimate means, variability, and distribution for the continuous variables: hours/week worked (HRSPERWK), personal income (PINCOME), combined household income (HINCOME), charges for care (CHARGE). The UNIVARIATE procedure was also used to estimate frequency and distribution for the categorical variables: currently employed (CURNTJOB), employed in past year (JOBPAYR), and payor source (PAYOR). Because combined household income was skewed, it was recoded into five dummy variables for analysis: group $0=\$ 0 ; \$ 0<$ group $1<\$ 400 ; \$ 399<$ group $2<\$ 600 ; \$ 599<$ group $3<\$ 1000$; and $\$ 999<$ group $4<\$ 5000$ ). Hours worked per week was recoded into three dummy variables for analysis: HRSWORKO (no hours worked/week), HRSWORK1 (worked $<30$ hours/week), and HRSWORK2 (worked $\geq 30$ hours/week).

Illness variables. Illness variables were analyzed using the UNIVARIATE procedure to estimate means, variability, and distribution for the continuous variables: symptom score (SYMPTOM), worry score (WORRY), how much time in pain (PAINTIME), pain severity during hospitalization (PAINAMT), and pain severity at exit interview (PAINNOW). The UNIVARIATE procedure was also used to estimate frequency and distribution for the one categorical variable: severity of illness score (SIS).

Hospital variables. Hospital variables were analyzed using the UNIVARIATE procedure to estimate frequency and distribution of the categorical variables, including referral source for admission 
(RSOURCE), admission class (AMDCLASS), and discharge disposition (DISCHARGE). Also, the UNIVARIATE procedure was used to estimate means, variability, and distribution of the continuous variables which were the number of previous (NUMHOSP) and length of stay (LOS).

\section{Analysis of Aims}

Aim 1: Identify Relationships Among Patient and Nurse Perceived Quality and Goal Achievement

Research Question 1: What Are the Relationships Among PQUALG, PQUALT, PGOAL, NQUAL, and NGOAL?

Spearman rank correlations among PQUALG, PQUALT, PGOAL, NQUAL, and NGOAL were estimated using the Spearman option on the CORR procedure. An alpha $\leq .1$ was used to identify significant correlations. This significance level was used because the relationships, as described in this study, have not been investigated.

Aim 2: Develop Prediction Equations for Patient Perceived Quality and Patient Goal Achievement

Research Question 1: What Are the Predictors of Patient Perceived Quality?

Research Question 2: What Are the Predictors of Patient Goal Achievement?

The analysis of aim 2 was conducted in three steps. Each step will be described separately.

Step 1. The purpose of Step 1 was to identify univariate candidate predictor variables of patient quality variables. Associations of predictor variables (demographic, financial, illness, and hospital variables), PGOAL, and nurse quality variables with patient quality variables were identified using the LOGISTIC procedure. Crude measures of all associations, expressed as likelihood ratios, and $95 \%$ confidence 
intervals were obtained. A criterion to establish a variable as a candidate for possible inclusion in the multiple logistic regression was an alpha level of $<.2$. This significance level was selected to maximize the number of candidate variables because of potential multicollinearity among the patient demographic, financial, illness, and hospital variables. Variables significantly associated with patient quality variables were subsequently used as candidate variables in the regression models for PQUALG, PQUALT, and PGOAL described in Step 2. Nurse quality variables were included as potential candidate variables because theoretically the quality of nursing care could influence patient quality variables.

Step 2. The purpose of Step 2 was to identify independent predictor variables of patient quality variables. The patient quality variables were regressed on the candidate variables identified in Step 1 employing multiple logistic regression. Prediction indices were obtained using stepwise algorithms with an alpha level of $<.2$ for inclusion and exclusion.

Step 3. The purpose of Step 3 was to produce prediction indices for PQUALG, PQUALT, PGOAL while eliminating the slight rounding error present in prediction indices produced by the respective stepwise algorithms used in Step 2. PQUALG, PQUALT, PGOAL were regressed on the respective predictor variables identified in Step 2 . The final prediction indices were developed with multiple logistic regression, using backward elimination procedures. The significance level was changed from an alpha level of $\leq .2$ to an alpha level of $\leq .1$ at this step to reduce the risk of Type I errors. Adjusted odds ratios along 
with $95 \%$ confidence intervals were estimated for the predictors of PQUALG, PQUALT, and PGOAL.

Aim 3: Develop Prediction Equations for Nurse Perceived Quality and Nurse Goal Achievement

Research Question 1: What Are the Predictors of Nurse Perceived Quality?

Research Question 2: What Are the Predictors of Nurse Goal Achievement?

Step 1. The purpose of Step 1 was to identify univariate candidate predictor variables of nurse quality variables. Associations of predictor variables with NQUAL were identified using simple linear regression. Also, associations of predictor variables with NGOAL were identified using the LOGISTIC procedure. Crude measures of all associations, expressed as likelihood ratios, along with $95 \%$ confidence intervals were obtained. A criterion to establish a variable as a candidate for possible inclusion in the multiple logistic regression was an alpha level of $<.2$. This significance level was selected to maximize the number of candidate variables because of potential multicollinearity among the patient demographic, financial, illness, and hospital variables. Variables significantly associated with nurse quality variables were subsequently used as candidate variables in the regression models for NQUAL and NGOAL described in Step 2.

Step 2. The purpose of Step 2 was to identify independent predictor variables of nurse quality variables. The nurse quality variables were regressed on the candidate variables identified in Step 1 employing multiple linear regression for NQUAL and multiple logistic regression for NGOAL. Prediction indices were obtained using stepwise algorithms with an alpha level of $<.2$ for inclusion and exclusion. 
Step 3. The purpose of Step 3 was to estimate prediction indices for NQUAL and NGOAL while eliminating the slight rounding error present in prediction indices produced by the respective stepwise algorithms used in Step 2. NQUAL and NGOAL were regressed on the respective predictor variables identified in Step 2. Using backward elimination procedures, the final prediction indices were developed for NQUAL with multiple linear regression and for NGOAL with multiple logistic regression. The significance level was changed from an alpha level of $\leq .2$ to $\leq .1$ at this step to reduce the risk of Type I errors. In addition, the predictors of NQUAL were examined using analysis of variance to estimate the least square means for the subgroups, since the two predictors of NQUAL were categorical, not continuous, variables. Adjusted odds ratios along with $95 \%$ confidence intervals were estimated for the predictors of NGOAL.

Aim 4: Determine Congruence Between Predictors of Patient Perceived Quality and Nurse Perceived Quality

Research Question 1: Are There Differences in the Predictors of Patient and Nurse Perceived Quality?

Analysis for this aim consisted of identifying predictors common to the prediction models for PQUALG, PQUALT, and NQUAL.

Aim 5: Determine Congruence Between Predictors of Patient Goal Achievement and Nurse Goal Achievement

Research Question 1: Are There Differences in the Predictors of Patient and Nurse Goal Achievement?

Analysis for this aim consisted of identifying predictors common to the prediction models for PGOAL and NGOAL. 
Chapter 4. Results

Demographic and Descriptive Statistics

\section{Sample}

The sample included 199 hospitalized adults. Of 280 eligible patients, 41 declined participation, for a response rate of $85.4 \%$ $(n=239)$. This response rate compares favorably with that of Nelson, Rubin, Hays, and Meterko. ${ }^{148}$ of the 239 patients participating in the initial interview, 199 were retained in the sample after the exit interview, for a reinterview rate of $83.3 \%$. See Figure 3 for sample attrition.

One-way analyses of variance were conducted to determine if either nonparticipants or patients not reinterviewed were different from the participating patients. Nonparticipants and patients not reinterviewed, in comparison to participating patients, did not differ in age, gender, race, or payor source. Table 3 presents means, standard errors, and significance values for group effects for age. Table 4 presents number and frequency for gender, race, and payor source by group and across groups and significance values for group effects.

The sample $(n=199)$ included 107 men and 92 women (Table 5). Their mean age was 39 years and their mean education was 11 years. The majority $(85 \%)$ were black, $13.6 \%$ were white, $55.3 \%$ were single. The religious preference of participants was predominately protestant $(88.4 \%)$. The sample reported a mean score of $80.1 \mathrm{~mm}(\mathrm{SD}=24.6)$ for how important religion was as a source of strength and comfort. 


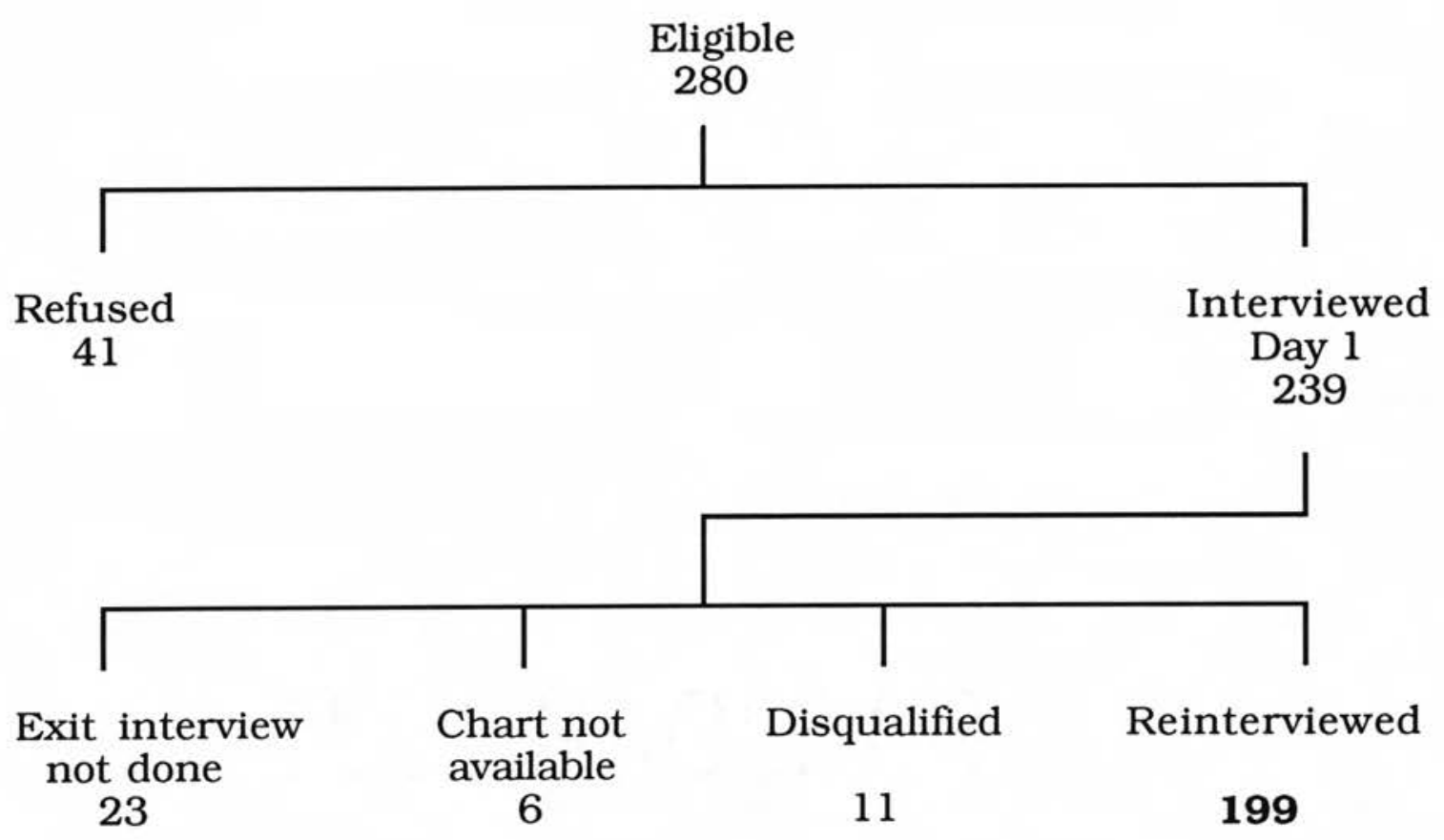

Figure 3. Sample attrition. 
Table 3. Least square means and standard errors of age for sample attrition.

\begin{tabular}{|c|c|c|c|c|c|c|c|c|c|}
\hline \multirow[b]{2}{*}{ Variable } & \multicolumn{2}{|c|}{ Participants } & \multicolumn{2}{|c|}{ Nonparticipants } & \multicolumn{2}{|c|}{$\begin{array}{c}\text { Lost } \\
\text { participants }\end{array}$} & \multirow{2}{*}{$\begin{array}{c}\begin{array}{c}\text { Across } \\
\text { groups }\end{array} \\
\text { Mean }\end{array}$} & \multirow{2}{*}{$\begin{array}{c}\text { Significance } \\
\text { value of group } \\
\text { effects }^{\mathrm{a}}\end{array}$} & \multirow{2}{*}{$\begin{array}{c}\text { Significance } \\
\text { value of group } \\
\text { effects }^{b}\end{array}$} \\
\hline & Mean & $\mathrm{SE}$ & Mean & $\mathrm{SE}$ & Mean & $\mathrm{SE}$ & & & \\
\hline Age & 39.3 & 1.3 & 39.5 & 1.4 & 37.9 & 3.7 & 39.3 & 0.92 & 0.58 \\
\hline
\end{tabular}

${ }^{\mathrm{a}} \mathrm{p}$ value for $\mathrm{F}$ test of group effects.

${ }^{b}$ p value for Kruskal Wallis test of group effects. 
Table 4. Characteristics of participants, lost participants, and nonparticipants: discrete variables.

\begin{tabular}{|c|c|c|c|c|c|c|c|c|c|}
\hline \multirow[b]{2}{*}{ Variable } & \multicolumn{2}{|c|}{ Participants } & \multicolumn{2}{|c|}{ Nonparticipants } & \multicolumn{2}{|c|}{ Lost participants } & \multicolumn{2}{|c|}{ Across groups } & \multirow[t]{2}{*}{ p value } \\
\hline & $\mathrm{n}$ & $\%$ & $\mathrm{n}$ & $\%$ & $\mathrm{n}$ & $\%$ & $\mathrm{n}$ & $\%$ & \\
\hline \multicolumn{10}{|l|}{ Gender } \\
\hline Male & 107 & 53.8 & 84 & 56.0 & 15 & 65.2 & 206 & 55.4 & 6 \\
\hline Female & 92 & 46.2 & 66 & 44.0 & 8 & 34.8 & 166 & 44.6 & \\
\hline \multicolumn{10}{|l|}{ Race } \\
\hline Black & 170 & 85.4 & 124 & 82.7 & 19 & 82.6 & 313 & 84.1 & .7 \\
\hline White & 27 & 13.6 & 22 & 14.7 & 4 & 17.4 & 53 & 14.3 & \\
\hline Other & 2 & 1.0 & 4 & 2.7 & 0 & .0 & 6 & 1.6 & \\
\hline \multicolumn{10}{|l|}{ Payor source } \\
\hline Medicare & 29 & 14.6 & 29 & 19.2 & 2 & 8.7 & 60 & 16.1 & .3 \\
\hline Blue Cross & 7 & 3.5 & 5 & 3.3 & 0 & .0 & 12 & 3.2 & .7 \\
\hline Commercial insurance & 19 & 9.6 & 9 & 6.0 & 2 & 8.7 & 30 & 8.0 & .5 \\
\hline Medicaid & 57 & 28.6 & 44 & 29.1 & 6 & 26.1 & 107 & 28.7 & 1.0 \\
\hline No third party & 84 & 42.2 & 58 & 38.4 & 12 & 52.2 & 154 & 41.3 & .4 \\
\hline Other insurance & 3 & 1.5 & 5 & 3.3 & 1 & 4.4 & 9 & 2.4 & .5 \\
\hline
\end{tabular}

asignificance value from Pearson's chi square for group effects. 
Table 5. Description of sample $(n=199)$.

\begin{tabular}{|c|c|c|c|c|c|}
\hline Variable & Mean (SD) & Median & Range & $\mathrm{n}$ & Percent \\
\hline \multicolumn{6}{|l|}{ Gender } \\
\hline Male & & & & 107 & $53.8 \%$ \\
\hline Female & & & & 92 & $46.2 \%$ \\
\hline \multicolumn{6}{|l|}{ Race } \\
\hline Black & & & & 170 & $85.4 \%$ \\
\hline White & & & & 27 & $13.6 \%$ \\
\hline Other & & & & 2 & $1.0 \%$ \\
\hline \multicolumn{6}{|l|}{ Marital Status } \\
\hline Single & & & & 110 & $55.3 \%$ \\
\hline Married & & & & 56 & $28.1 \%$ \\
\hline Widowed & & & & 18 & $9.0 \%$ \\
\hline Separated & & & & 15 & $7.5 \%$ \\
\hline \multicolumn{6}{|l|}{ Religion } \\
\hline Protestant & & & & 176 & $88.4 \%$ \\
\hline Catholic & & & & 4 & $2.0 \%$ \\
\hline Muslim & & & & 1 & $0.5 \%$ \\
\hline None & & & & 18 & $9.0 \%$ \\
\hline \multicolumn{6}{|l|}{ Education } \\
\hline Less than high school & & & & 92 & $46.5 \%$ \\
\hline High School graduate & & & & 65 & $32.8 \%$ \\
\hline More than high school & & & & 41 & $20.7 \%$ \\
\hline Education in Years & $10.7(3.2)$ & 12 & $0-17$ & 198 & \\
\hline Religion Score & $80.1(24.6)$ & 91.0 & $3-100$ & & \\
\hline Age & $39.3(15.6)$ & 37 & $18-88$ & 199 & \\
\hline
\end{tabular}




\section{Descriptive Statistics}

Patient quality and nurse quality variables. Descriptive statistics for patient quality (PQUALG, PQUALT, and PGOAL) and nurse quality variables (NQUAL and NGOAL) are presented in Table 6 and plots of their distributions are shown in Figures 4-8.

Predictor variables. Descriptive statistics for patient demographic variables (GENDER, RACE, MARITAL, RELIGION, EDUCATION, RELIGSCR, and AGE) are presented in Table 5. Descriptive statistics for financial (CURNTJOB, JOBPAYR, HRSPERWK, PINCOME, HINCOME, PAYOR, CHARGE), illness (PAINTIME, PAINAMT, PAINNOW, SYMPTOM, WORRY, SIS), and hospital (REFERRAL SOURCE, ADMISSION CLASS, NUMHOSP, DISCHARG, UNIT) variables are presented in Tables 7,8 , and 9, respectively.

\section{Analysis of Aims}

\section{Aim 1: Identify Relationships Among Patient and Nurse Perceived} Quality and Goal Achievement

Research Question 1: What Are the Relationships Among PQUALG, PQUALT, PGOAL, NQUAL, and NQUAL?

Table 10 displays estimated Phi coefficients among PQUALG, PQUALT, PGOAL, NQUAL, and NGOAL. All three patient quality variables were significantly correlated $(p<.1)$ with each other. The nurse quality variables were not correlated with each other. PQUALT was correlated with PGOAL and PQUALG. PGOAL was correlated with both measures of patient perceived quality, PQUALG and PQUALT. PQUALG was correlated with PQUALT and NGOAL. NGOAL was correlated with PQUALG. NQUAL was not correlated with any of the patient quality variables nor with NGOAL. 
Table 6. Descriptive statistics for patient quality variables and nurse quality variables $^{a}(n=199)$.

\begin{tabular}{|c|c|c|c|c|c|}
\hline \multirow[b]{2}{*}{ Variable } & \multirow[b]{2}{*}{$\mathrm{n}$} & \multirow[b]{2}{*}{ Mean (SD) } & \multicolumn{3}{|c|}{ Quantile } \\
\hline & & & $25 \%$ & $50 \%$ & $75 \%$ \\
\hline \multicolumn{6}{|l|}{ Patient quality variables } \\
\hline Patient perceived quality global & 199 & $78.88(22.72)$ & 66.00 & 87.00 & 97.00 \\
\hline Patient perceived quality total & 197 & $79.37(20.79)$ & 70.25 & 86.00 & 96.13 \\
\hline Patient goal achievement & 199 & $68.18(23.75)$ & 50.50 & 73.00 & 87.00 \\
\hline \multicolumn{6}{|l|}{ Nurse quality variables } \\
\hline Nurse perceived quality & 199 & $50.73(15.66)$ & 39.97 & 50.16 & 61.11 \\
\hline Nurse goal achievement & 198 & $89.4(14.15)$ & 83.35 & 94.55 & 100.00 \\
\hline
\end{tabular}

apatient variables scored on $100 \mathrm{~mm}$ visual analogue scales. Nurse variables scored as percent compliance with standards. 


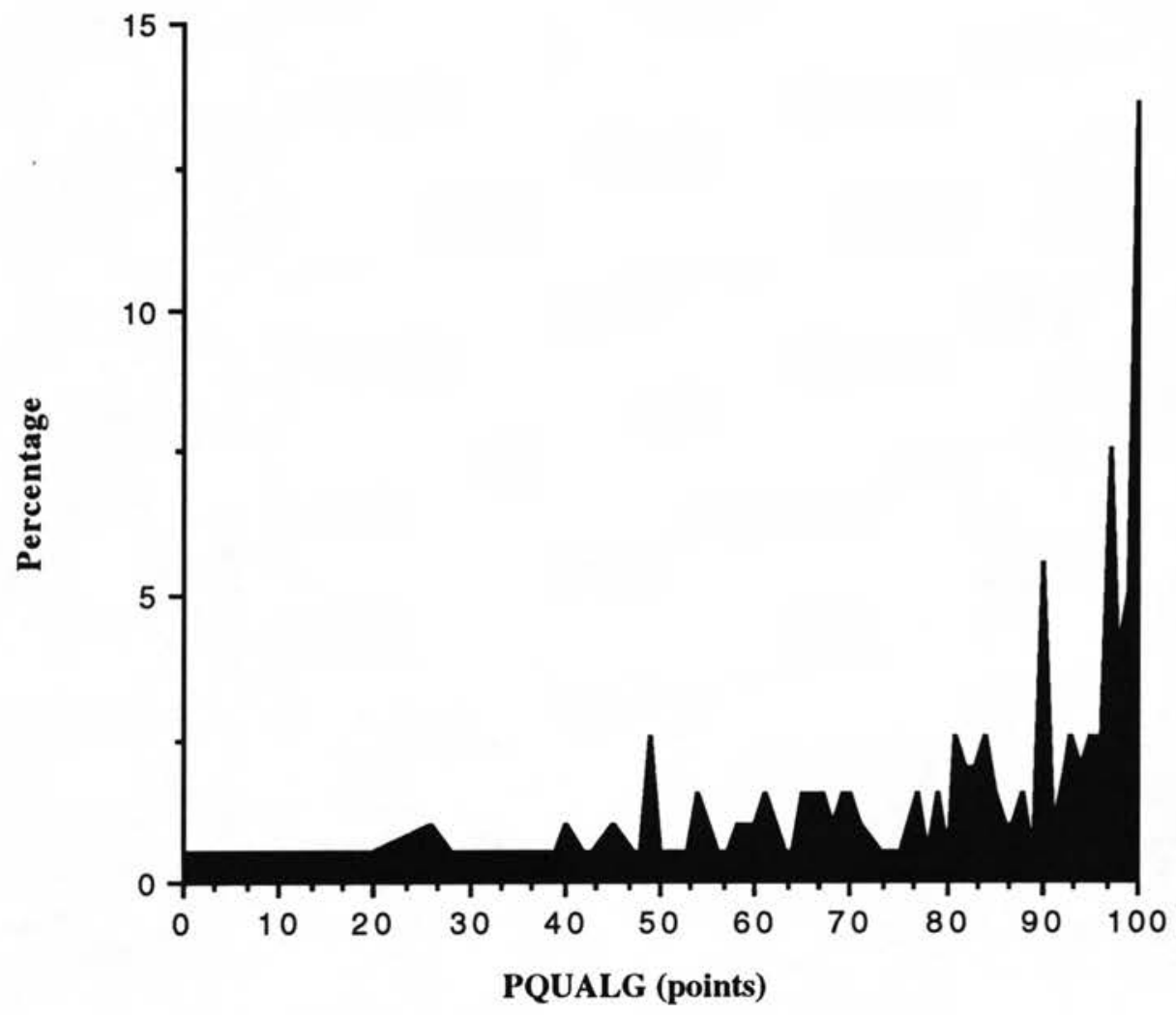

Figure 4. Distribution of patient perceived quality global. 


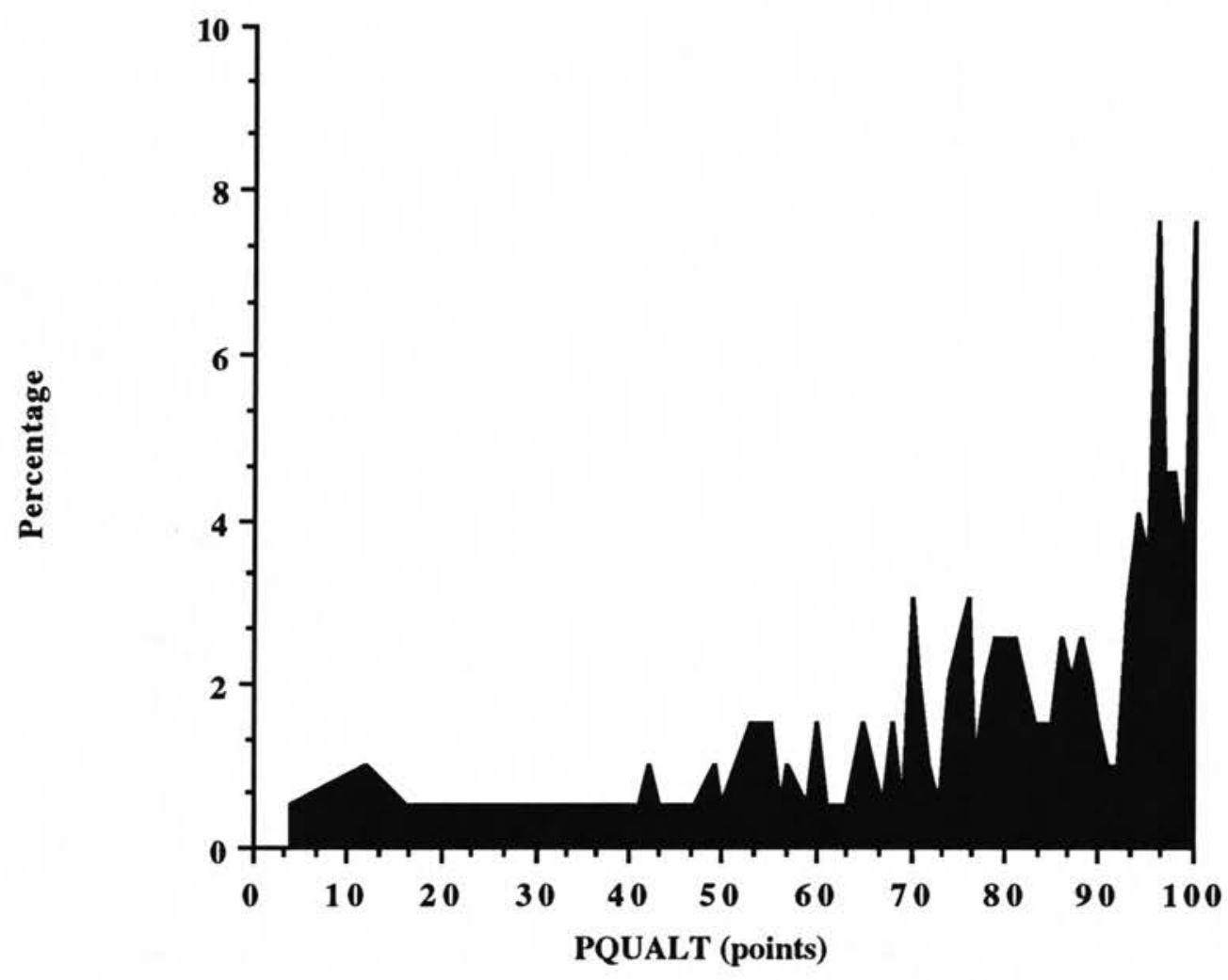

Figure 5. Distribution of patient perceived quality total. 


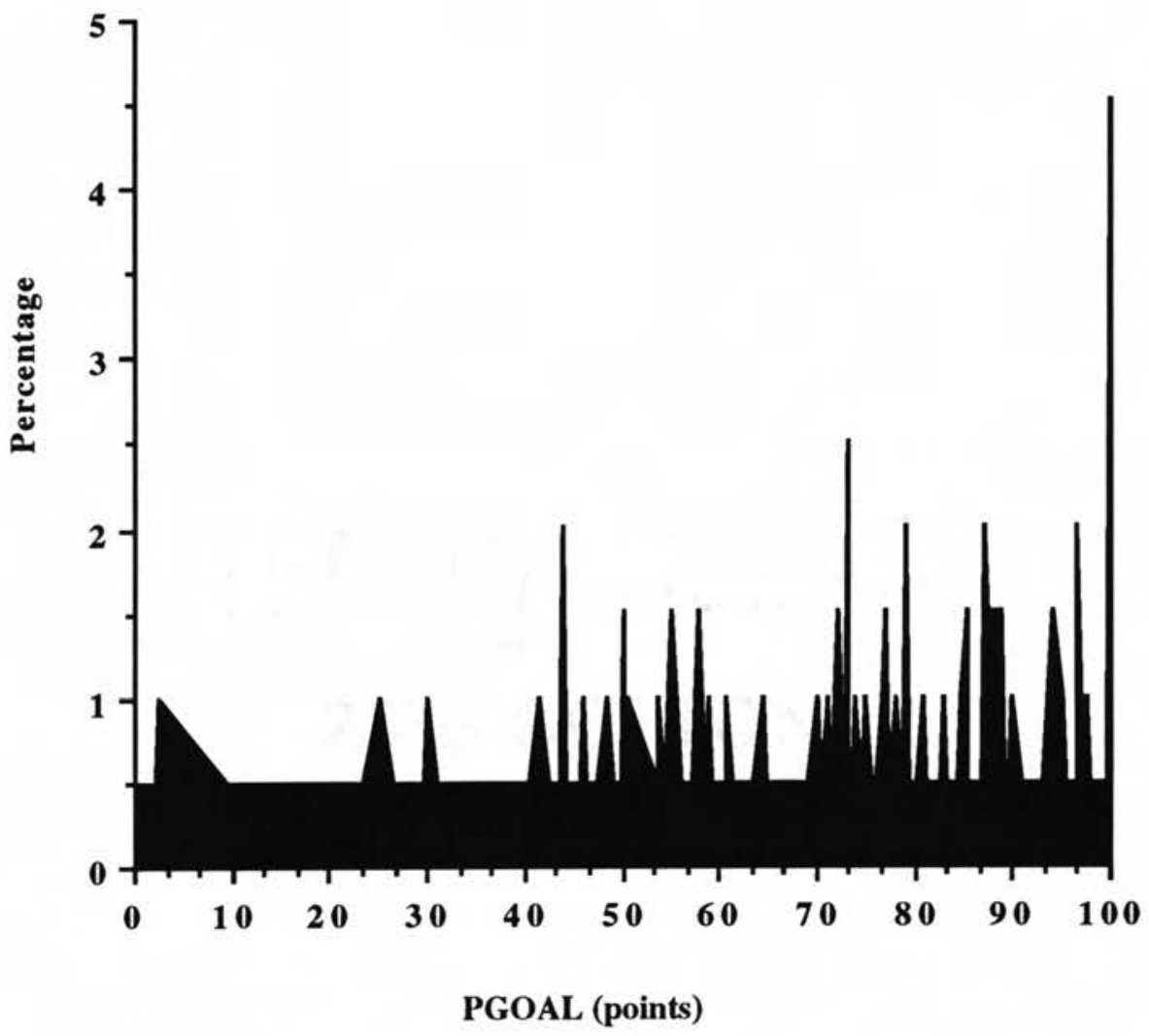

Figure 6. Distribution of patient goal achievement. 


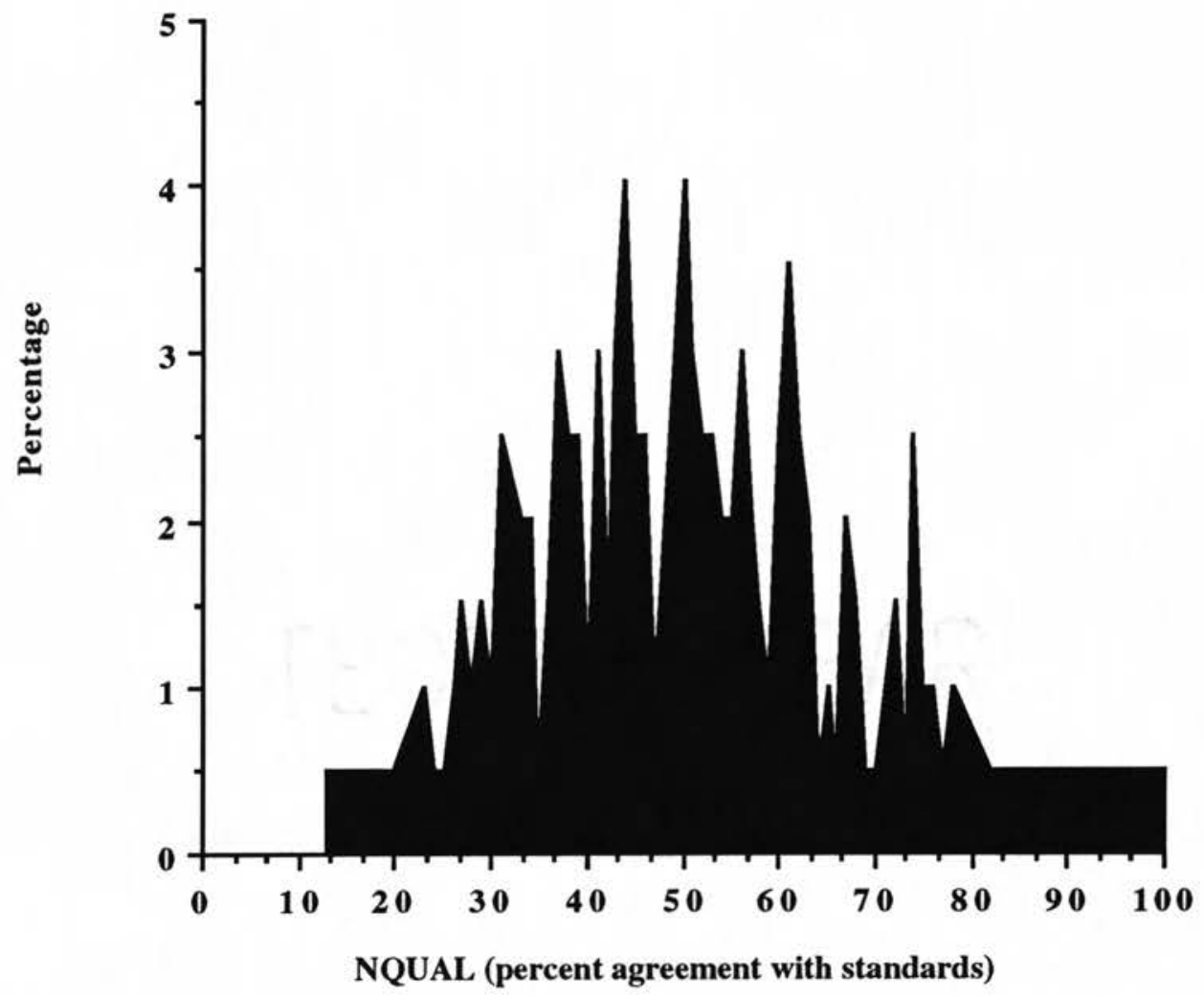

Figure 7. Distribution of nurse perceived quality. 


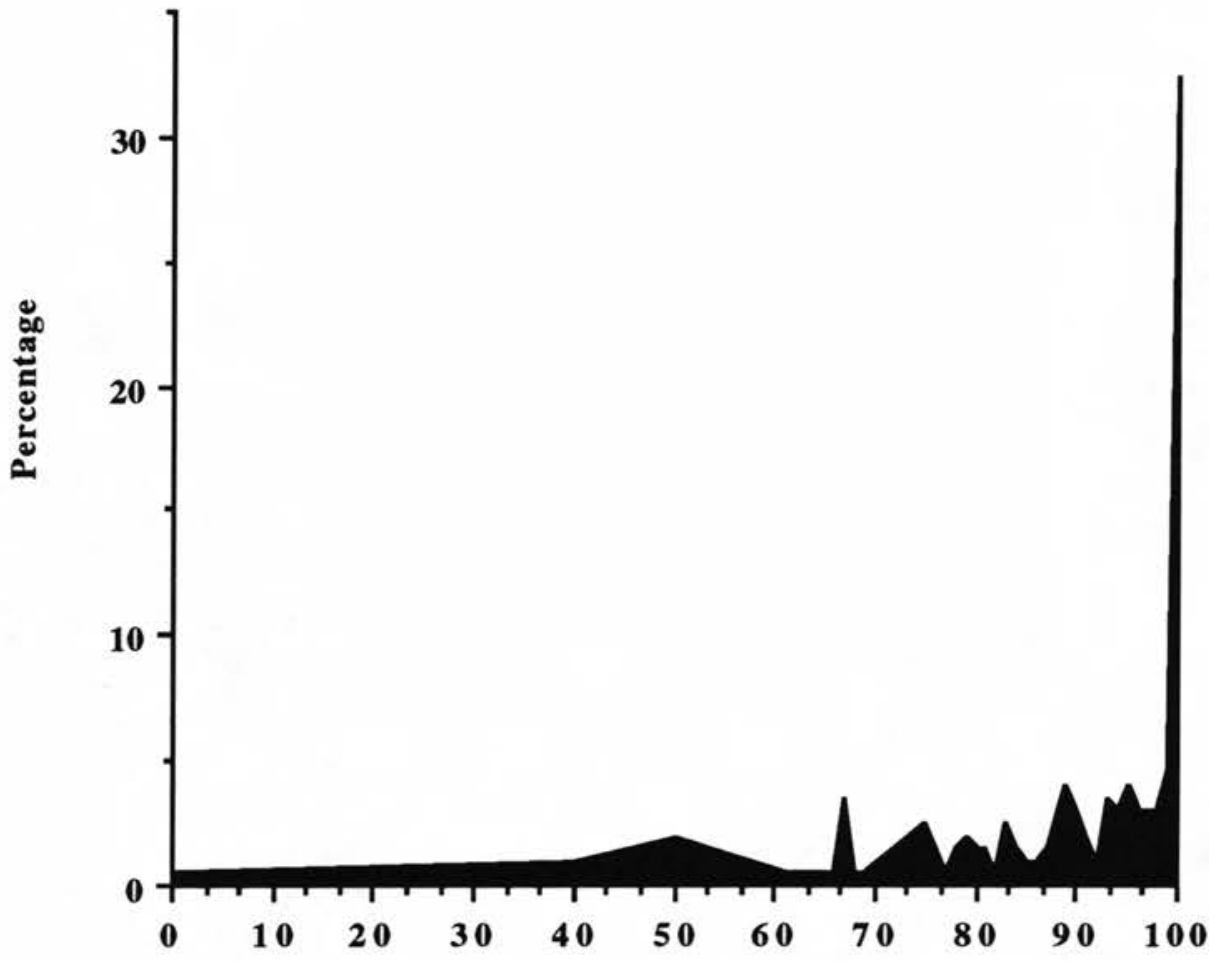

NGOAL (percent agreement with standards)

Figure 8. Distribution of nurse goal achievement. 
Table 7. Descriptive statistics for financial variables $(n=199)$.

\begin{tabular}{llllll}
\hline Variable & Mean (SD) & Median & Range & n & Percent \\
\hline
\end{tabular}

Payor source

No third party payor

$84 \quad 42.2 \%$

Medicaid

$57 \quad 28.6 \%$

Medicare

$29 \quad 14.6 \%$

Commercial insurance

$19 \quad 9.5 \%$

Blue Cross

$7 \quad 3.5 \%$

Other insurance

$31.5 \%$

Currently employed

$55 \quad 27.6 \%$

Employed in past year

$99 \quad 49.7 \%$

Hours worked/ week

38.20 (13.30)

40

8-80

55

$\begin{array}{lllll}\text { Personal income (\$) } \quad 456.56(550.10) & 400.00 & 0.00-5,000.00 & 189\end{array}$

Household income (\$) $\quad 793.00(845.05) \quad 493.00 \quad 0.00-5,000.00 \quad 148$

Total charges (\$)

$6,653.51(6084.94) \quad 4782.39$

$0.00-37,643.48 \quad 199$ 
Table 8. Descriptive statistics for illness variables $(n=199)$.

\begin{tabular}{llllll} 
Variable & Mean (SD) Median & Range & Percent \\
\hline
\end{tabular}

Severity of illness score (SIS)

Organ failure potential:
$0=$ none
$59 \quad 30.9 \%$
$1=$ low
$57 \quad 29.8 \%$
2 = moderate
$42 \quad 22.0 \%$
$3=$ high
$33 \quad 17.3 \%$
$4=$ organ damage present
$0 \quad .0 \%$

Pain experience in hospital ${ }^{\mathrm{a}}$

Severity in general

Amount of time in pain

Severity at exit interview

Worry score ${ }^{\mathrm{a}}$

Symptom score ${ }^{\mathrm{a}}$
$58.4(31.8)$

60.0

0-100

199

$51.3(28.7) \quad 52.0$

0-100

199

$20.7(24.8)$

8.0

0-100

199

$62.6(33.5)$

91.0

0-100

199

$81.1(24.5)$

71.0

0-100

199

aMeasured with $100 \mathrm{~mm}$ visual analogue scales. 
Table 9. Descriptive statistics of hospital variables $(n=199)$.

\begin{tabular}{|c|c|c|c|c|c|}
\hline Variable & Mean (SD) & Median & Range & $\mathrm{n}$ & Percent \\
\hline \multicolumn{6}{|l|}{ Referral source } \\
\hline Emergency department & & & & 133 & $66.8 \%$ \\
\hline Physician & & & & 45 & $22.6 \%$ \\
\hline Clinic & & & & 16 & $8.0 \%$ \\
\hline Other health facility & & & & 1 & $.5 \%$ \\
\hline Unknown & & & & 4 & $2.0 \%$ \\
\hline \multicolumn{6}{|l|}{ Admission class } \\
\hline Emergency & & & & 136 & $68.3 \%$ \\
\hline Urgent & & & & 44 & $22.1 \%$ \\
\hline Elective & & & & 16 & $8.0 \%$ \\
\hline Unknown & & & & 3 & $1.5 \%$ \\
\hline \multicolumn{6}{|l|}{ Discharge disposition } \\
\hline Home & & & & 196 & $98.5 \%$ \\
\hline Other general hospital & & & & 1 & $.5 \%$ \\
\hline Skilled nursing facility & & & & 1 & $.5 \%$ \\
\hline Expired & & & & 1 & $.5 \%$ \\
\hline Previous hospitalization & $5.0(5.7)$ & 3.0 & $0-30$ & 199 & \\
\hline Length of stay in days & $5.5(4.6)$ & 4.6 & $1.1-35.7$ & 199 & \\
\hline
\end{tabular}


Table 10. Estimated Pearson correlations among patient quality variables and nurse quality variables $(\mathrm{n}=199)$.

\section{PQUALG PQUALT NGOAL NQUAL}

Patient quality variables

Patient perceived $\begin{array}{lll}.60 * * * * & .13^{*} \quad-.09\end{array}$

quality global (PQUALG)

Patient perceived

.09

.07

quality total (PQUALT)

Patient goal

$.14^{*}$

$.17^{* *}$

$-.04$

.01

achievement (PGOAL)

Nurse quality variables

Nurse perceived

quality (NQUAL)

Nurse goal achievement (NGOAL)

Note: $\mathrm{p}$ values are two tailed: ${ }^{*} \mathrm{p}<.1 ;{ }^{* *} \mathrm{p}<.05 ;{ }^{* * *} \mathrm{p}<.01 ;{ }^{* * * *} \mathrm{p}<.001$. 
Aim 2: Develop Prediction Equations for Patient Perceived Quality and Patient Goal Achievement

Research Question 1: What Are the Predictors of Patient Perceived Quality?

PQUALG. PQUALG was significantly associated ( $\leq \leq .2)$ with 11 candidate predictor variables which included one demographic, three financial, one illness, four hospital variables, PGOAL, and NGOAL. Table 11 displays the estimated beta coefficients, standard errors, and p values from simple logistic regression for these candidate predictor variables. The estimated likelihood ratios and $95 \%$ confidence intervals for these candidate predictor variables are presented in Table 12.

PQUALG was regressed on these 11 candidate predictor variables, using stepwise multiple logistic regression. The resulting prediction index identified five predictors with an alpha $\leq .1$. PQUALG was regressed on these five predictors, using multiple logistic regression. The significant independent predictors of PQUALG were (a) pain severity at exit interview, (b) clinic referral, (c) Unit 1, (d) patient goal achievement, and (e) being a recipient of Medicare. The estimated beta coefficients, standard errors, and p values are presented in Table 13 and the estimates of adjusted odds ratios and $95 \%$ confidence intervals for these predictors are presented in Table 14.

PQUALT. PQUALT was significantly associated ( $\leq .2)$ with 15 candidate predictor variables which included two demographic, six financial, three illness, two hospital variables, PGOAL, and NGOAL. Table 15 displays the estimated beta coefficients, standard errors, and p values from simple logistic regression for these candidate predictor variables. The estimated likelihood ratios and $95 \%$ confidence 
Table 11. Beta coefficients, standard errors, $p$ values, and deltas from simple logistic regression for predictors of patient perceived quality global (PQUALG) $(n=199)$.

\begin{tabular}{lcccc}
\hline Variables & Beta & S.E. & $\mathrm{p}$ & Delta \\
\hline Patient goal achievement & .83 & .44 & .06 & Yes/no \\
Pain severity at exit interview & -.01 & .01 & .08 & Point \\
Number of prior hospitalizations & -.04 & .03 & .15 & Event \\
Age & -.02 & .01 & .10 & Years \\
Payor source: Medicare & -.96 & .52 & .06 & Yes/no \\
Payor source: no third party & .58 & .31 & .09 & Yes/no \\
Referral source: physician & -.67 & .40 & .09 & Yes/no \\
Referral source: clinic & 1.07 & .53 & .04 & Yes/no \\
Unit 1 & .97 & .32 & .00 & Yes/no \\
Working > 29 hours/ week & .57 & .34 & .10 & Yes/no \\
Nurse goal achievement & .55 & .31 & .07 & Yes/no \\
\hline
\end{tabular}


Table 12. Likelihood ratios estimated as odds ratios for predictors of patient perceived quality global (PQUALG) $(\mathrm{n}=199)$.

\begin{tabular}{lcccc}
\hline & & \multicolumn{2}{c}{$95 \%$ confidence interval } & \\
\cline { 3 - 4 } Variables & Odds ratio & Lower limit & Upper limit & Delta \\
\hline Patient goal achievement & 2.30 & .97 & 5.45 & Yes/no \\
Pain severity at exit interview & .99 & .98 & 1.00 & Point \\
Number of prior hospitalizations & .96 & .90 & 1.02 & Event \\
Age & .98 & .96 & 1.00 & Years \\
Payor source: Medicare & .38 & .14 & 1.05 & Yes/no \\
Payor source: no third party & 1.68 & .92 & 3.05 & Yes/no \\
Referral source: physician & .51 & .24 & 1.12 & Yes/no \\
Referral source: clinic & 2.92 & 1.03 & 8.22 & Yes/no \\
Unit 1 & 2.65 & 1.41 & 4.99 & Yes/no \\
Working > 29 hours/ week & 1.76 & .90 & 3.46 & Yes/no \\
Nurse goal achievement & 1.73 & .95 & 3.15 & Yes/no \\
\hline
\end{tabular}


Table 13. Prediction index from multiple logistic regression for patient perceived quality global (PQUALG) $(\mathrm{n}=199)$.

\begin{tabular}{lcccc}
\hline Variables & Beta & S.E. & p & Delta \\
\hline Intercept & -1.16 & .32 & .0003 & \\
Pain severity at exit interview & -.01 & .01 & .06 & Point \\
Referral source: clinic & 1.33 & .58 & .02 & Yes/ no \\
Unit 1 & .98 & .34 & .00 & Yes/no \\
Patient goal achievement & .88 & .47 & .06 & Yes/no \\
Payor source: Medicare & -.96 & .55 & .08 & Yes/no \\
\hline
\end{tabular}


Table 14. Adjusted odds ratios and $95 \%$ confidence intervals from multiple logistic regression of predictors of patient perceived quality global $(\mathrm{PQUALG})(\mathrm{n}=199)$.

\begin{tabular}{lrrrrr}
\hline & & \multicolumn{2}{c}{$95 \%$ confidence interval } & \\
\cline { 3 - 4 } Variables & Odds ratio & Lower limit & Upper limit & Delta \\
\hline Pain severity at exit interviewa & .99 & .97 & 1.00 & Point \\
Referral source: clinic & 3.78 & 1.22 & 11.78 & Yes/no \\
Unit 1 & 2.67 & 1.37 & 5.18 & Yes/ no \\
Patient goal achievement & 2.40 & .96 & 6.03 & Yes/no \\
Payor source: Medicare & .38 & .13 & 1.12 & Yes/no \\
\hline
\end{tabular}

apain was measured as a continuous variable, so that for every millimeter increase in pain there was a $1 \%$ decrease in the PQUALG score. Alternately, the relative risk of a low PQUALG score for patients at the limits $(75 \%, 25 \%)$ of the interquartile range for pain was $1.03(36 \mathrm{~mm}-1 \mathrm{~mm})=1.03^{35}=2.90$. 
Table 15. Beta coefficients, standard errors, $p$ values, and deltas from simple logistic regression for predictors of patient perceived quality total (PQUALT) $(n=199)$.

\begin{tabular}{lcccc}
\hline Variables & Beta & S.E. & $\mathrm{p}$ & Delta \\
\hline Patient goal achievement & 1.05 & .45 & .02 & Yes/no \\
Pain severity at exit interview & -.02 & .01 & .02 & Point \\
Amount of time in pain & -.01 & .01 & .16 & Point \\
Religion score & -.01 & .13 & .14 & Point \\
Age & -.02 & .01 & .15 & Years \\
Worry score & .01 & .01 & .03 & Point \\
Worked hours per week & .01 & .01 & .11 & Hours/ week \\
Payor source: Medicare & -.87 & .57 & .12 & Yes/no \\
Payor source: no third party & .48 & .33 & .14 & Yes/no \\
Referral source: physician & -.58 & .43 & .17 & Yes/no \\
Unit 1 & .76 & .34 & .03 & Yes/no \\
Working 0 hours/ week & -.49 & .35 & .16 & Yes/no \\
Currently employed & -.49 & .35 & .16 & Yes/no \\
Working > 29 hours/ week & .55 & .36 & .13 & Yes/no \\
Nurse goal achievement & .42 & .33 & .20 & Yes/no \\
\hline & & & & \\
\hline
\end{tabular}


intervals for these candidate predictor variables are presented in Table 16.

PQUALT was regressed on these 15 candidate predictor variables, using stepwise multiple logistic regression. The resulting prediction index identified five predictors with an alpha $\leq .1$. PQUALT was regressed on these five predictors, using multiple logistic regression. The significant independent predictors of PQUALT were (a) pain severity on exit interview, (b) worry score, (c) patient goal achievement, (d) clinic referral, (e) Unit 1 . The estimated beta coefficients, standard errors, and p values are presented in Table 17 and the estimates of adjusted odds ratios and $95 \%$ confidence intervals are presented in Table 18.

Research Question 2: What Are the Predictors of Patient Goal Achievement?

PGOAL. PGOAL was significantly associated $(\mathrm{p} \leq .2)$ with nine candidate predictor variables which included two demographic, four financial, one illness, and two hospital variables. Table 19 displays the estimated beta coefficients, standard errors, and p values from simple logistic regression for these candidate predictor variables. The estimated likelihood ratios and $95 \%$ confidence intervals for these candidate predictor variables are presented in Table 20.

PGOAL was regressed on these nine candidate predictor variables, using stepwise multiple logistic regression. The resulting prediction index identified six predictors with an alpha $\leq .1$. PGOAL was regressed on these six predictors, using multiple logistic regression. The significant independent predictors of PGOAL were (a) pain severity at exit interview, (b) working part time ( 30 hours/week), (c) recipient of Blue Cross, (d) being white, (e) being female, 
Table 16. Likelihood ratios estimated as odds ratios for predictors of patient perceived quality total (PQUALT) $(\mathrm{n}=199)$.

\begin{tabular}{lcccc}
\hline & & \multicolumn{2}{c}{$95 \%$ confidence interval } & \\
\cline { 3 - 4 } Variables & Odds ratio & Lower limit & Upper limit & Delta \\
\hline Patient goal achievement & 2.86 & 1.19 & 6.87 & Yes/ no \\
Pain severity at exit & .98 & .97 & 1.00 & Point \\
interview & & & & \\
Amount of time in pain & .99 & .98 & 1.00 & Point \\
Religion score & .99 & .98 & 1.00 & Point \\
Age & .98 & .96 & 1.01 & Years \\
Worry score & 1.01 & 1.00 & 1.02 & Point \\
Worked hours per week & 1.01 & 1.00 & 1.03 & Hours/ week \\
Payor source: Medicare & .42 & .14 & 1.27 & Yes/no \\
Payor source: no third party & 1.61 & .85 & 3.06 & Yes/no \\
Referral source: physician & .56 & .24 & 1.30 & Yes/no \\
Unit 1 & 2.13 & 1.09 & 4.18 & Yes/no \\
Working 0 hours/ week & .61 & .31 & 1.21 & Yes/no \\
Currently employed & .61 & .31 & 1.21 & Yes/no \\
Working $>$ 29 hours/ week & 1.73 & .85 & 3.52 & Yes/no \\
Nurse goal achievement & 1.53 & .81 & 2.89 & Yes/no \\
\hline & & & & \\
\hline
\end{tabular}


Table 17. Prediction index from multiple logistic regression for patient perceived quality total (PQUALT) $(\mathrm{n}=199)$.

\begin{tabular}{lcccc}
\hline Variables & Beta & S.E. & $\mathrm{p}$ & Delta \\
\hline Intercept & -2.49 & .53 & .0001 & \\
Pain severity at exit interview & -.02 & .01 & .01 & Point \\
Worry score & .02 & .01 & .01 & Point \\
Patient goal achievement & 1.14 & .48 & .02 & Yes/no \\
Referral source: clinic & 1.03 & .60 & .08 & Yes/ no \\
Unit 1 & .82 & .37 & .03 & Yes/ no \\
\hline
\end{tabular}


Table 18. Adjusted odds ratios and $95 \%$ confidence intervals from multiple logistic regression for predictors of patient perceived quality total (PQUALT) $(n=199)$.

$95 \%$ confidence interval

Variables

Odds ratio

Lower limit

Upper limit

Delta

Pain severity at exit interviewa

.98

.96

1.00

Point

Worry score

1.00

1.02

1.03

Point

Patient goal achievement

3.12

1.21

8.03

9.01

4.69
.87

1.11
2.28

apain was measured as a continuous variable, so that for every millimeter increase in pain there was a $2 \%$ decrease in the PQUALT score. Alternately, the relative risk of a low PQUALT score for patients at the limits $(75 \%, 25 \%)$ of the interquartile range for pain was $1.03(36 \mathrm{~mm}-1 \mathrm{~mm})=1.03^{35}=2.90$. 
Table 19. Beta coefficients, standard errors, $\mathrm{p}$ values, and deltas from simple logistic regression for predictors of patient goal achievement (PGOAL) $(n=199)$.

\begin{tabular}{lcccc}
\hline Variables & Beta & S.E. & p & Delta \\
\hline Pain severity at exit interview & -.03 & .01 & .04 & Point \\
Household income categorya & -.24 & .20 & .23 & Category \\
Payor source: Blue Cross & 1.13 & .87 & .20 & Yes/ no \\
Payor source: Medicaid & -1.14 & .64 & .07 & Yes/no \\
Admission class: emergency & .93 & .57 & .10 & Yes/no \\
Referral source: emergency room & 1.01 & .57 & .08 & Yes/no \\
Race: white & .79 & .52 & .13 & Yes/no \\
Gender: female & .75 & .45 & .09 & Yes/no \\
Working < 30 hours/ week & 1.58 & .77 & .04 & Yes/no \\
\hline
\end{tabular}

aCategories for monthly combined household income are: group $0=\$ 0$; $\$ 0<$ group $1<\$ 400 ; \$ 399<$ group $2<\$ 600 ; \$ 599<$ group $3<\$ 1000$; $\$ 999<$ group $4<\$ 5001$. 
Table 20. Likelihood ratios estimated as odds ratios for predictors of patient goal achievement (PGOAL) $(\mathrm{n}=199)$.

\section{$95 \%$ confidence interval}

Variables

Odds ratio Lower limit Upper limit Delta

Pain severity at exit interview .97

.95

1.00 Point

Household income category ${ }^{a}$

.53

1.16 Category

Payor source: Blue Cross

3.09

.57

$16.90 \quad$ Yes/ no

Payor source: Medicaid

.09

1.12 Yes/ no

Admission class: emergency

2.54

.83

$7.78 \quad$ Yes/ no

Referral source: emergency room

2.74

.90

8.37 Yes/ no

Race: white

2.20

.79

6.14 Yes/ no

Gender: female

2.12

.88

$5.10 \quad$ Yes/ no

Working $<30$ hours/ week

4.86

1.08

$21.80 \quad$ Yes/no

aCategories for monthly combined household income are: group $0=\$ 0$; $\$ 0<$ group $1<\$ 400 ; \$ 399<$ group $2<\$ 600 ; \$ 599<$ group $3<\$ 1000$; $\$ 999<$ group $4<\$ 5001$. 
and 6) household income. The estimated beta coefficients, standard errors, and p values are presented in Table 21 and the estimates of adjusted odds ratios and $95 \%$ confidence intervals for these predictors are presented in Table 22 .

Aim 3: Develop Prediction Equations for Nurse Perceived Quality and Nurse Goal Achievement

Research Question 1: What Are the Predictors of Nurse Perceived Quality?

NQUAL. NQUAL was significantly associated $(p \leq .2)$ with five demographic, two financial, and three hospital variables. NQUAL was regressed on these ten variables, using stepwise multiple linear regression. Two predictors had an alpha $\leq .1$; NQUAL was regressed on these two variables. Multiple linear regression identified being widowed and being a recipient of Medicaid as independent predictors of nurse perceived quality. Table 23 presents the estimated regression coefficients and standards errors. The amount of variance explained by the two variables is only $6 \%$. The interaction effect of being widowed and receiving Medicaid did not have a significant association with nurse perceived quality and was therefore not included in the multiple linear regression model (Table 24). Additional analyses identified that one subgroup, widowed and nonrecipient of Medicaid, had significantly higher mean NQUAL score compared to the other three subgroups (Table 25). 
Table 21. Prediction index from multiple logistic regression for patient goal achievement (PGOAL) $(\mathrm{n}=199)$.

\begin{tabular}{lcccc}
\hline Variables & Beta & S.E. & $\mathrm{p}$ & Delta \\
\hline Intercept & -.50 & .77 & .51 & \\
Pain severity at exit interview & -.03 & .01 & .03 & Point \\
Working < 30 hours/week & 1.97 & .84 & .02 & Yes/no \\
Payor source: Blue Cross & 1.94 & .96 & .04 & Yes/no \\
Race: white & 1.39 & .58 & .02 & Yes/no \\
Gender: female & .77 & .48 & .11 & Yes/no \\
Household income categorya & -.37 & .21 & .08 & Category \\
\hline
\end{tabular}

aCategories for monthly combined household income are: group $0=\$ 0$; $\$ 0<$ group $1<\$ 400 ; \$ 399<$ group $2<\$ 600 ; \$ 599<$ group $3<\$ 1000$; $\$ 999<$ group $4<\$ 5001$. 
Table 22. Adjusted odds ratios and $95 \%$ confidence intervals from multiple logistic regression for predictors of patient goal achievement (PGOAL) $(n=199)$.

\begin{tabular}{lcccc}
\hline & & \multicolumn{2}{c}{$95 \%$ confidence interval } & \\
\cline { 3 - 4 } Variables & Odds ratio & Lower limit & Upper limit & Delta \\
\hline Pain severity at exit interviewa & .97 & .95 & 1.00 & Point \\
Working < 30 hours/ week & 7.18 & 1.38 & 37.45 & Yes/no \\
Payor source: Blue Cross & 6.95 & 1.05 & 45.91 & Yes/no \\
Race: white & 4.03 & 1.28 & 12.65 & Yes/no \\
Gender: female & 2.16 & .85 & 5.49 & Yes/no \\
Household income category $\mathrm{b}$ & .69 & .45 & 1.05 & Category \\
\hline
\end{tabular}

apain was measured as a continuous variable, so that for every millimeter increase in pain there was a $3 \%$ decrease in the PGOAL score. Alternately, the relative risk of a low PGOAL score for patients at the limits $(75 \%, 25 \%)$ of the interquartile range for pain was $1.03^{(36 \mathrm{~mm}-1 \mathrm{~mm})}=1.03^{35}=2.90$.

bCategories for monthly combined household income are: group $0=\$ 0$; $\$ 0<$ group $1<\$ 400 ; \$ 399<$ group $2<\$ 600 ; \$ 599<$ group $3<\$ 1000$; $\$ 999<$ group $4<\$ 5001$. 
Table 23. Estimated regression coefficients and standard errors from multiple regression for predictors of nurse perceived qualitya (NQUAL) $(n=199)$.

\begin{tabular}{lccccc}
\hline Variable & df & Beta & S.E. & p value & Standardized beta \\
\hline Intercept & 1 & 51.31 & 1.32 & .0001 & \\
Medicaid & 1 & -6.22 & 2.40 & .01 & -.18 \\
Widowed & 1 & 9.31 & 3.79 & .02 & .17 \\
\hline
\end{tabular}

$\mathrm{aR}^{2}=0.0573$. 
Table 24. Two-way analysis of variance: mean nurse perceived quality by Medicaid recipient status and widow status $(\mathrm{n}=198)$.

\begin{tabular}{lcccc}
\hline Effect & df & Mean square & F & p \\
\hline Medicaid recipient & 1 & 1368.55 & 5.86 & 0.02 \\
Widowed & 1 & 1412.99 & 6.05 & 0.02 \\
$\begin{array}{l}\text { Medicaid * widowed } \\
\text { interaction }\end{array}$ & 1 & 263.13 & 1.13 & 0.29 \\
Residual & 195 & 233.50 & & \\
\hline
\end{tabular}


Table 25. Least squares means and standard errors for nurse perceived quality from two-way analysis of variance $(n=199)$.

\begin{tabular}{lccccc}
\hline & & $\mathrm{n}$ & LSMeans & S.E. & p value \\
\hline \multirow{2}{*}{ Payor source: Medicaid } & Yes & 57 & 47.80 & 3.08 & 0.02 \\
& No & 142 & 57.29 & 2.40 & \\
Marital status: widowed & Yes & 18 & 56.68 & 3.69 & 0.02 \\
& No & 181 & 48.40 & 1.27 & \\
Medicaid*widowed & & & & & \\
interaction & No/ no & 131 & 51.07 & 1.34 & $\mathrm{~b}$ \\
& No/ yes & 11 & 63.51 & 4.61 & $\mathrm{c}$ \\
& Yes/no & 50 & 45.72 & 2.16 & $\mathrm{a}$ \\
& Yes/ yes & 7 & 49.87 & 5.78 & $\mathrm{a}, \mathrm{b}$ \\
\hline
\end{tabular}

$\mathrm{aR}^{2}=0.063$.

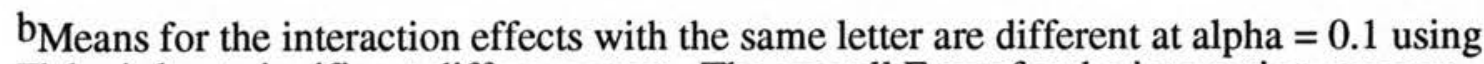
Fisher's least significant difference test. The overall F-test for the interaction was not significant $(\mathrm{p}>.2)$. 
Research Question 2: What Are the Predictors of Nurse Goal Achievement?

MGOAL. NGOAL was significantly associated $(\mathrm{p} \leq .2)$ with eight candidate predictor variables which included one demographic, two financial, two illness, and three hospital variables. Table 26 displays the estimated beta coefficients, standard errors, and p values from simple logistic regression for these candidate predictor variables. The estimated likelihood ratios and $95 \%$ confidence intervals for these candidate predictor variables are presented in Table 27.

NGOAL was regressed on these eight candidate predictor variables, using stepwise multiple logistic regression. The resulting prediction index identified three predictors with an alpha $\leq .1$. NGOAL was regressed on these three predictors, using multiple logistic regression. The significant independent predictors of NGOAL were pain severity at exit interview, severity of illness score, and being married. The estimated beta coefficients, standard errors, and $p$ values are presented in Table 28 and the estimates of adjusted odds ratios and $95 \%$ confidence intervals for these predictors are presented in Table 29.

Aim 4 Determine the Congruence Between Predictors of Patient and Nurse Perceived Quality

Research Question 1: Are There Differences in the Predictors of Patient and Nurse Perceived Quality?

There was no congruence between the predictors of patient perceived quality and nurse perceived quality. 
Table 26. Beta coefficients, standard errors, $p$ values, and deltas from simple logistic regression for predictors of nurse goal achievement (NGOAL) $(n=199)$.

\begin{tabular}{lcccc} 
Variables & Beta & S.E. & p & Delta \\
\hline Pain severity at exit interview & -.01 & .01 & .10 & Point \\
Number of prior hospitalizations & -.04 & .03 & .18 & Event \\
Length of time on unit & -.07 & .04 & .06 & Days \\
Household income category $\mathrm{a}$ & -.29 & .13 & .03 & Category \\
Total charges for care & .00 & .00 & .07 & Dollars \\
Married & -.43 & .33 & .18 & Yes/ no \\
Unit 1 & .54 & .29 & .06 & Yes/ no \\
Severity of illness scoreb & -.47 & .15 & .00 & Rank \\
\hline
\end{tabular}

aCategories for monthly combined household income are: group $0=\$ 0$; $\$ 0<$ group $1<\$ 400 ; \$ 399<$ group $2<\$ 600 ; \$ 599<$ group $3<\$ 1000$; $\$ 999<$ group $4<\$ 5001$.

bSeverity of illness score (SIS) categories indicate potential for organ damage and are: SIS $0=$ none; SIS 1 = low; SIS $2=$ moderate; SIS $3=$ high; SIS $4=$ damage present. None of the participants had a SIS of 4. 
Table 27. Likelihood ratios estimated as odds ratios for predictors of nurse goal achievement (NGOAL) $(n=199)$.

\section{5\% confidence interval}

Variables

Odds ratio Lower limit Upper limit

Delta

Pain severity at exit interview .99

$1.00 \quad$ Point

Number of prior hospitalizations

.97

.92

1.02 Event

Length of time on unit

.93

.86

1.00 Days

Household income categorya

.75

.58

$.97 \quad$ Category

Total charges for care

1.00

1.00

1.00 Dollars

Married

1.23 Yes/ no

Unit 1

1.72

.97

$3.04 \quad$ Yes/no

Severity of illness score ${ }^{b}$

.63

.47

$.83 \quad$ Rank

aCategories for monthly combined household income are: group $0=\$ 0$;

$>\$ 0<$ group $1<\$ 400 ; \$ 399<$ group $2<\$ 600 ;>\$ 599<$ group $3<\$ 1000$;

$>\$ 999<$ group $4<\$ 5001$.

bSeverity of illness score (SIS) categories indicate potential for organ damage and are: SIS $0=$ none; SIS 1 = low; SIS $2=$ moderate; SIS $3=$ high; SIS $4=$ damage present. None of the participants had a SIS of 4. 
Table 28. Prediction index from multiple logistic regression for nurse goal achievement (NGOAL) $(\mathrm{n}=199)$.

\begin{tabular}{lcccc}
\hline Variables & Beta & S.E. & $\mathrm{p}$ & Delta \\
\hline Intercept & .91 & .32 & .004 & \\
Pain severity at exit interview & -.02 & .01 & .02 & Point \\
Married & -.64 & .36 & .07 & Yes/ no \\
Severity of illness score & -.57 & .16 & .00 & Rank \\
\hline
\end{tabular}

aSeverity of illness score (SIS) categories indicate potential for organ damage and are: SIS $0=$ none; SIS 1 = low; SIS $2=$ moderate; SIS $3=$ high; SIS $4=$ damage present. None of the participants had a SIS of 4. 
Table 29. Adjusted odds ratios and $95 \%$ confidence intervals from multiple logistic regression for predictors of nurse goal achievement (NGOAL) $(n=199)$.

\begin{tabular}{lccccc}
\hline & & \multicolumn{2}{c}{$95 \%$ confidence interval } & \\
\cline { 3 - 4 } Variables & Odds ratio & Lower limit & Upper limit & Delta \\
\hline Pain severity at exit interviewa & .98 & .97 & 1.00 & Point \\
Not married & 1.89 & .94 & 3.79 & Yes/ no \\
Severity of illness score & & .57 & .42 & .77 & Rank \\
\hline
\end{tabular}

aPain was measured as a continuous variable, so that for every millimeter increase in pain there was a $2 \%$ decrease in the NGOAL score. Alternately, the relative risk of a low NGOAL score for patients at the limits $(75 \%, 25 \%)$ of the interquartile range for pain was $1.03(36 \mathrm{~mm}-1 \mathrm{~mm})=1.03^{35}=2.90$.

bSeverity of illness score (SIS) categories indicate potential for organ damage and are: SIS $0=$ none; SIS $1=$ low; SIS $2=$ moderate; SIS $3=$ high; SIS $4=$ damage present. None of the participants had a SIS of 4. 
Aim 5: Determine the Congruence Between Predictors of Patient and Nurse Goal Achievement

Research Question 1: Are There Differences in the Predictors of Patient and Nurse Goal Achievement?

Only one of the six predictors of PGOAL and of the three

predictors of NGOAL was the same, pain severity at exit interview. 
Chapter 5. Discussion

\title{
Specific Aims
}

\begin{abstract}
Aim 1: Identify Relationships Among Patient and Nurse Perceived Quality and Goal Achievement
\end{abstract}

Research Question 1: What Are the Relationships Among PQUALG, PQUALT, PGOAL, NQUAL, and NGOAL?

PQUALG and PQUALT were correlated with each other $(r=.60$,

$\mathrm{p}<.001)$. Patient value (PGOAL) was significantly correlated with both measures of patient perceived quality (PQUALG: $r=.14, p<.1$; and PQUALT: $\mathrm{r}=.17, \mathrm{p}<.05)$. PQUALG was correlated with nurse value (NGOAL: $\mathrm{r}=.13, \mathrm{p}<.1$ ). Nurse quality (NQUAL) was not correlated with any patient quality variables or with NGOAL.

PQUALG correlated with PQUALT. Of the significant correlations identified for Aim 1, this was the highest, explaining $36 \%$ of the shared variance. This significant correlation between PQUALG and PQUALT indicates that they have convergent validity: they are measuring the same construct. PQUALG can be used alone to measure patient perceived quality, because PQUALG and PQUALT were moderately correlated. Using PQUALG alone would be especially useful with populations who lack the energy, comfort, or interest to participate in longer interviews or to fill out questionnaires. In fact, in this study, two patients completed the 1 item patient perceived quality global question when they were unable to complete the 8 item patient perceived quality total questions.

PGOAL correlated with PQUALG and PQUALT. PGOAL was significantly correlated with both measures of patient perceived quality, PQUALG and 
PQUALT. The shared variance of PQUALG and PGOAL $(r=.14, p<.1)$ was $2 \%$. The shared variance of PQUALT and PGOAL $(r=.17, p<.05)$ was $3 \%$. The significant positive relationships between PGOAL and both measures of patient perceived quality supports the theorectically proposed relationship between value and quality in Larrabee's model of quality. This relationship between patient goal achievement and patient quality is consistent with previous findings that patient satisfaction with hospital care quality is related to patient expectations being met. ${ }^{76}$

As patient goal achievement increases so does patient perceived quality. This finding has clinical significance because hospitals and health care providers are striving toward improved customer responsiveness in order to maintain or increase market share. This relationship between patient perceived quality and PGOAL suggests that nurses should discover ways to maximize patient goal achievement as a means of improving patient perceived quality. $\mathrm{King}^{161,162}$ reported that mutual goal planning between nurses and patients increased patient goal attainment.

The noteworthy lack of correlation between PGOAL and NGOAL suggests that the patient goals and the nurse goals are not similar and that mutual goal setting had not occurred. The equally noteworthy lack of correlation between PGOAL and NQUAL suggest that nursing interventions were not planned to facilitate patient goal achievement. The nursing process, the criteria source for the measurement of NGOAL and NQUAL, theoretically should influence patient goal achievement, if the care is mutually planned between the patient and nurse. Absence of relationships between PGOAL and NGOAL and PGOAL and NQUAL suggests that, for the majority of the participants, the care was not mutually 
planned. Also, this lack of relationship suggests that the nursing process, while it may have been beneficial relative to some of the patient needs, did not address activities to enhance achievement of patient goals for hospitalization.

It is possible that the relationship between NQUAL and PGOAL and between NQUAL and PGOAL is influenced by educational preparation of nurses, nursing care delivery method, or management style of nurse managers. The RNs, who are required by hospital policy to initiate the nursing care plans, were predominately graduates of associate degree or diploma schools of nursing. Perhaps a relationship between PGOAL and NGOAL or PGOAL and NQUAL would be demonstrated if the nursing care was planned by baccalaureate nurses. Another possible influence on nursing care planning is the staff mix. On these nursing units, RNs comprise $25 \%$ of the nursing staff, compared to $55 \%$ in other safety net hospitals. ${ }^{119}$ Delivering care with a small percentage of RNs to attend to the professional nurse responsibilities may adversely influence the quality of the nursing process.

The finding of this study that patient goal achievement was correlated with patient perceived quality, coupled with King's findings, ${ }^{161,162}$ indicate that one way to positively influence patient perceived quality is through mutually planning goals and related interventions. Patient perception of nursing care quality has been identified as the major predictor of patient perception of hospital care quality, patient intent to recommend a hospital, and patient intent to return in the future. ${ }^{76,115}$ Therefore, administrators of hospital nursing services should establish, as a key focus of their quality improvement programs, the ongoing monitoring, evaluation, and 
improvement of patient and nurse mutual goal planning and achievement. This is especially important for safety net hospitals which want to maintain or increase their market share of patients with third party payors.

PQUALG correlated with NGOAL. The shared variance of PQUALG and NGOAL was $2 \%$. Although this is a small shared variance, the correlation of PQUALG and NGOAL suggests that nurse goals do address some of the patients' expectations about nursing care, even if the nurse goals are different from patient goals. In other words, the correlation between PQUALG and NGOAL suggests that the sample's definition of good nursing care includes some of the same aspects of care for which nurses set goals. PQUALG may measure this sample's concept of good nursing care better than PQUALT does, since there is a correlation between NGOAL and PQUALG but not between NGOAL and PQUALT. Therefore, for this and similar patient populations, PQUALG may be the preferred method for measuring patient perceived quality.

Nurses need to know what expectations are inherent in their patients' definitions of good nursing care and how important each type of expectation is to the patient perceptions of quality. If those expectations are not realistic or are antagonistic for achievement of desired health outcomes, then individualized patient counseling and patient education may help patients develop realistic expectations. ${ }^{76}$ If patients' expectations are realistic and nurses know how important those expectations are to patient perceived quality, then nurses will be able to deliberately target those expectations in their practice and in their quality improvement programs. 
For instance, if nurses learn that pain relief, adequate information, and courteousness are their patient populations' most valued expectations of good nursing care, they could address these while planning care for individuals. Also, nurses could then identify pain management, patient education, and customer relations as important aspects of care in their program planning and evaluation. The relationship between PQUALG and NGOAL should be strengthened if nurses better understand how patients' define good nursing care and if they plan to meet realistic patient expectations.

NQUAL not correlated with PQUALG or PQUALT. The lack of correlation between NGOAL and PQUALG or PQUALT is a noteworthy finding since PQUALG was correlated with NGOAL and since NQUAL and NGOAL measured theoretically related dimensions of the nursing process. This lack of correlation between NQUAL and either PQUALG or PQUALT suggests three interpretations.

First, the lack of association may be largely due to measurement error of nurse perceived quality, if chart documentation was incomplete. For example, if patients expected the nurses to help relieve pain and nurses gave patients pain medications but did not chart that, patient perceived quality scores might not be correlated with NQUAL scores.

A second interpretation of the lack of relationship between NQUAL and patient perceived quality may be partially due to a possible tendency for patients to rate nursing care quality above average. In one study, ${ }^{115}$ the mean patient satisfaction with hospital care was 3.9 on a scale from 1 to 5 . Also, Abramowitz, Cote, and Berry ${ }^{76}$ observed that patients generally rate overall satisfaction with hospital care high. 
And third, the lack of correlation between NQUAL and PQUALG or NQUAL and PQUALT suggests that patients cannot evaluate the aspects of nursing care measured by NQUAL. Quality improvement programs still need to evaluate those aspects of nursing care that only a nurse can evaluate, to account for professional and technical competency. However, the lack of correlation between PQUALG and NQUAL suggests that, in hospitals striving to be customer responsive, quality improvement programs should implement on-going strategies for evaluating, from patient and nurse perspectives, those aspects of nursing care which patients can evaluate.

NGOAL and NQUAL not correlated. The lack of correlation between NGOAL and NQUAL contradicts the belief that nurse goal achievement is influenced by nurse perceived quality, as they were measured in this study. 17,25,162-165 This relationship most likely was not demonstrated because of the incomplete documentation of nursing interventions, from which NQUAL scores were derived.

A second possible explanation for the lack of relationship between NGOAL and NQUAL is that some of the nursing diagnoses on the nursing care plans were inappropriate. The related nursing interventions were never implemented because they were inappropriate, but, for some reason, the nurse documented that the related nurse goal had been achieved by the patient. Therefore, the validity of the assumption that the nursing diagnoses are appropriately selected for patients needs to be investigated.

The lack of relationship between NGOAL and NQUAL may be due to differences in nursing process skills among nurses, which may be influenced by educational preparation. Future investigations of the 
relationship between nurse goal achievement and nurse perceived quality, using chart data, require improved documentation and evidence that nursing diagnoses are appropriately selected. Such investigations should also examine the influence of educational preparation of nurses on measures of NGOAL and NQUAL.

Aim 2: Develop Prediction Equations for Patient Perceived Quality and Patient Goal Achievement

Research Question 1: What Are the Predictors of Patient Perceived Quality?

Patient perceived quality qlobal. The five predictors of PQUALG were (a) pain severity at exit interview $(O R=.99)$, (b) clinic referral $(O R=3.78,(c)$ Unit $1(O R=2.67$, (d) patient goal achievement $(O R=2.40)$, and (e) being a recipient of Medicare $(O R=.38)$. Although the shared variance of PQUALG and PGOAL was only $2 \%$, patients with high PGOAL scores were 2.4 times more likely to have high PQUALG scores than patients with low PGOAL scores, after adjusting for all other variables in the model. PGOAL as a predictor of PQUALG provides initial support for the proposed relationship between value and quality in Larrabee's model of quality. This finding is consistent with the finding of Abramowitz, et al..$^{76}$ that patient expectations were related to patient satisfaction.

The finding that PGOAL was a predictor of excellent PQUALG has clinicial significance, especially to hospitals and health care providers, who are striving toward improved customer responsiveness in order to maintain or increase market share. Nurses need to ask patients/families early in their health care experience what their own goals are for that experience. In planning nursing care, nurses need to incorporate patient goals in the plan so that care activities 
enhance achievement of the patient's own goals, as well as achievement of the nurses' goals for the patient. Evaluation of effectiveness should include the degree to which the patient thinks his own goals have been met. Collaboration on the planning, implementation, and evaluation should positively influence goal achievement. ${ }^{161,162}$ And, patient goal achievement positively influences patient perceptions of quality, according to this study's findings.

Two hospital variables, Unit 1 and clinic referral, were predictors of excellent PQUALG. Patients hospitalized on Unit 1 were at least twice as likely as patients on Unit 2 to perceive nursing care quality as excellent. This finding is consistent with two previous studies which demonstrated that unit differences were predictive of patient satisfaction. ${ }^{166,167}$

The finding that unit was a predictor of excellent PQUALG suggests two possible explanations. First, there may be a real difference in nursing care quality that patients can detect. If so, the difference is a matter of degree of excellence, since the mean PQUALG score was high on both units. Second, patients on the two units may have different expectations of nursing care quality.

Clinic referral was the second hospital variable found to be a predictor of excellent PQUALG. This relationship suggests that patients referred from the clinic are different from patients referred from other sources in some way. Saturation of primary care and outpatient services at safety nets hospitals has created long waiting times and motivated increased use of the emergency room for primary care. ${ }^{119}$ Perhaps there are differences in the patients who use the clinic versus the emergency room for primary care. Perhaps clinic 
referred patients' expectations of care quality are different from those referred from other sources. Maybe the nursing staff in the clinic prepare patients for the hospitalization experience. Maybe the clinic patients had been hospitalized on the same unit before and knew what the nursing care quality was like. The meaning of clinic referral as a predictor of patient perceived quality needs further clarification.

One financial variable, being a Medicare nonrecipient, was a predictor of excellent PQUALG. This contrasts with the Meterko, Nelson, and Rubin study finding that payor source was not a predictor of patient judgments of hospital quality. ${ }^{63}$ But, the sample in that study had dissimilar patient characteristics from the present sample. This finding also contrasts with Blue Cross recipient as a predictor of PGOAL.

The finding that being a Medicare nonrecipient was a predictor of excellent PQUALG suggests that some aspect of nursing care was of better quality for nonrecipients than recipients of Medicare. However, Medicare as a payor source was not related to NQUAL or to NGOAL: so, if there was a difference in care, it was not related to the aspects measured by these nurse variables. It is likely that being a nonrecipient of Medicare, clinic referral, gender, and race are proxy variables for other characteristics of the population who receive care at this safety net hospital.

Finally, one illness variable, low pain severity at exit interview was a predictor of excellent PQUALG. Pain had the potential for being the most important predictor of PQUALG for some patients and the least important for others, because it was a continuous variable. The higher 
the pain score the lower the PQUALG score. Since the odds ratio was .99 , the PQUALG score would decrease $1 \%$ for every millimeter increase in pain. This relationship of pain with PQUALG supports previous findings that effective pain relief is associated with better satisfaction with nursing care. ${ }^{168}$ Also, pain during hospital stay has previously been significantly related to patients' overall perception of hospital quality. ${ }^{115}$

Effective management requires deliberate planning and implementation of appropriate strategies. Recently, the Oncology Nursing Society published standards for the management of cancer pain $^{167}$ and the Agency for Health Care Policy and Research published guidelines for "aggressive pain management before, during, and after surgery. ${ }^{169}$ The strategies in these guidelines better equip providers today to manage pain effectively. Hospital nursing services should adopt these guidelines as standards of practice, incorporate them in their quality improvement programs, and evaluate their usefulness in achieving pain management goals.

The findings of this study indicate that effective pain management will positively influence patient perceptions of nursing care quality. Incentive for effective pain management is augmented by patient perceptions of nursing care quality being the principle predictor of patient perceptions of hospital quality, ${ }^{76,115}$ intent to recommend and intent to return to a hospital. ${ }^{115}$

Patient perceived quality total. The five predictors of PQUALT were (a) pain severity on exit interview $(O R=.98)$, (b) worry score $(O R=1.01),(c)$ patient goal achievement $(O R=3.12)$, (d) clinic referral $(O R=2.80)$, and $(e)$ Unit $1(O R=2.28)$. The first four of 
these variables were also predictors of PQUALG, providing further evidence of construct validity between PQUALG AND PQUALT. Although the shared variance of PQUALT and PGOAL was only $3 \%$, patients with high PGOAL scores were three times more likely to have high PQUALT scores than patients with low PGOAL scores, after adjusting for all other variables in the model. PGOAL as a predictor of PQUALT supports the proposed relationship between value and quality in Larrabee's model of quality.

Pain had the potential for being the most important predictor of PQUALT for some patients and the least important for others, because it was a continuous variable. The higher the pain score the lower the PQUALT score. Since the odds ratio was .98 , the PQUALT score would decrease $2 \%$ for every millimeter increase in pain.

Low pain severity at exit interview was a more significant predictor $(p<.5)$ of excellent PQUALT than of excellent PQUALG $(p<.1)$. This may mean that PQUALT is more sensitive to the influence of pain than PQUALG. This finding suggests that PQUALT may be the preferred measure of patient perceived quality when investigating pain. Worry score, an illness variable, was the fifth predictor variable of excellent PQUALT. The more worried patients were about their chief symptom on admission, the higher their PQUALT score. One possible reason for this relationship would be underlying differences between those who were very worried and those who were not. Or, perhaps patients who were more worried about their chief symptom placed greater weight or value on their expectations of nursing care quality. This possibility would be clarified by learning which of the eight PQUALT items worry score was related to, especially since worry was not a predictor of PQUALG. 
Research Question 2: What Are the Predictors of Patient Goal Achievement?

Patient goal achievement. The six independent predictors of PGOAL were (a) working less than 30 hours per week $(O R=7.18)$, (b) recipient of Blue Cross $(O R=6.95)$, (c) being white $(O R=4.03)$, (d) being female $(O R=2.16)$, (e) pain severity at exit interview $(O R=.97)$, and (f) household income $(\mathrm{OR}=.69)$.

Three financial variables were predictors of patient goal achievement. Patients who worked part time ( $<30$ hours/week), were recipients of Blue Cross, and had low combined household income were more likely than others to have successful patient goal achievement. Successful patient goal achievement could be positively influenced by having realistic goals ${ }^{76}$ and good baseline health, ${ }^{19}$ for which having a job and health care insurance may be proxies. This may explain Blue Cross as a predictor if recipients of Blue Cross have better access to primary care and, perhaps, better baseline health than the nonrecipients of Blue Cross. Participants in lower income categories may have different, or perhaps, more realistic goals for hospitalization than those in the higher income categories.

Working part time was a dichotomous variable with not working part time composed of both full time workers and the unemployed. It seems unlikely that patients working part time would have more realistic goals than patients who were unemployed and who worked full time. Perhaps working part time was a proxy for other patient characteristics excluded from the prediction model, because of multicollinearity with model variables. 
Two demographic variables, white race and female gender, were predictors of successful patient goal achievement. Why whites were four times more likely than blacks and females two times more likely than males to report successful patient goal achievement is not clear. Perhaps there were differences in the type or achievability of patient goals identified by blacks and whites and identified by males and females. Perhaps black males were more willing than other participants to acknowledge unsuccessful patient goal achievement. Qualitative analysis of this sample's goals should be informative. Race and gender as predictors of patient goal achievement need further clarification. The demographic and financial variables may be proxies for other characteristics of this sample.

Finally, one illness variable, low pain severity at exit interview, was a significant predictor of successful PGOAL. Pain had the potential for being the most important predictor of PGOAL for some patients and the least important for others, because it was a continuous variable. The higher the pain score the lower the PGOAL score. In other words, the PGOAL score would decrease $3 \%$ for every millimeter increase in pain score. For example, a patient with a pain score of $50 \mathrm{~mm}$ would be 150 times more likely to have a low PGOAL score than a patient with a $0 \mathrm{~mm}$ pain score.

The relationship of pain with PGOAL is understandable because many of the participants stated that pain was their chief symptom and listed absent or decreased pain as one of their goals for hospitalization. The identified relationship suggests that these patients generally scored their achievement of the pain relief goal low if their pain was not as low as they had hoped by the time of exit interview. 
Providers' concern about pain, which has been described as "the most frequent symptom", ${ }^{170}$ is historic. ${ }^{171}$ Patient goals are likely to be influenced by the pain they experience. ${ }^{172}$ Yet, nurses tend to rely on verbal reports of pain. ${ }^{173,174}$ And, patients who do not verbally request pain medication are likely not to receive pain relief interventions. ${ }^{175}$ Therefore, nurses need to help patients verbalize their goals relative to pain and collaboratively develop and implement a pain management plan.

Aim 3: Develop Prediction Equations for Nurse Perceived Quality and Nurse Goal Achievement

Research Question 1: What Are the Predictors of Nurse Perceived Quality?

Nurse perceived quality. One demographic variable, being widowed, and one financial variable, being a nonrecipient of Medicaid, were predictors of NQUAL. This finding suggests that Medicaid nonrecipients and widows, which could be proxy variables of older adult females, receive preferential nursing care or that nurses chart more completely on those patients. The interaction effect of being a Medicaid recipient and widowed was not significant as a predictor of NQUAL, but there were significant differences in the subgroups. Specifically, the 11 patients who were Medicaid nonrecipients and widowed had a higher mean NQUAL score and it was significantly different from the other subgroups. Are nurses more compassionate, caring, and comprehensive in their chart documentation for widows who are nonrecipients of Medicaid than for other patients? This possibility needs to be further explored, since it implies preferential treatment. More likely, these two predictors are proxies for other characteristics of the sample. 
Being Medicaid nonrecipients and widowed may not remain as predictors of NQUAL in a study primarily designed to identify predictors of NQUAL. This model accounted for $6 \%$ of the explained variance in NQUAL, indicating a weak prediction model. In fact, this finding may be a Type I error. This study was designed to test the linkage between value and quality, primarily focusing on patient perceptions. Feasibility prevented including variables most likely to be associated with predicting or influencing nurse perceived quality. Such structure variables as staffing ratios, staffing patterns, workload, patient acuity scores, method of nursing care delivery, nurse education, and managerial style may have more influence on the nursing care quality than patient characteristics would. ${ }^{17,18,25,84,176}$

Research Question 2: What Are the Predictors of Nurse Goal Achievement?

Nurse goal achievement. The three predictors of NGOAL were (a) pain severity on exit interview $(O R=.98)$, (b) being married 1.89 , and $(c)$ severity of illness score $(O R=.57)$. Two illness variables, low pain at exit interview and low Severity of Illness Score (SIS) were predictors of excellent NGOAL. Pain at exit interview was also a predictor of successful PGOAL.

The relationships between pain and NGOAL and between pain and PGOAL suggest some congruence between patient goals for pain relief and nurse goals and between patient and nurse perceptions of goal achievement. In this study, many patients had pain and many of the nursing care plans addressed pain management, selecting as one nursing diagnosis "alteration in comfort: pain". One of the accompanying nurse goals for this nursing diagnosis was "patient will verbalize a decrease 
in or relief of pain". This goal is congruent with patients' goal for pain relief. Thus, the demonstrated relationship between pain at exit interview and nurse goal achievement suggests that some portion of nursing care was focused on pain relief, an aspect of nursing care which was important to patients. ${ }^{168,170}$

What remains to be learned is how congruent nurse goals are with patient goals and whether there are differences in the influence of pain on nurse goal achievement for different nurse goals. Understanding the relationship between pain and nurse goal achievement is important for two reasons. First, nurses need to know what influence pain has on achievement of nurse goals besides pain relief so that care can be planned accordingly. Second, nursing quality improvement coordinators need to account for the influence of pain on nurse goal achievement when conducting process and outcome monitors, because such monitors evaluate nurse goals as outcome indicators of nursing care quality.

Low SIS on admission as a predictor of excellent nurse goal achievement suggests two possible explanations. First, a high SIS, meaning higher risk of organ damage, suggests a baseline health status which may impede achievement of some nurse goals. Second, patients with low SIS on admission may need less complex nursing care that is quicker to give and to document than the nursing care needed by patients with higher SIS.

Being not married was also a predictor of excellent nurse goal achievement. Marital status, as such, does not seem a logical predictor of nurse goal achievement. It is unlikely that being married would be an obstacle to achieving the types of nurse goals that were 
measured in this study. Therefore, marital status must have emerged as a proxy for some other characteristic not otherwise measured in this study or for a combination of characteristics whose relationship with NGOAL was confounded by intercorrelations.

\section{Aim 4: Determine Congruence Between Predictors of Patient and Nurse Perceived Quality}

Research Question 1: Are There Differences in the Predictors of Patient and Nurse Perceived Quality?

There was no congruence between predictors of patient perceived quality and nurse perceived quality. A likely explanation is that patients evaluated different dimensions of nursing care quality than the dimensions measured by NQUAL. Also likely is that patients cannot evaluate the dimensions of nursing care quality which were measured by NQUAL.

Quality improvement programs still need to evaluate those aspects of nursing care that only a nurse can evaluate, to account for professional and technical competency. However, quality improvement programs in hospitals striving to be customer responsive should implement ongoing strategies for evaluating, from patient and nurse perspectives, those aspects of nursing care which patients can evaluate. For instance, goal achievement and nursing actions for pain management can be evaluated by both patients and nurses. Nurses should focus quality improvement activities on pain management, since pain relief is an important patient goal and patient goal achievement and pain relief are predictors of patient perceptions of quality. Similarily, nurses need to identify other important patient goals that pertain to aspects of nursing care which patients can evaluate and include those in their quality improvement program. 
Aim 5: Determine Congruence Between Predictors of Patient and Nurse Goal Achievement.

Research Question 1: Are There Differences in the Predictors of Patient and Nurse Goal Achievement?

Pain severity on exit interview was the only variable which was a predictor of both patient and nurse goal achievement. This predictor congruence probably occurred because of some matching between pain relief as both a patient and a nurse goal. The absence of any other congruent predictors and absence of NGOAL as a predictor of PGOAL suggest that most of the nurse and patient goals were dissimilar.

Nurses need to know what expectations are inherent in their patients' definitions of good nursing care and how important each type of expectation is to patient perceptions of quality. If those expectations are not realistic, then patient education can help patients develop realistic expectations. ${ }^{76}$ If those expectations are realistic and nurses know how important they are to patient perceived quality, then nurses will be able to deliberately target those expectations in their practice and in their quality improvement programs.

For instance, if nurses learn that pain relief, adequate information, and courteousness are their patients' most valued expectations of good nursing care, they could give top priority to pain management, patient education, and customer relations in their program planning and evaluation and in their practice with patients. There may still be discrepancies in patient and nurse goal achievement, even with collaboration between patients and nurses in planning and implementing activities for goal achievement. ${ }^{73}$ However, there should be more congruence between predictors of PQUALG and NGOAL with such collaboration than without it. 


\section{Strengths and Limitations}

Generalizability. The generalizability of this study is limited to other metropolitan, tertiary, safety net hospitals with similar patient populations. Although the National Association of Public Hospitals does not collect demographic data for safety net hospital patients, comparisons can be made on payor source. Private insurance represented a low percentage of payor source for the sample (14.6\%) and for other safety net hospitals $(15 \%) .^{119}$ Also, a high percentage of patients in the sample $(42.4 \%)$ and in other safety net hospitals $(30 \%)$ had no third party payor. ${ }^{119}$ Thus, in terms of financial resources for health care, the sample was comparable to other safety net hospital populations.

The sample was comparable to the hospital population in race and age, being predominately black and young. A higher percent of the sample was male $(53.8 \%)$ in comparison to the hospital population $(36 \%)$. The difference in gender is probably related to the large perinatal service of the hospital, whose patients were not included in the study. This sample contrasts with the sample, drawn from 10 hospitals, which tested the Patients' Judgments of Hospital Quality Questionnaire. ${ }^{148}$ In that sample the mean age in years was 46 compared to 39 in this study, $63 \%$ were female compared to $46 \%$ in this study, $90 \%$ white compared to $13.6 \%$ in this study, and approximately $50 \%$ had education beyond high school compared to $20.7 \%$ in this study. ${ }^{148}$

Several features of the sample limit generalizability. The sample included adults with acute care needs hospitalized on two general medical-surgical nursing units equipped with a bedside computer system for nursing care planning and chart documentation. Therefore, the 
results are not applicable to children, adults with critical care or maternity needs, or patients in ambulatory care settings, homes, or nursing care homes. Also, the results may not be applicable to medical-surgical nursing units without bedside computer systems. Feasibility issues and previous findings that satisfaction with nursing care was a major predictor of patient perceptions of hospital quality $^{115}$ justified limiting this study to one site and one discipline. However, use of one site and one discipline limits generalizability.

\section{Measurement}

Validity. Several issues threaten the measurement validity of the patient and nurse quality variables in this study. No standardized instruments have been developed for measuring patient goal achievement, nurse goal achievement, or nurse perceived quality as defined in this study. Assumptions were made that the questions used would measure the study concepts intended and not other phenomena.

The VAS as a scoring format for the patient questions was a strength of this study since it is appropriate for the dynamic, subjective nature of the study concepts, it was thought by a panel of experts at the study site to be appropriate for use with the sample, it has demonstrated more sensitivity to changes in a measured phenomenon than other scales, and it yields ratio level data. However, the use of the VAS has not been previously tested in a predominately black population. Measurement issues for patient perceived quality, patient goal achievement variables, nurse perceived quality, and then nurse goal achievement are now addressed in turn. 
Patient perceived quality global. Two measurement issues, "ceiling effect" and scale response bias, relative to patient perceived quality global emerged in this study. First, "ceiling effect" is evident in the extreme negative skew of patient perceived quality global. The first possible explanation for this "ceiling effect" is that the right hand anchor, "very good", on the visual analogue scales did not indicate superlative to this patient population. This anchor violates the principle that the anchors suggest the complete absence or the complete presence of the phenomenon being measured. However, during scale development, the investigator designed the patient interviews to have a 6 th grade reading level. In consultation with expert nurses at the study hospital, "very good" was selected as a more appropriate right hand anchor for this sample than "excellent".

During patient interviews, the researcher heard patients with less than 10th grade education using superlative words like "excellent", "outstanding", and "extremely good". Therefore, many patients may have marked the visual analogue scale on the extreme right hand side because they thought the care was better than how they define "very good". The scales need to be revised with a more superlative right hand anchor, such as "excellent".

"Ceiling effect," alternatively, may represent a tendancy of this population to rate patient perceived quality well above average. Streiner and Norman ${ }^{177}$ suggest a Likert type scale with 7 instead of 5 boxes for measuring such phenomena. The boxes range left to right with these labels: "out!, below average, average, above average, much above average, excellent, great!"177 Such a scale may help patients distinguish between degrees of excellence in quality. However, such a 
scale would not be useful if the phenomenon patient perceived quality is not normally distributed.

Second, scale response bias may have occurred with patient perceived quality total since all eight of the items had the identical scale. Using a combination of scales, such as visual analogue, Cantril ladder, and Likert scales, may minimize this type of response bias. ${ }^{177}$

Patient perceived quality total. As with PQUALG, "ceiling effect" and "scale response bias" produced an extreme negative skew of PQUALT. An inappropriate right hand anchor, scale construction, and use of only one scale are likely the explanations for the skewness of PQUALT, since the identical scale was used as for PQUALG. An alternate explanation is that patients may tend to rate the quality of nursing care above average.

Patient goal achievement. "Ceiling effect" is evident in the negative skew of patient goal achievement. A plausible explanation for this skew is a tendency of this patient population to rate patient goal achievement above average. The scale configuration did not allow patients to distinguish between degrees of excellence in goal achievement. ${ }^{177}$ Redesigning the scale may yield a more normal data distribution, unless patient goal achievement is inherently not normally distributed.

Nurse perceived quality. Nurse perceived quality was normally distributed and analzyed as a continuous variable. Measurement error of NQUAL is suggested by the lack of correlation between NQUAL and NGOAL and the discrepancy of mean NQUAL scores and NGOAL scores, which measured related dimensions of the nursing process. NQUAL probably 
accurately measured documented care, but documented care may not accurately reflect nursing care given.

NQUAL had the potential of being skewed because prior quality assurance results of charting showed significant improvement after implementation of bedside computer terminal documentation. ${ }^{121}$ However, that quality assurance review did not examine the comprehensiveness of charting the nursing process. During chart review for this study, the researcher observed that there often were no preprogrammed statements to document nursing interventions specified in the nursing care plans. Documentation of nursing interventions was the data source for NQUAL scores. There were no short-cut options for documenting nursing interventions. Therefore, to document the elements of the pain management plan developed by the patient/family and staff, the nurse had to type in a statement. Likely, this lack of preprogrammed selections contributed to incomplete charting of nursing interventions. So, NQUAL may not accurately reflect the nursing care given. An alternate possibility is that charting did accurately reflect the care given, but nurses do not consistently implement their plans of care. While the validity of nurse perceived quality is a concern and needs to be established, use of chart data remains a viable source of data for quality of nursing care research. Charted data is the legal evidence of nursing care given. Nurses are motivated by legal and reimbursement issues to minimize missing data in charting. Although nurses often give more care than they document, ${ }^{118}$ more comprehensive documentation has been demonstrated with the implementation of bedside computer systems. ${ }^{121}$ 
One strength of this study is that nurses documented care using a computerized documentation system. More hospitals are implementing computerized chart documentation systems, especially at the encouragement of the Joint Commission on Accreditation of Health Care Organizations, as a means to improve documentation. ${ }^{122,123}$ Finally, because of feasibility issues with data collection, chart data is very often the primary source of information used to assess the quality of care and direct quality improvement activities in hospitals. Nursing care quality research that uses data charted on computer systems, will help identify areas for programming changes that will further enhance the comprehensiveness of documentation, thereby, improving data validity.

Improving the validity of the patient and nurse variables is anticipated to strengthen the relationships among patient goal achievement, patient perceived quality, nurse goal achievement, and nurse perceived quality. Likewise, the relationships between pain severity and the patient and nurse variables will be strengthened. Most likely, the prediction equations will change. Some of the predictor variables may become nonsignificant and different variables may become significant.

Nurse goal achievement. The extreme negative skew of NGOAL, when NQUAL was normally distributed, suggests measurement error. Two related factors, programming and scoring, probably contributed to the skewness of nurse goal achievement. First, for many goals in the computer nursing care plan dataset there were no companion statements to select for documenting the patient's specific behaviors for nurse goal achievement. For instance, in the care plan "Alteration in 
Comfort: Pain, Actual" one nurse goal is "Patient/family will participate in pain management plan developed with staff". There is not a statement in the care documentation program for the nurse to select that "patient/family did participate in developing a pain management plan". So, to document patient achievement of some nurse goals, the nurse must type in a statement. Alternately, the nursing staff, when learning to use the bedside terminal computer documentation system, had been instructed that it was acceptable to document patient achievement of nurse goals by selecting, on the care plan itself, the option that "the patient has achieved" the goal. This was more timely for busy nurses than typing in statements and many nurses used this option.

Second, scoring during chart review probably contributed to the inflated mean nurse goal achievement score, also. The data collectors credited the "goal has been achieved" statement when it was present, except on goals related to such things as vital signs, physical assessment parameters, relief from pain, and relief of fever. For this type of goal and when "goal has been achieved" was missing, credit was given when specific documentation was found in the nurses notes. When "goal has been achieved" was credited, some of the goal behaviors were things that needed to be evaluated just once and some could have been evaluated more than once. It is possible that those goal behaviors that could have been evaluated more than once may have been scored lower if the one time statement "goal has been achieved" had not been credited. How much this scoring strategy inflated the mean nurse goal achievement score is unknown. 


\section{Design}

The design of the study was appropriate for investigating the proposed relationship between quality and value. Obtaining the patients' goals within 24 hours after admission increased the chances that patients would still be anticipating goal achievement and minimized the likelihood of symptom severity or the patients' recall of symptom severity being greatly reduced. If the investigator had asked patients to identify their goals for hospitalization just prior to discharge, they probably would have had only one goal: to be discharged home. And, there probably would have been no variability in patient goal achievement, since $98.5 \%$ of the patients were discharged home. The study design enhanced reliability of patient data, because the investigator collected all of the patient interview data. This strategy eliminated the influence of differences in interviewing technique by multiple interviewers.

Construct validity for measurement of nurse perceived quality and nurse goal achievement was inherent in designing measurements of the process and outcome elements of the nursing process. Assumptions had been made that the questions used for measuring nurse perceived quality and nurse goal achievement do measure those and not other phenomena. NQUAL scores were obtained from a sampling, rather than a census, of the process criteria appropriate for each patient. Therefore, NQUAL scores may not accurately reflect the true score that would be obtained if NQUAL were evaluated for all process criteria (nursing actions) selected for each patient. However, patients' needs vary in importance; therefore, so do the corresponding nursing diagnoses, goals (outcome), and actions (process). The NQUAL score was intended to 
measure process criteria of the most important (first three) nursing diagnoses. Similarily, NGOAL was a sampling of outcome criteria for the three most important nursing diagnoses. Therefore, if documentation were comprehensive, nurse perceived quality and nurse goal achievement would likely be valid measures of the dimension of nursing care quality intended.

Finally, construct validity for measurement of patient perceived quality was enhanced because PQUALT was developed from the Nursing and Daily Care Subscale, ${ }^{75}$ a standardized subscale of the Patients' Judgments of Hospital Quality Questionnaire. This questionnaire had been developed in consultation with hospital patients; however, the patient characteristics of that sample were not representative of safety net hospital samples. Therefore, scale modifications were made, in consultation with nurses experienced with caring for the hospital population. However, a limitation of the design is that the psychometric properties of the modified subscale (PQUALT) remain to be established.

\section{Theoretical Framework}

A strength of this study is that it was primarily a patient focused investigation of quality, examining the same episodes of care from both patient and nurse perspectives. Most quality investigations are provider focused and most patient satisfaction investigations only elicit patient perceptions. The reason quality investigations have not simultaneously included provider and patient perceptions is that existing quality models are conceptually limited. Patient and provider perceptions are integral dimensions of Larrabee's model of quality, since it is wholistic in nature. Thus, Larrabee's model of quality 
provides a framework for describing or explaining some aspects of reality which cannot be addressed using the existing quality models. Some of those aspects of reality, such as patient value and related behaviors, may have a significant impact on outcomes of care and, therefore, warrant investigation. A limitation of this study was that the linkages of concepts in the model had not been investigated previously.

\section{Theoretical Framework}

\section{Quality and Value as Intrinsic Worth}

Patient goal achievement was used to measure value as something intrinsically desirable, the first of three meanings of value identified in Larrabee's model of quality. This study demonstrated initial support for the proposed linkage between quality and value, since value, measured as patient goal achievement, was a predictor of both measures of patient perceived quality. Patient perceived quality global may include concepts of nursing care quality that this population valued as highly as patient goal achievement, since, as a predictor of patient perceived quality global, patient goal achievement was not significant at alpha of .05. The concepts included in this population's definition of nursing care, which patient perceived quality global measured quantitatively, need to be identified and used to revise the patient perceived quality total subscale to improve it's construct validity when used with this population. This can be achieved by qualitative analysis of this population's goals for hospitalization. 


\section{Quality and Value as Relative Worth}

This study also provided initial support for value as relative worth being a predictor of quality. Worry score, an item intended to measure value as relative worth of the patient's chief symptom, was a significant predictor of patient perceived quality total in this study. Worry must be more strongly related to some of the PQUALT subscale items than others, since worry was not predictive of patient perceived quality global.

Nurses could plan care that is more congruent with patient perceptions if they knew how important different patient goals are to patients. Patient goal achievement is intrinsically desirable because it will positively benefit the patient in some manner. Therefore, patient goal achievement may be used to measure beneficence, another concept in Larrabee's model. Patients often have more than one goal for a health care experience. Different goals are likely to be valued with different degrees of importance, ${ }^{168}$ suggesting the second meaning of value in Larrabee's Model: relative worth, utility, or importance. The model proposes that, when something is potentially beneficial, there is a positive relationship between its value as relative worth and perception of quality. This proposed relationship can be investigated measuring beneficence as patient goal achievement, value as the relative worth of patient goals, and quality as patient perceived quality.

The relationship between nurse goal achievement and nurse perceived quality was not designed to test value as a predictor of quality, since nurse perceived quality was derived from data about events that were antecedent to nurse goal achievement. Theoretically, 
there should have been a relationship between these two nurse variables though, since they measured related dimensions of the nursing process. Measurement error prevented demonstrating that relationship.

Also, theoretically, there should have been a relationship between the two nurse variables and patient goal achievement, if the nurses involved patients/families in care planning. The lack of a relationship suggests that patients and nurses have different goals and are unaware of each others' goals. Finally, the lack of a relationship between nurse perceived quality and patient perceived quality suggests there is no linkage between the dimensions of nursing care quality measured from the patients' perspective and from the nurses' perspective. Demonstrating such a linkage may depend on nurses' developing evaluation strategies to measure from both perspectives those dimensions of nursing care quality that patients can evaluate.

\section{Quality and Beneficence}

Unanticipated support for the relationship between beneficence and quality was demonstrated by pain on exit interview being a predictor of patient perceived quality. The strength of this relationship may change in investigations which use a revised scale for measuring patient perceived quality. However, it can be argued that, for anyone in pain, pain relief is beneficial and pain management is potentially beneficial.

Quality and Prudence and Quality and Justice,

The relationships among quality, prudence, and justice proposed in Larrabee's model of quality were not the focus of this study. However, several financial variables were included and several relationships 
emerged between patient and nurse quality variables and payor source, employment status, and household income which require further illucidation. But, the linkages among quality, prudence, and justice, need further clarification in Larrabee's model of quality before investigation of these linkages is designed.

\section{Future Research}

\section{Measurement}

PQUALG, PQUALT, and PGOAL. Future research should address scale construction and vocabulary most appropriate for populations in safety net hospitals. Scales that will minimize the "ceiling effect" when measuring PQUALG, PQUALT, and PGOAL, yet are user friendly, are needed. Also, the vocabulary used on scales or in directions for scales should be appropriate for the populations included in research studies.

PQUALG and PQUALT. The strength of the correlation $(r=.60)$, between PQUALG and PQUALT indicates that they are not identical measures of the same concept, even though they have concurrent validity. Low pain at exit interview was a stronger predictor of PQUALT than of PQUALG, suggesting that PQUALT may be the preferred measure of patient perceived quality when investigating relationships between patient perceived quality and pain or pain relief.

However, PQUALG was correlated with NGOAL while PQUALT was not. This relationship suggests that this sample's definition of good nursing care includes some dimensions not measured by PQUALT. PQUALG may be more highly correlated with some of the PQUALT questions than others. Is PQUALG so weakily correlated with any of the subscale items 
as to suggest that those items measure an element of quality not included in this population's global view of good nursing care quality? Conversely, does PQUALG measure an element of quality not included in PQUALT? Answers to these questions would help improve the construct validity of these measures for patient perceived quality or indicate which measure to use in different investigations.

PQUALG has criterion validity because of the significant shared variance with PQUALT. However, it is less time consuming to answer one global question than to answer the eight questions which made up PQUALT. Investigators evaluating patient perceived quality should consider using PQUALG, with appropriate anchors, especially when interviewing patients who feel too sick or weak, are in too much pain, or lack interest to complete longer interviews.

NQUAL. Validity of NQUAL as a measurement of nurse perceived quality should be investigated. A study determining the congruence between charted data, observation data, and data self-reported by the nurses about nursing care given may provide information about the validity of NQUAL.

NGOAL. Scoring strategy is thought to explain part of the measurement error of NGOAL in this study. This source of measurement error can be eliminated in future research by not crediting the statement "patient has achieved" the goal when the nurse goal related to a patient behavior for which repeated statements could or should have been documented. Validity of NGOAL can be strengthened by demonstrating that selected nursing diagnoses and related nurse goals are appropriate for specific patients. 


\section{Design}

Future investigations should be designed to study the influence on patient perceptions of quality associated with patient choice or lack of choice about which hospital they are admitted to, preconceived expectations of poor care in a safety net hospital, or previous hospitalization at the study site.

Future investigations should be designed to include more than one discipline, because Larrabee's model of quality is wholistic and this study did not investigate the influence of other disciplines on patient perceived quality. Feasibility issues and previous findings that satisfaction with nursing care was a major predictor of patient perceptions of hospital quality ${ }^{76,115}$ justified this limited scope.

\section{Generalizability}

The generalizability of this study's findings can be increased by replication with children, adults with critical care, maternity, or long term care needs in other safety net hospital, hospitals which are not safety net hospitals, ambulatory care settings, nursing homes, and homes. Replication on nursing units with and without computer documentation systems may also increase the generalizablity of this study's findings.

\section{Theoretical Framework}

Quality and value. Further investigations are needed to provide additional support of the relationship between quality and value demonstrated by this study. Larrabee's model of quality proposes that value has three meanings. This study investigated the relationship between quality and value as intrinsic worth, measured as goal 
achievement. Initial support for the relationship between quality and value as relative worth, measured as worry, was also demonstrated in this study. The relationship between quality and value as fair return on exchange remains to be investigated.

Quality and beneficence. This study demonstrated initial support for the relationship between quality and beneficence since low pain on exit interview was a predictor of all three patient quality variables. Low pain on exit interview can be interpreted as pain relief, which would benefit the well being of patients. Patients who have no pain have goals relative to other needs besides pain relief. Is there a difference in the relationship between beneficence and quality for patients with pain and patients with no pain? Future studies should be designed to investigate the relationship between quality and beneficence for patients with pain and for patients with no pain.

Quality and prudence and quality and justice. The relationships between quality and prudence and justice have not been investigated. In Larrabee's model of quality prudence pertains to individual judgments about use of personal resources and justice pertains to providers and policymakers judgments about use of public funds. The economic and political climate of today's health care system has created concern about the nature of the relationship between quality and prudence and between quality and justice. Future investigations need to examine these relationships. 


\section{Conclusion}

of the many findings in this study, three were key. First, patient value was a predictor of patient quality. This finding provides initial support for the theoretically proposed relationship between quality and value in Larrabee's model of quality. The clinical implication is that nurses should maximize patient goal achievement, by collaborating with patients to identify patient defined goals and plan, implement, and evaluate goal achievement from patient and nurse perspectives.

Second, there was no relationship between nurse quality and patient quality, patient value, or nurse value. This finding failed to support the relationship between nurse quality and nurse value, as measured in this study. This finding also suggested that patients and nurses evaluate different dimensions of nursing care quality and that patients cannot evaluate the dimensions of nursing care measured by NQUAL in this study. Therefore, quality improvement programs in hospitals striving to be customer responsive should include ongoing strategies for evaluating, from both the patient and nurse perspectives, those aspects of nursing care which patients can evaluate.

Third, pain severity at exit interview was a predictor of patient quality, patient value, and nurse value. This finding provided initial support for the theoretically proposed relationship between quality and beneficence in Larrabee's model of quality, because pain relief is of benefit to patients. There are at least four clinical implications of this finding. One, hospitals should adopt aggressive pain management guidelines. Two, nurses should help patients identify their goals 
relative to pain. Three, nurses should collaboratively plan, implement, and evaluate pain management plans with patients. And, four, hospitals should incorporate effective pain management in their quality improvement programs.

Providers are motivated to attend to the relationships between quality and patient goal achievement and quality and pain severity because helping patients meet their goals and achieve pain relief will benefit patients. Positively influencing patient perceived quality will also benefit providers, because patient perceptions of quality have previously been predictors of patient intent to recommend and return to a hospital. 


\section{Chapter 6. References}

1. McDaniel, C. \& Nash, J.G. (1990). Compendium of instruments measuring patient satisfaction with nursing care. Quality Review Bulletin, May, 182-188.

2. Beck, D.F., \& Dempsey, J. (1990). Health care costs: The other point of view. Health Care Supervisor, $\underline{9}(2), 1-11$.

3. Breslow, L. (1974). Quality and cost control: Medicare and beyond. Medical Care, 12 (2), 95-114.

4. Scitovsky, A.A., \& Snyder, N.W.. (1972). Effect of coinsurance on use of physician services. Social Security Bulletin, 35, June, 3-19.

5. Nightingale, F. (1958). Notes on matters affecting the health, efficiency, and hospital administration of the British Army. London, Harrison \& Sons.

6. Nightingale, F. (1969). Notes on nursing: What it is and what it is not. New York: Dover Publications, Inc. (Original work published in 1859.)

7. Codman, E.A. (1914). The product of a hospital. Surgery, Gynecology and Obstetrics, 18, January-June, 491-496.

8. Donabedian, A. (1966). Evaluating the quality of medical care. Milbank Memorial Fund Quarterly, 44 (3), July, suppl: 166-206.

9. Lang, N.M., \& Clinton, J.F. (1984). Assessment of quality of nursing care. Annual Review of Nursing Research, 2 , 135-163.

10. Institute of Medicine: Committee on nursing home regulation. (1986). Improving the quality of care in nursing homes. National Academy Press: Washington, D.C.

11. Taylor, A.G., \& Haussman, G.M. (1988). Meaning and measurement of quality nursing care. Applied Nursing Research, 1 (2), August, 84-88.

12. Bullough, V.L., \& Bullough, B. (1969). The emergence of modern nursing. New York: The MacMillian Company.

13. Lee, R.I., \& Jones, L.W. (1933). The fundamentals of good medical care. Chicago: University of Chicago Press.

14. Lambertsen, E.C. (1965). Evaluating the quality of nursing care. Hospitals, 39, November 1, 61-62, 64, 66.

15. Densen, P.M. (1965). The quality of care. Yale Journal of Biology and Medicine, 37, 523. 
16. DeGeyndt, W. (1970). Five approaches for assessing the quality of care. Hospital Administration, 15 (21), 21-42.

17. American Nurses Association. (1975). A plan for the implementation of the standards of nursing practice. Kansas City, MO: Author.

18. Lang, N.L. (1974). A model for quality assurance in nursing. Unpublished doctoral dissertation, Marquette University.

19. Doessel, D.P, \& Marshall, J.V. (1985). A rehabilitation of health outcome in quality assessment. Social Science Medicine, $21(12), 1319-1328$.

20. Phaneuf, M.C. (1964). Nursing audit. Nursing Outlook, May, 42-45.

21. Starfield, B. (1974). Measurement of outcome: A proposed scheme. Health and Society, Winter, 39-50.

22. O'Brien, N., Lowe, C., \& Rennebohm, H. (1987). A managerial perspective on controlling the quality of patient care. Dimensions, May, 22-23, 26-28.

23. Horn, B.J., \& Swain, M.A. (1978). Criterion measures of nursing care quality. DHEW Pub. No. PHS78-3187. Hyattsville, MD: National Center for Health Services Research.

24. Hegyvary, S.T., \& Chamings, P.A. (1975). The hospital setting and patient care outcomes. Journal of Nursing Administration, May, 36-42.

25. Hegyvary, S.T., \& Haussmann, R.K.D. (1976). Monitoring nursing care quality. Journal of Nursing Administration, $\underline{6}(9), 3-9$.

26. Howland, D., \& McDowell, W.E. (1964). The measurement of patient care: A conceptual framework. Nursing Research, 13 (1), 4-7.

27. Wyszewianski, L. (1988a). Quality of care: past achievements and future challenges. Inquiry, 25, Spring, 13-22.

28. Wyszewianski, L. (1988b). The emphasis on measurement in quality assurance: Reasons and implications. Inquiry, 25, Winter, 424-436.

29. Donabedian, A. (1985). The epidemiology of quality. Inquiry, 22, Fall, 282-292.

30. Williamson, J. (1988). Future policy directions for quality assurance: Lessons from the health accounting experience. Inquiry, 25, Spring, 67-77. 
31. Lohr, K.N. (1988). Outcome measurement: concepts and questions. Inquiry, 25, Spring, 37-50.

32. Lefcowitz, M.J. (1973). Poverty and health: A re-examination. Inquiry, 10, March, 3-13.

33. Cordero, A.L. (1964). The determination of medical care needs in relation to a concept of minimal adequate care: An evaluation of the curative outpatient services in a rural health center. Medical Care, 2, April-June, 95-103.

34. Fuchs, V.R. (1974). Who shall live? Health, economics, and social choice. New York: Basic Books, Inc., Publishers.

35. Fuchs, V.R. (1979). Economics, health, and post-industrial society. Milbank Memorial Fund Quarterly, 57 (2), 153-182.

36. Feldstein, P.J. (1988). Health care economics. New York: John Wiley \& Sons.

37. Lave, J.R., \& Lave, L.B. (1970). Medical care and its delivery: An economic appraisal. Law and Contemporary Problems, 35, Spring, 252-266.

38. Robinson, J.C. (1988). Hospital quality competition and the economics of imperfect information. The Milbank Quarterly, 66 (3), 465-481.

39. Ginsburg, P.B. \& Hammons, G.T. (1988). Competition and the quality of care: The importance of information. Inquiry, 25, Spring, 108-115.

40. Chang, C. (1981). Towards a better understanding of healthcare economics. Medical Group Management, 28 (2), March/April, pp. 48-52.

41. Price, R. (1989). CRS Report for Congress: Medicare and Medicaid nursing home reform provisions in the omnibus budget reconciliation act of 1987, P.L. 100-23. 89-463 EPW, August 10. Washington, D.C.: Congressional Record Service, the Library of Congress.

42. U.S. Public Law 92-603, 92nd Congress, 2nd Session, 1972.

43. Bunker, J.P. (1988). Is efficacy the gold standard for quality assessment? Inquiry, 25 (1), 51-58.

44. Wright, D. (1984). An introduction to the evaluation of nursing care: A review of the literature. Journal of Advanced Nursing, 9 , 457-467.

45. Zimmer, M.J. (1974a). A model for evaluating nursing care. Hospitals, 48, March 1, 91-95, 131. 
46. Zimmer, M.J. (1974b). Quality assurance for outcomes of patient care. Nursing Clinics of North America, 9 (2), June, 305-315,

47. Phaneuf, M.C. (1966). The nursing audit for evaluation of patient care. Nursing Outlook, June, 51-54.

48. Phaneuf, M.C. (1968). Analysis of a nursing audit. Nursing outlook, January, 57-60.

49. Phaneuf, M.C. (1969). Quality of care: Problems of measurement. American Journal of Public Health, 59 (10), 1827-1832.

50. Donabedian, A., Wheeler, J.R.C., \& Wyszewianski, L. (1982). Quality, cost, and health: An integrative model. Medical Care, 20 (10), October, 975-992.

51. Steffen, G.E. (1988). Quality medical care: A definition. Journal of the American Medical Association, 260 (1), July 1 , 56-61.

52. Joint Commission on Accreditation of Healthcare Organizations. (1989). Accreditation manual for hospitals: 1990. Chicago, IL: Author, 310.

53. Veatch, R.M., \& Fry, S.T. (1987). Case studies in nursing ethics. Philadelphia: J.B. Lippincott Company.

54. Deming, W.E. (1986). Out of crisis. Cambridge, Mass: Massachusetts Institute of Technology, Center for Advanced Engineering Study.

55. Mann, N.R. (1985). The keys to excellence: The story of the Deming philosophy. Los Angeles: Prestwick Books.

56. Juran, J.M., \& Gryna, Jr., F.M. (1980). Quality planning and analysis. New York: McGraw-Hill Book Company.

57. Crosby, P. B. (1979). Quality is free: The art of making quality certain. New York: McGraw-Hill Book Company.

58. Townsend, P.L. (1986). Commit to quality. New York: John Wiley \& Sons, Inc.

59. Garvin, D.A. (1988). Managing quality: The strategic and competitive edge. New York: The Free Press.

60. Groocock, J.M. (1986). The chain of quality: Market dominance through product superiority. New York: John Wiley \& Sons, Inc.

61. Peters, T.J., \& Waterman, Jr., R.H. (1982). In search of excellence: Lessons from America's best-run companies. New York: Harper \& Row, Publishers. 
62. Guaspari, J. (1985). I know it when I see it. New York: AMACOM.

63. Meterko, M., Nelson, E.C., \& Rubin, H.R. (Eds.). (1991). Patient judgments of hospital quality: report of a pilot study. Medical Care, 28 (9), Supplement, s1-s56.

64. Hinshaw, A.S. \& Atwood, J.R. (1991). A patient satisfaction instrument: precision by replication. Nursing Research, 31 (3), 170-175.

65. Abdellah, F.G. \& Levine, E. (1957a). Polling patients and personnel: Part I. What patients say about their nursing care. Hospitals, 31 (Nov 1), 44-48.

66. Abdellah, F.G. \& Levine, E. (1957b). Polling patients and personnel: Part II. What factors affect patients' opinions of their nursing care. Hospitals, 31 (Nov 16), 61-62,64.

67. Abdellah, F.G. \& Levine, E. (1957c). Developing a measure of patient and personnel satisfaction with nursing care. Nursing Research, $\underline{5}(3), 100-108$.

68. Eriksen, Lillian. (1988). Measuring patient satisfaction with nursing care: A magnitude estimation approach. In C.F. Waltz \& O.L. Strickland (Eds.), Measurement of nursing outcomes, Volume 1 (pp. 523-537). New York: Springer Publishing Company.

69. Matthews, D.A. \& Feinstein, A.R. (1989). A new instrument for patients ratings of physician performance in the hospital setting. Journal of General Internal Medicine, $\underline{4}$ (Jan/Feb), 14-22.

70. Matthews, D.A. (1986). How patients appraise physicians (letter). New England Journal of Medicine, 314 (20), 1318.

71. Forgan Morle, K.M. (1984). Patient satisfaction: care of the elderly. Journal of Advanced Nursing, 9 , 71-76.

72. Taylor, A.G., Hudson, K., \& Keeling, A. (1991). Quality nursing care: the consumers' perspective revisted. Journal of Nursing Quality Assurance, $\underline{5}(2), 23-31$.

73. Frederick, B.J., Sharp, J.Q., \& Atkins, N. (1988). Quality of patient care: Whose decision? Journal of Nursing Quality Assurance, $\underline{2}$ (3), 1-10.

74. Rubin, H.R. (1990). Patient evaluations of hospital care: A review of the literature. Medical Care, 28 (9), suppl: s3-s9.

75. Rubin, H.R., Ware, J.E., \& Hays, R.D. (1991). The PJHQ questionnaire: exploratory factor analysis and empirical scale construction. Medical Care, 28 (9), s22-s29. 
76. Abramowitz, S., Cote, A.A., \& Berry, E. (1987). Analyzing patient satisfaction: A multianalytic approach. Quality Review Bulletin, April, 122 .

77. Rosenberg, G., Speedling, E.J., Rehr, H., \& Morrison, B.J. (1985). Some effects of a hospital employee strike on patient satisfaction. Mt. Sinai Journal of Medicine, $\underline{52}$ (4), 259-264.

78. Speedling, E.J., \& Rosenberg, G. (1986). Patient well-being: A responsibility for hospital managers. Health Care Management Review, 11 (3), 9-19.

79. Lembcke, P.A. (1967). Evolution of the medical audit. Journal of the American Medical Association, 199 (8), February 20, 543-550.

80. McGinnis, S. (1975). History of nursing audit. Quality Review Bulletin, 1, May-July, 10-12.

81. Pfefferkorn, B. (1932). Measuring nursing, quantitatively and qualitatively. American Journal of Nursing, 32 (1), 80-84.

82. Burgess, M.A. (1932). Quality nursing. American Journal of Nursing, 32 (10), 1045-1053.

83. Schwartz, D.R. (1948). Nursing care can be measured. American Journal of Nursing, 48 (3), 149.

84. Reiter, F., \& Kakosh, M.E. (1963). Quality of nursing care: A report of a field study to establish criteria: 1950-1954. New York: New York Medical College, Graduate School of Nursing.

85. Berwick, D.M. (1989). Continuous improvement as an ideal in health care. New England Journal of Medicine, 320 (1), 53-56.

86. Laffel, G., \& Blumenthal, D. (1989). The case for using industrial quality management science in health care organizations. Journal of the American Medical Association, $262(20), 2869-2 \overline{873}$.

87. Gillem, T.R. (1988). Deming's 14 points and hospital quality: Responding to the consumer's demand for the best value health care. Journal of Nursing Quality Assurance, $\underline{2}$ (3), 70-78.

88. Kritchevsky, S.B. \& Simmons, B.P. (1991). Continuous quality improvement: Concepts and applications for physician care. Journal of the American Medical Association, 266 (13), 1817-1823.

89. Weisbrod, B.A. (1985). America's health care dilemma. Challenge, September/October, 30-34.

90. Pirsig, R.M. (1974). Zen and the art of motorcycle maintenance. New York: William Mor row \& Company, Inc. 
91. Donabedian, A. (1988a). The quality of care. How can it be assessed? Journal of the American Medical Association, 260 (12), Sept $23 / 30,1743-1748$.

92. Donabedian, A. (1988c). Quality and cost: Choices and responsibilities. Inquiry, 25, 90-99.

93. Brook, R.H., Davies-Avery, A., Greenfield, S., Harris, L.J., Lelah, T., Solomon, N.E., \& Ware, J.E., Jr. (1977). Assessing the quality of medical care using outcome measures: An overview of the method. Medical Care, 15 (9), September, 1-84.

94. Marek, K.D. (1989). Outcome measurement in nursing. Journal of Nursing Quality Assurance, $\underline{4}$ (1), 1-9.

95. Larson, E., \& Oram, L.F. (1989). From process to outcome in infection control. Journal of Nursing Quality Assurance, $\underline{4}$ (1), 18-26.

96. Lower, M.S., \& Burton, S. (1989). Measuring the impact of nursing interventions on patient outcomes: The challenge of the 1990s. Journal of Nursing Quality Assurance, 4 (1), 27-34.

97. Miller, J. (1989). Evaluating structure, process, and outcome indicators in ambulatory care: The AMBUQUAL approach. Journal of Nursing Quality Assurance, $\underline{4}$ (1), 40-47.

98. Schroeder, P.S., \& Maibusch, R.M. (1984). Nursing quality assurance: A unit-based approach. Rockville, MD: Aspen Publishers, Inc.

99. Schroeder, P.S. (1991). Improving health care quality in the nineties. In P.S. Schroeder (Ed.) The encyclopedia of nursing care quality VolumeI: Issues and strategies for nursing care quality (1-6). Gaithersburg, MD: Aspen Publishers, Inc.

100. Aristotle. (1943). On man in the universe. L.R. Loomis (Ed.) Toronto: D. Van Nostrand Company, Inc. (Original work written sometime between 366-322 B.C.)

101. Aristotle. (1983.) The categories of interpretation. In Aristotle in twenty-three volumes (H.P. Cooke, Trans.). Cambridge, MA: Harvard University Press. (Original work written sometime between 366-322 B.C.)

102. Aristotle. (1985). Nicomachean ethics (T. Irwin, Trans.). Indianapolis, Ind.: Hackett Publishing Company, Inc. (Original work written sometime between $366-322$ B.C.)

103. Beauchamp, T.L. (1982). Philosophical ethics: An introduction to moral philosophy. New York: Mc-Graw-Hill Book Company.

104. Collingwood, R.G. (1970). The idea of nature. London: Oxford University Press. 
105. Edwards, P. (Ed.) (1967). The encyclopedia of philosophy. New York: Macmillan Publishing Co., Inc. \& The Free Press.

106. Reese, W.L. (1980). Dictionary of philosophy and religion: Eastern and Western thought. Atlantic Highlands, N. J.: Humanities Press.

107. Wilson, J. (1963). Thinking with concepts. Cambridge, England: Cambridge University Press.

108. Walker, L.O., \& Avant, K.C. (1988). Strategies for theory construction in nursing. Norwalk, Connecticut: Appleton \& Lange.

109. Gove, P.B. (Ed.) (1976). Webster's third new international dictionary of the English language unabridged. Springfield, MA.: G.\& C. Merriam Company, Publishers.

110. Williamson, J. (1978). Assessing and improving outcomes in health care: The theory and practice of health accounting. Cambridge, MA: Ballinger Publishing Co.

111. Shapiro, S. (1976). End result measurements of quality of medical care. Milbank Memorial Fund Quarterly, 45, 7-30.

112. Mech, A.B. (1980). Evaluating the process of nursing care in long term care facilities. Quality Review Bulletin, 6 (3), March, 24-30.

113. McAuliff, W.E. (1978). On the statistical validity of standards used in profile monitoring of health care. American Journal of Public Health, 68 (7), 645-651.

114. Donabedian, A. (1980). The definition of quality and approaches to its assessment. Ann Arbor, MI: Health Administration Press, 27.

115. Hays, R.D., Nelson, E.C., Rubin, H.R., Ware, J.E., \& Meterko, M. (1991). Further evaluations of the PJHQ scales. Medical Care, $28(9), s 29-s 39$.

116. Yura, H., \& Walsh, M.B. (1988). The nursing process: Assessing, planning, implementing, and evaluating. 5th ed. Norwalk, Conn.: Appleton \& Lange.

117. Goldmann, R.C. (1990). Nursing process components as a framework for monitoring and evaluation activities. Journal of Nursing Quality Assurance, 4 (4), 17-25.

118. Larrabee, J.H., Rodgers, V.O., Corsey, R., Murff, E.W., Barnoud, K., \& Knight, M. (1992). Developing and implementing computer-generated nursing care plans. Journal of Nursing Care quality, $6(2), 56-62$. 
119. Gage, L.S., Weslowski, V.B., Andrulis, D.P., Hintz, E., \& Camper, A.B. (1991.) America's safety net hospitals: The foundation of our nations' health system. Washington, D.C.: National Association of Public Hospitals.

120. The Regional Medical Center at Memphis. (1990). 1990 annual report. Memphis, TN: Author.

121. Barnoud, K., Fifer, M., Larrabee, J., Rodgers, V., Corsey, R., \& Lee, J. (1991, May). Evaluation of bedside computer terminals: Project MED. Paper presented at Focus on Excellence, the 6th Annual Information Technology in Health Sciences Conference, sponsored by the University of Tennessee, Health Sciences Center, Memphis, TN.

122. Patterson, C. (1990). Quality assurance, control, and monitoring: The future role of information technology from the Joint Commission's perspective. Computers in Nursing, 8 (3), 105-110.

123. Joint Commission on Accreditation of Health Care Organizations. (1992). Joint Commission AMH: Accreditation manual for hospitals. Oak Brook Terrace, Illinois: Author.

124. University of Michigan. (1991). Guide to resources and services. Ann Arbor, Michigan: Author.

125. Hinshaw, A.S. \& Atwood, J.R. (1982). A patient satisfaction instrument: precision by replication. Nursing Research, 31, $170-175,191$.

126. Draper, N.R. \& H. Smith. (1981). Applied regression analysis. New York: John Wiley and Sons, $2 \overline{98}$.

127. Wewers, M.E., \& Lowe, N.K. (1990). A critical review of visual analogue scales in the measurement of clinical phenomena. Research in Nursing \& Health, 13 (4), 227-236.

128. Gift, A. G. (1989). Visual analogue scales: Measurement of subjeative phenomena. Nursing Research, 38 (5), 286-288.

129. Joyce, C.R.B., Zutshi, D.W., Hrubes, V., \& Mason, R.M. (1975). Comparison of fixed interval and visual analogue scales for rating chronic pain. European Journal of Clinical Pharmacology, $8,415-4 \overline{20}$.

130. Seymour, R.A. (1982). The use of pain scales in assessing the efficacy of analgesics in post-operative dental pain. European Journal of Clinical Pharmacology, 23, 441-444.

131. Hart, J., Hill, H.M., Bye, C.E., Wilkinson, R.T., \& Peck, A.W. (1976). The effects of low doses of amylobarbitone sodium and diazepam on human performance. British Journal of Clinical Pharmacology, 3 , 289-298. 
132. Glassman, A.H., Jackson, W.K., Walsh, B.T., \& Roose, S.P. (1984). Cigarette craving, smoking withdrawal, and clonidine. Science, 226, 864-866.

133. Herbert, M., Bourke, J.B., \& Rose, J.M. (1979). The assessment of preoperative medication by a visual analogue technique. In D.J. Oborne, M.M. Gruneberg, \& J.R. Eiser (Eds.), Research in psychology and medicine, Volume $1,(411-417)$. New York: Academic Press.

134. Presant, C.A., Klahr, C., \& Hogan, L. (1981). Evaluating quality of life in oncology patients: Pilot observations. Oncology Nursing Forum, $8(3), 26-30$.

135. Padilla, G.V., Presant, C., Grant, M.M., Metter, G., Lipsett, J., \& Heide, F. (1983). Quality of life index for patients with cancer. Research in Nursing \& Health, $6,117-126$.

136. Scott, J., \& Huskisson, E.C. (1976). Graphic representation of pain. Pain, 2, 175-184.

137. Sriwatanakul, K., Kelvie, W., Lasagna, L., Calimlim, J.F., Weis, O.F., \& Mehta, G. (1983). Studies with different types of visual analogue scales for measurement of pain. Clinical Pharmacology and Therapeutics, 34 (2), 234-239.

138. Huskisson, E.C. (1983). Visual analogue scales. In R. Melzack (Ed.) Pain measurement and assessment (pp. 33-40). New York: Raven Press.

139. Aldus Corporation. (1987). Aldus PageMaker ${ }^{r}$ : Reference Manual. Seattle, WA: Aldus Corporation.

140. Lorig, K. (1984). Measurement of pain (Letter to the Editor). Nursing Research, 33, 376.

141. Little, J.C., \& McPhail, N.I. (1973). Measures of depressive mood at monthly intervals. British Journal of Psychiatry, 122, $447-452$.

142. Davies, B., Burrows, G., \& Poynton, C. (1975). A comparative study of four depression rating scales. Australian and New Zealand Journal of Psychiatry, $\underline{9}$ (1), 21- 24 .

143. Gift, A.G., Plaut, S.M., \& Jacox, A.K. (1986). Psychologic and physiologic factors related to dyspnea in subjects with chronic obstructive pulmonary disease. Heart and Lung, 15, 595-601.

144. Doak, C.C., Doak, L.G., \& Root, J.H. (1985). Teaching patients with low literacy skills. Philadelphia: J. B. Lippincott.

145. Ware, J.E., \& Berwick, D.M. (1990). Conclusions and recommendations. Medical Care, 28 (9), supplement, 39-42. 
146. Wandelt, M.A., \& Phaneuf, M.C. (1972). Three instruments for measuring the quality of nursing care. Hospital Topics, August, 20-29.

147. Haussmann, R.K.D., Hegyvary, S.T., \& Newman, J.F. (1978). Provider-client interaction: quality of care (process). In M.J. Ward and C.A. Lindeman (Eds.) Instruments for measuring nursing practice and other health care variables, volume 2 . Boulder, CO: Western Interstate Commission for Higher Education.

148. Nelson, E.C., Rubin, H.R., Hays, R.D., \& Meterko, M. (1991). Response to Questionnaire. Medical Care, 28 (9), s18-s22.

149. Meterko, M. \& Rubin, H.R. (1990). Patient judgements of hospital quality: A taxonomy. Medical Care, 28 (9), Supplement, s10-14.

150. Wilson, C.K. (1986). Strategies for monitoring the cost and quality of care. Journal of Nursing Quality Assurance, 1 (1), 55-65.

151. Weinberger, M., \& Oddone, E. (1989). Strategies to reduce hospital readmissions: A review. Quality Review Bulletin, August, 255-260.

152. Longest, B.B. (1978). An empirical analysis of the quality/cost relationship. Hospital \& Health Services Administration, $\underline{23}$ (4), Fall, 20-35.

153. Brook, R.H., Davies, A.R., \& Kamberg, C.J. (1980). Selected reflections on quality of medical care evaluation in the $1980 \mathrm{~s}$. Nursing Research, 29 (2), 127-133.

154. Ehrat, K.S. (1987). The cost-quality balance: An analysis of quality, effectiveness, efficiency, and Cost. Journal of Nursing Administration, 17 (5), 6-14.

155. Zander, K. (1988). Nursing case management: Strategic management of cost and quality outcomes. Journal of Nursing Administration, 18 (5), 23-30.

156. Mediqual ${ }^{r}$ Systems Inc. (1988). Medisgroups $^{r}$ II: An overview. Westbourough, MA: Author.

157. Polit, D.F., \& Hungler, B.P. (1987). Nursing research: Principles and methods. Philadelphia: J.B. Lippincott, 157.

158. Microsoft Corporation. (1990). Microsoft $^{r}$ Excel: User's guide. Redmond, Washington: Author.

159. SAS Institute Inc. (1990). SAS $^{r}$ user's guide: Basics, version 6, third edition, Volume 1. Cary, NC: Author. 


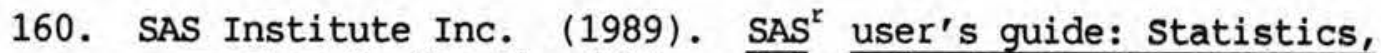
version 6, fourth edition, Volume 2. Cary, NC: Author.

161. King, I. (1981.) A theory of nursing: Systems, concepts, process. New York: John Wiley and Sons.

162. King, I. (1988). Measuring health goal attainment in patients. In C.F. Waltz and O.L. Strickland (Eds.) Measurement of nursing outcomes: Measuring client outcomes, Volume I. New York: Springer Publishing Company, 108-117.

163. Berg, H.V. (1974). Nursing audit and outcome criteria. Nursing Clinics of North America, $\underline{9}$ (2), 331-335.

164. Hilger, E.E. (1974). Developing nursing outcome criteria. Nursing Clinics of North America, 9 (2), 323-330.

165. Mills, w.C. (1989) Unit based outcomes developed through nursing diagnoses. Journal of Nursing Quality Assurance, 4 (1), 10-17.

166. Hinshaw, A.S., \& Atwood, J.R. (1979). Care/comfort quality criterion and standards: An empirical model tested for patient and staff outcomes. In E. Bauwens (Ed.) Clinical nursing research: Its strategies and findings II. Indianapolis, Ind.: Sigma Theta Tau.

167. Spross, J., McGuire, D.B., \& Schmitt, R.M. (1990). Oncology Nursing Society position paper on cancer Pain. Oncology Nursing Forum, 17 (4), 597-614.

168. Hull, M. (1989). Family needs and supportive nursing behaviors during terminal cancer: a review. Oncology Nursing Forum, 16 (6), 787-792.

169. Meehan, J.B. (1992). Pain management guideline released. The American Nurse. April, 2.

170. Ferrell, B.R., Wisdom, C., Rhiner, M., \& Alleto, J. (1991). Pain management as a quality of care outcome. Journal of Nursing Quality Assurance, $\underline{5}$ (2), 50-58.

171. Jacox, A.K. (1977). Pain: A source book for nurses and other health professionals. Boston: Little, Brown, and Company.

172. Domask, M.E., \& Childs, S. (1988). Patient and nurse perceptions of analgesic administration times. Journal of Nursing Quality Assurance, $\underline{2}$ (3), 64-69.

173. Barnhouse, A.H., Kolodychuk, G.R., Pankratz, C., \& Olinger, D.A. (1988). Evaluation of acute pain: A comparison of patient and nurse perspectives. Journal of Nursing Quality Assurance, $\underline{2}$ (3), 54-63. 
174. Baer, E., Davis, L., \& Leib, R. (1970). Inferences of physical pain and psychological distress, in relation to verbal and nonverbal patient communication. Nursing Research, 19, 388-392.

175. Bond, M.R., \& Pilowsky, I. (1966). Subjective assessment of pain and its relationship to the administration of analgesics in patients with advance cancer. Journal of Psychosomatic Research, 10, 203-208.

176. Carter, J.H., Mills, A.C., Homan, S.M., Blaesing, S.L., Heater, B.S., Stoll, L.D., Mornin, C., \& Corrigan, M.K. (1988). Correlating the quality of care with nursing resources and patient parameters: a longitudinal study. In Scherubel, J. (Ed.), Patients and purse strings II, (pp. 331-345), (NLN Pub. No. 20-2191). New York: National League for Nursing.

177. Streiner, D.L. \& Norman, G.R. (1989). Health measurement scales: A Practical guide to their development and use. New York: Oxford University Press. 


\section{Appendices}

I. Initial Interview Schedule

II. Exit Interview Schedule

III. Chart Review Form 
Appendix I

Initial Interview Schedule

( $75 \%$ of original size) 


\section{INITIAL INTERVIEW}

Name:

Study Number:

Unit:

Account Number:

Medical Record Number:

Admitting Diagnosis:

Admission Date:

Ist Interview Date:

2nd Interview Date:

Discharge Date:

Marital/Partner Status: single=S married/together $=M$ separated $=\mathbf{x}$ widowed $=\mathbf{W}$

Gender:

male $=\mathbf{M}$ female $=F$

Race:

white $=\quad W$ black $=\quad$ B other= $\mathbf{O}$ 


\section{INITIAL INTERVIEW}

We are interested in knowing more about the kinds of people who come to The MED for care.

Before being in The MED this time, about how many times have you been admitted to a hospital?

What is your date of birth?

$$
\overline{\text { month }} \overline{\text { day }} \quad-\overline{\text { year }}
$$

What is the highest grade or year you finished in school?

No schooling. 00

Not Answered.

What is your religious preference?

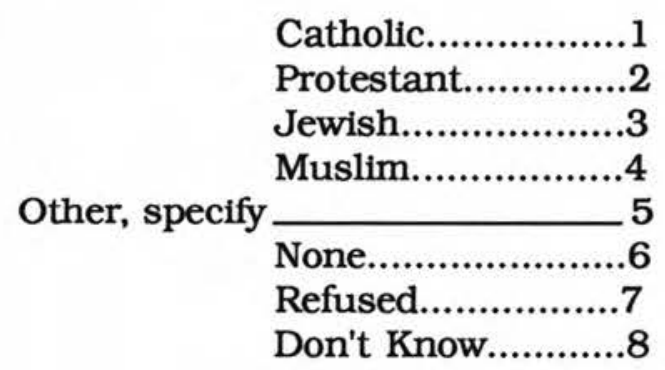




\section{INITIAL INTERVIEW}

I have some questions which you will answer by placing a mark on a line. Here is an example of the line.

Not At All

A Whole Lot

For example, if I ask you "how much is religion a source of strength and comfort to you", and you don't think religion is a source of much strength and comfort, you would place a mark near the lower left end of the line.

How much is religion a source of strength and comfort to you?

Not At All

A Whole Lot 


\section{INITIAL INTERVIEW}

Now, I have some questions about your health and why you are in The MED.

What is your biggest health problem that caused you to be in The MED NOW?

How bad is your

(chief symptom)?

Not Bad At All

Very Bad

How worried are you about this health problem?

Not Worried At All 


\section{INITLAL INTERVIEW}

People have different hopes or goals for how being in The MED will help them with their health.

Tell me about your FIRST hope or goal for being in The MED .

(If clarification needed: "For instance, you said your biggest health problem was . How do you hope being in The MED will help you with that problem?)

Tell me your SECOND hope or goal for being in The MED.

(If clarification needed: Do you have other health problems in addition to your biggest health problem? If YES, what are your hopes for how the MED can help you with those?)

Tell me your THIRD hope or goal for being in The MED. 


\section{INITLAL INTERVIEW}

Now, I have some questions about employment.

Have you worked at a job for pay within the past year?

Yes................01
No.................
Not answered

Are you CURRENTLY working at a job for pay?

$$
\begin{aligned}
& \text { Yes.................01 } \\
& \text { No................ } 02 \\
& \text { Not answered }
\end{aligned}
$$

How many hours per week do you usually work?

Hours per week...

Not answered.

Not applicable.

We are trying to get some idea of the income range of people who come to The MED for care.

Last month, what was your PERSONAL income?

(take-home)

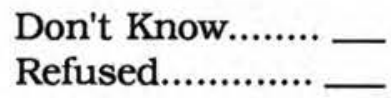

Last month, what was your combined HOUSEHOLD income? (take-home) 
Appendix II

Exit Interview Schedule

(75\% of original size) 


\section{EXIT INTERVIEW}

\section{PGA}

People have different hopes or goals for how being in the MED will help them with their health. When I first talked with you, you told me your goals for being here at the MED. I am going to remind you of each of those goals. Then, I am going to ask you how much each goal has been met. Your goal can be met all the way, not at all, or somewhere in between.

I will ask you to answer by marking a place along a line like this to show about how much each goal was met:

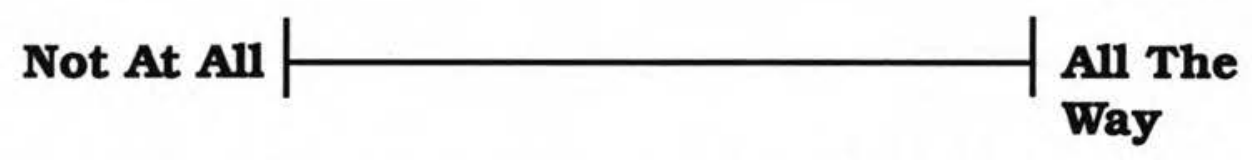

\section{PGA}

1. Your FIRST goal was;

This goal was met:

Not At All

All The

Way 


\section{EXIT INTERVIEW}

\section{PGA}

2. Your SECOND goal was:

This goal was met:

Not At All

All The

Way

3. Your THIRD goal was:

This goal was met:

Not At All

\section{All The \\ Way}




\section{EXIT INTERVIEW}

About how much of the time were you in pain while you were here?

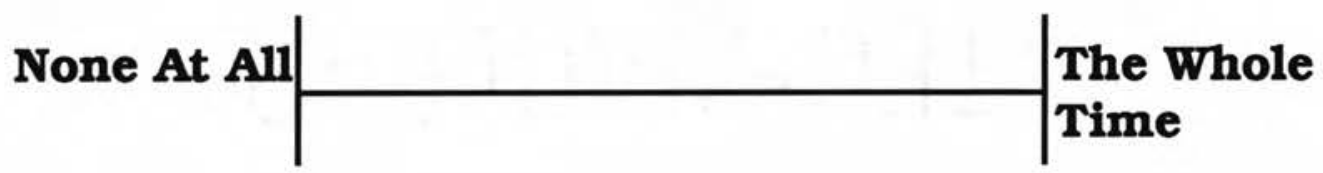

About how much pain did you have?

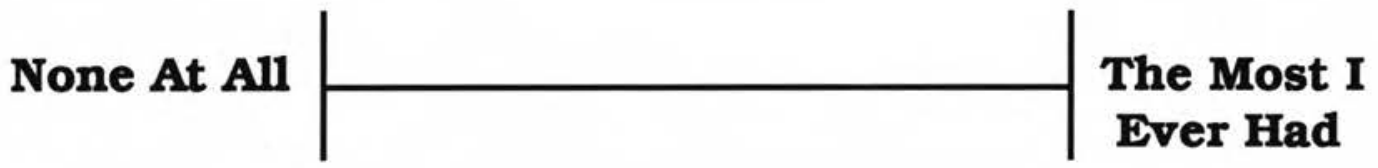

About how much pain are you in RIGHT now?

None At All

\begin{tabular}{|l|l}
\hline & The Most I \\
& Ever Had
\end{tabular}




\section{EXIT INTERVIEW}

\section{QUALITY}

NOW, I would like to talk with you about the nursing care you received while you were here this time.

I will read you several statements. After each one, I would like for you to tell me how poor or how good you think the nurses did.

I will ask you to answer by marking a place along a line like this to show about how good or how poor you think your NURSING care was:

Very Poor

Very Good

\section{PPQ-G}

Overall, how good was the nursing care you received? 


\section{EXIT INTERVIEW}

\section{QUALITY}

Quality is a word people use to describe how good or how poor something is. We say something has good quality or it has poor (bad) quality.

When you think of good quality in nursing care, what does that mean to you?

Other Comments: 


\section{EXIT INTERVIEW}

\section{PPQ-S}

1. The nursing staff were willing to work with you to meet your needs. (How poor or how good did they do?)

Very Poor

Very Good

2. The nursing staff worked well with each other to take care of you. ( How poor or how good did they do?)

Very Poor

Very Good

3. The nursing staff helped you feel comfortable or relaxed. (How poor or how good did they do?)

Very Poor

Very Good 


\section{EXIT INTERVIEW}

PPQ-S

4. Your nurses did a good job giving you care with things like giving you medicine and doing IVs.

(How poor or how good did they do?)

Very Poor

Very Good

5. The nurses checked on how you were doing often enough. (How poor or how good did they do?)

Very Poor

Very Good

6. Your nurses were quick to help you when you called. (How poor or how good did they do?)

Very Poor

Very Good 


\section{EXIT INTERVIEW}

PPQ-S

7. Your nurses were polite, kindly, and friendly with you. (How poor or how good did they do?)

Very Poor

Very Good

8. Your nurses did a good job of sharing facts about your illness with you, your family, and your doctor. (How poor or how good did they do?)

Very Poo

Very Good 
Appendix III

Chart Review Form 


\begin{tabular}{|l|l|}
\hline Study \# & \\
\hline Unit & \\
\hline Account \# & \\
\hline Med Record \# & \\
\hline
\end{tabular}

Data Collector:

Date of Collection:

Amt. of collection time:

Dates of Care Reviewed:

\begin{tabular}{|l|l|}
\hline Date/Time on Unit: & \\
\hline Date/Time D/C: & \\
\hline
\end{tabular}

\section{Instructions:}

1. Transcribe in the appropriate places on this form the following items:

a. the first 3 nursing diagnosis

b. the critical OUTCOME indicators (-if there aren't $\underline{3}$, then copy up to $\underline{2}$ noncritical indicators for a total of 3 OR - if there aren't any critical indicators, copy up to 3 OUTCOME indicators.)

c. the critical NURSING INTERVENTION indicators (- or the first 3 if no critical indicators are included in the NCP)

2. Examine the NCP for "Ending Date" on outcomes and interventions. Use this information when deciding "how many times something should have been done".

3. Review the nursing care documented using the critical indicators as criteria.

Code for response
$1=$ yes
$0=$ no
$\mathrm{NA}=$ not applicable (explain) 
I. Nursing Diagnosis (write in)

Expected Outcomes (write in)

1.

For this expected outcome:
a. How many times should it have been assessed?
b. How many times was it assessed?
c. How many times was it met?

2 .

For this expected outcome:
a. How many times should it have been assessed?
b. How many times was it assessed?
c. How many times was it met?

3.

For this expected outcome:
a. How many times should it have been assessed?
b. How many times was it assessed?
c. How many times was it met?

Aggregate percent for outcomes

Nursing Interventions (write in):

1.

How many times should it have been done?

How many times was it done?

$\frac{1}{\circ)}$

2 .

How many times should it have been done?

How many times was it done?

$\%)$

3.

How many times should it have been done?

How many times was it done?

\%)

Aggregate percent for interventions 
II. Nursing Diagnosis (write in)

Expected Outcomes (write in)

1.

For this expected outcome:
a. How many times should it have been assessed?
b. How many times was it assessed?
c. How many times was it met?

2 .

For this expected outcome:
a. How many times should it have been assessed?
b. How many times was it assessed?
c. How many times was it met?

3.

For this expected outcome:
a. How many times should it have been assessed?
b. How many times was it assessed?
c. How many times was it met?

Aggregate percent for outcomes

Nursing Interventions (write in):

1.

How many times should it have been done?

How many times was it done?

\%)

2.

How many times should it have been done?

How many times was it done?

3 .

How many times should it have been done?

How many times was it done? 
III. Nursing Diagnosis (write in)

Expected Outcomes (write in)

1.

For this expected outcome:

a. How many times should it have been assessed?

b. How many times was it assessed?

c. How many times was it met?

2 .

For this expected outcome:

a. How many times should it have been assessed?

b. How many times was it assessed?

c. How many times was it met?

3.

For this expected outcome:
a. How many times should it have been assessed?
b. How many times was it assessed?
c. How many times was it met?

Aggregate percent for outcomes

Nursing Interventions (write in):

1.

How many times should it have been done?

How many times was it done?

\%)

2 .

How many times should it have been done?

How many times was it done?

\%)

3.

How many times should it have been done?

How many times was it done?

\%)

Aggregate percent for interventions \% 


\section{VITA}

June Hansen Larrabee received a Bachelor of Science in Nursing degree from the Medical College of Georgia, Augusta in 1968 and a Master of Science degree from the College of Nursing, Boston University in 1971. She has been involved in nursing quality assurance since 1974 as a nursing quality assurance manager, nursing quality assurance coordinator, clinical nurse specialist, and nurse educator. Ms. Larrabee has publications focusing on nursing quality assurance, as well as nursing care quality issues related to the nursing process and the care of neuro trauma and scleroderma patients. She has presented on nursing quality assurance at state and national meetings.

Ms. Larrabee is a member of the American Nurses Association, Southern Nursing Research Society, Sigma Theta Tau, and Sigma Xi. She has been listed in outstanding Young Women of America, Who's Who in American Nursing, and The World Who's Who of Women. Ms. Larrabee received the Sigma Theta Tau, Beta Theta Chapter, Scholarship Award in 1989 and Research Award in 1990 and the quality improvement award for Leadership Excellence from the Regional Medical Center, Memphis in 1990. Ms. Larrabee entered the Doctor of Philosophy in Nursing program at the University of Tennessee, Memphis in 1988. 